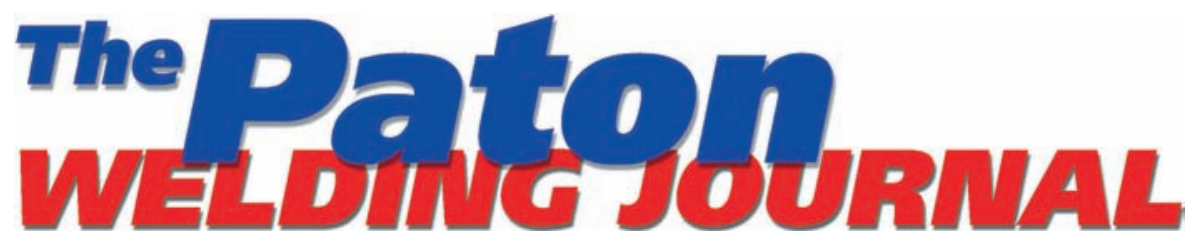

September 2017 No. 9

Published since 2000

EDITORIAL BOARD

Editor-in-Chief B.E. Paton

Scientists of PWI, Kiev S.I. Kuchuk-Yatsenko (vice-chief ed.), V.N. Lipodaev (vice-chief ed.)

Yu.S. Borisov, G.M. Grigorenko A.T. Zelnichenko, V.V. Knysh,

I.V. Krivtsun, Yu.N. Lankin, L.M. Lobanov, V.D. Poznyakov, I.A. Ryabtsev, K.A. Yushchenko

Scientists of Ukrainian Universities V.V. Dmitrik, NTU «KhPI», Kharkov V.V. Kvasnitsky, NTUU «KPI», Kiev V.D. Kuznetsov, NTUU «KPI», Kiev

\section{Foreign Scientists} N.P. Alyoshin

N.E. Bauman MSTU, Moscow, Russia Guan Qiao

Beijing Aeronautical Institute, China A.S. Zubchenko

DB «Gidropress», Podolsk, Russia M. Zinigrad

Ariel University, Israel V.I. Lysak

Volgograd STU, Russia

Ya. Pilarczyk

Welding Institute, Gliwice, Poland U. Reisgen

Welding and Joining Institute, Aachen, Germany G.A. Turichin

St. Petersburg SPU, Russia

Founders

E.O. Paton Electric Welding Institute, NASU International Association «Welding» Publisher

International Association «Welding» Translators

A.A. Fomin, O.S. Kurochko, I.N. Kutianova Editor

N.G. Khomenko

Electron galley

D.I. Sereda, T.Yu. Snegiryova Address

E.O. Paton Electric Welding Institute, International Association «Welding» 11 Kazimir Malevich Str. (former Bozhenko Str.), 03680, Kiev, Ukraine

Tel.: (38044) 20060 16, 2008277

Fax: (38044) 20082 77, 2008145

E-mail: journal@paton.kiev.ua

www.patonpublishinghouse.com

State Registration Certificate

KV 4790 of 09.01.2001

ISSN 0957-798X

doi.org/10.15407/tpwj2017.08.01

Subscriptions

$\$ 348,12$ issues per year

air postage and packaging included.

Back issues available. All rights reserved.

This publication and each of the articles contained herein are protected by copyright.

Permission to reproduce material contained in this ournal must be obtained in writing from the Publisher.

\section{CONTENTS}

\section{SCIENTIFIC AND TECHNICAL}

Degtyarev V.A. Influence of the ratio of dynamic and static stresses on brittle fracture resistance of low-alloyed steel welded joints

Shelyagin V.D., Bernatsky A.V., Khaskin V.Yu., Shuba I.V. and

Siora A.V. Investigation of physical features and technological

capabilities of continuous optical discharge

Efremenko B.V., Belik A.G., Chejlyakh Ya.A. and Bakhrami Alamdarlo M. investigation of formation of wear-resistant alloy structure in surfacing using flux-cored strip PL-AN-111

Grigorenko G.M., Adeeva L.I., Tunik A.Yu., Korzhik V.N. and

Kapitanchuk L.M. Features of the structure of plasma-arc coatings produced at application of flux-cored wires with a steel sheath and filler from $\mathrm{B}_{4} \mathrm{C}$ and $\mathrm{ZrO}_{2}$ nanopowder

Markashova L.I., Tyurin Yu.N., Kolisnichenko O.V., Berdnikova E.N., Kushnareva O.S., Polovetsky E.V. and Titkov E.P. Effect of structure on properties of $\mathrm{Al}_{2} \mathrm{O}_{3}$ and $\mathrm{Al}$ (or Ti) mechanical mixture coatings produced by multichamber detonation spraying method

Borisov Yu.S., Borisova A.L., Burlachenko A.N., Tsymbalistaya T.V. and Senderowski $C$. Structure and properties of alloyed powders based on $\mathrm{Fe}_{3} \mathrm{Al}$ intermetallic for thermal spraying produced using mechanochemical synthesis method

\section{INDUSTRIAL}

Zhemanyuk P.D., Petrik I.A. and Chigilejchik S.L. Results of implementation of orbital welding in manufacture and repair of thin-wall pipelines

Ryabtsev I.A., Rozert R., Turyk E. and Ryabtsev I.I. Classification and characteristic of defects of deposited layers according to the international standard ISO 6520-1:2007

Moltasov A.V. Approximate calculation of radius of weld transition to base metal of welded butt joint according to normalized parameters

Kyrychok V.V. and Torop V.M. Engineering approach to determination of stress intensity factor and parameters of growth of axial crack in circumferential weld of pipeline 


\title{
INFLUENCE OF THE RATIO OF DYNAMIC AND STATIC STRESSES ON BRITTLE FRACTURE RESISTANCE OF LOW-ALLOYED STEEL WELDED JOINTS
}

\author{
V.A. DEGTYAREV \\ G.S. Pisarenko Institute for Problems of Strength, NASU \\ 2 Timiryazevskaya Str., 01014, Kiev-14, Ukraine. E-mail: ips@ipp.kiev.ua
}

\begin{abstract}
Results of experimental studies of the influence of the ratio of static and dynamic stresses on limit stresses and second critical brittleness temperature of butt welded joints with a crack on 09G2 and 12GN2MFAYu steels under the conditions of room and low (to $-80^{\circ} \mathrm{C}$ ) temperatures are analyzed. It is found that at the specified temperature the dynamic component of critical stress decreases linearly with increase of static stress. It is shown that decrease of limit stresses and increase of the second critical brittleness temperature take place at increase of the dynamic factor. Critical brittleness temperatures of welded joints of steel with higher mechanical properties are significantly lower. It is found that ignoring the dynamic stresses leads to underestimated values of limit stress and overestimated values of second critical brittleness temperature. Presented analysis of research allows a more substantiated approach to assessment of brittle fracture resistance of structural elements made from the studied materials, and determination of their safety margins. 7 Ref., 1 Table, 7 Figures.
\end{abstract}

Keyw or d s : welded joint, critical brittleness temperature, limit stress diagram, yield point

Increase of reliability and reduction of the number of failures of metal structure elements during winter operation period is a highly urgent task [1-3]. Transition of quasibrittle to brittle fracture is characterized by second critical brittleness temperature, $T_{\text {cr2 }}$. For structures, exposed to static or just dynamic impact, it is determined at static or dynamic loading of samples [4]. In practice, however, the absolute majority of structural elements operate under the conditions of simultaneous impact of static and dynamic loads. Therefore, if $T_{\mathrm{cr} 2}$ is determined at static loading, it can yield underestimated values, if it is done at dynamic load the values can be overestimated. Only combined loading, allowing for the real ratio of static and dynamic stresses, enables application of welded joints with maximum effectiveness. Known is the work [5], where change of static stresses and critical brittleness temperature of samples with a crack from low-carbon and low-alloyed steels was studied at combined loading. The sample was statically stretched by application of stepwise increasing load with subsequent impact of a transverse shock pulse, the magnitude of which was not determined. An essential lowering of static nominal breaking stresses and increase of critical brittleness temperatures was noted. However, no publications were found in literature, in which dependencies of breaking stresses and critical brittleness temperatures of welded joints on different ratios of static and dynamic loads are studied. It is known that brittle fracture resistance of metal structure elements depends on a number of factors, in particular, on temperature, deformation rate, as well as their cross-sectional dimensions and defects present in them.

(C) V.A. DEGTYAREV, 2017
In this connection, structural strength and second critical brittleness temperatures of welded joints containing defects of the type of fatigue cracks were studied in this work, depending on temperature and nature of applied forces.

Equipment, materials and testing procedure. Butt welded joints of low-alloyed steels 09G2 $\left(\sigma_{t}=\right.$ $\left.=518 \mathrm{MPa}, \sigma_{\mathrm{y}}=330 \mathrm{MPa}\right)$, and 12GN2MFAYu $\left(\sigma_{\mathrm{t}}=\right.$ $=710 \mathrm{MPa}, \sigma_{\mathrm{y}}=620 \mathrm{MPa}$ ) were used as research material. Samples of $400 \times 48 \times 24 \mathrm{~mm}$ size were cut out of a plate $24 \mathrm{~mm}$ thick in as-delivered condition with the butt weld, directed normal to the rolling direction. Thickness selection is due to the need to determine the studied characteristics for structures, made from rolled stock of the above thicknesses. The initiating notch in the sample was made so that the fatigue crack grown afterwards, was in the plane running through the line of fusion of weld metal with base metal. Therefore, test results belonged to the heat-affected zone (HAZ) metal. Initial fatigue cracks were grown from the notch up to sample mid-height, in keeping with the requirements of GOST 25.506-85 [6] at zero-to-tension loading cycle. For observation of the cracks weld reinforcement was milled, and the anticipated crack growth site was polished. Diagram of loading the cracked sample in the unit developed for these studies based on repeated impact drop-hammer DSO-1 [7], is given in Figure 1. The unit consists of static loading mechanism, sample attachment assembly and shock loading mechanism. Sample 4, mounted on two stationary supports 3 and 5 , was statically loaded by weights 7 through lever 8 and rod 9 with support 10 . Compared to three-point loading, console loading allows testing samples with much larger cross-sectional dimensions. Dynamic loading was per- 
formed by free-falling load 1 of $10 \mathrm{~kg}$ weight, mounted in guiding ball-bearings 2 . At sample testing under the conditions of just dynamic loading support 10 was stationary fixed. Load raising height was controllable.

Thus, testing of welded samples with pre-grown fatigue cracks was conducted at static, dynamic and combined loading in a broad range of climatic temperatures. The latter kind of loading was carried out by sample bending under constant static load up to specified nominal stress $\sigma^{\text {st }}$ with subsequent application of dynamic load, which was increased to the specified degree, increasing the load drop height, and, thus, dynamic stress $\sigma^{\mathrm{d}}$. Their measurements and respective values of notch edge displacement $V$, measured by a sensor, specially made in the form of a cramp, were used to plot deformation diagrams with «P-V» coordinates, on which limit load $P_{\text {st }}$ was noted, corresponding either to the moment of appearance of a tear in the blunted crack tip on the sample side surface, that was indicative of the start of crack movement through its entire thickness, or to brittle fracture of the sample. Use of a standard two-console sensor at dynamic loading was not possible, as the arising force of inertia caused additional sagging of its elastic elements, and this led to a significant error in measurement of the notch edge displacement. It was applied at static loading of samples.

Commercial TV system PTU-61 was used for observation of crack growth and formation of a plastic zone in its tip. To increase measurement accuracy, the TV camera was connected to MBS-1 microscope through a special transition piece that allowed magnifying the observed object 109 times. Low-temperature testing was performed using a system of cooling and automatic maintenance of sample temperature in the range of $20--100{ }^{\circ} \mathrm{C}$ [3]. To reduce heat losses, the sample was placed into a specially prepared chamber.

Reaction $R^{\mathrm{d}}$ of support 10 to the impact of dynamic load was determined by strain gauge 6 , glued to the lower plane of the sample, and reaction $R^{\mathrm{st}}$ of the same support to the action of static load - by the weight of calibrated loads 7 and known value of the ratio of the arms of the lever of $2^{\text {nd }}$ kind, equal to 1:50.

Critical stress at combined loading in sample net section was defined as

$$
\sigma_{\mathrm{cr}}=\sigma^{\mathrm{st}}+\sigma^{\mathrm{d}}=\frac{6\left(R^{\mathrm{st}}+R^{\mathrm{d}}\right) L}{t(b-l)^{2}},
$$

where $l$ is the length of fatigue crack, determined after sample fracture as the mean arithmetic by three points on the crack contour [6]; $t$ is the sample width. Other designations are given in the Figure.

Let us designate limit stress at static loading as $\sigma_{0}^{\mathrm{st}}$, and that at dynamic loading as $\sigma_{0}^{\mathrm{d}}$.

Analysis of investigation results. According to experimental data (Table), Figure 2 presents in relative coordinates the limit stress diagrams (LSD) of butt welded joints of steel 09G2 (a), determined at

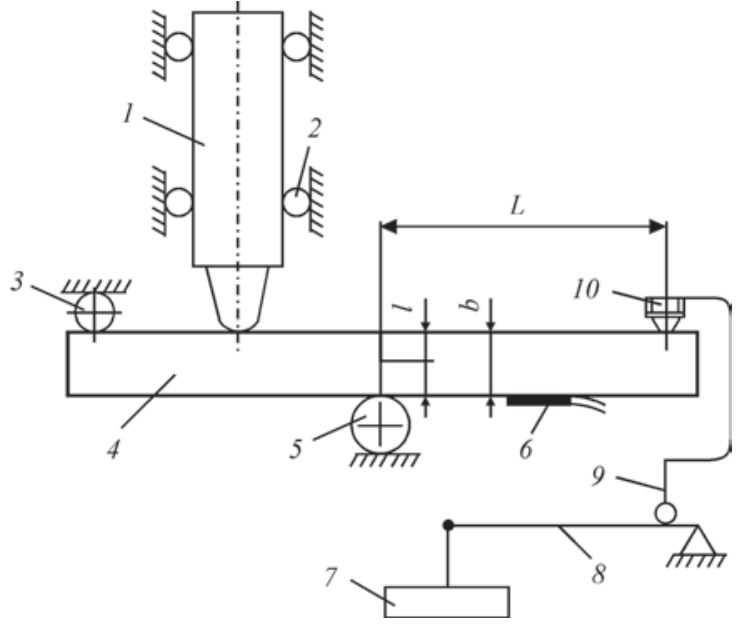

Figure 1. Schematic of welded sample loading (for description see the text)

temperatures of $20,-20,-60{ }^{\circ} \mathrm{C}$ and $12 \mathrm{GN} 2 \mathrm{MFAYu}$ (b) at $0,-40$ and $-80^{\circ} \mathrm{C}$, respectively. Several samples were tested at each temperature, assigning different $\sigma^{\text {st }}$, and the correspondence of limit breaking $\sigma^{\mathrm{d}}$ and critical stresses $\sigma_{\text {cr }}$ was determined. Limit stresses not only at static $\sigma_{0}^{\mathrm{st}}$, but also at dynamic $\sigma_{0}^{\mathrm{d}}$ loading were found at the same temperatures. Considering the experience of earlier full-scale investigations of samples from $09 \mathrm{G} 2$ steel, which are indicative of linear dependence between $\sigma^{\mathrm{d}}$ and $\sigma^{\text {st }}$ at different temperatures, this work required a smaller number of samples of welded joints of these steels, confirming the availability of the above dependence. At $20^{\circ} \mathrm{C}$ temperature for joints of 09G2 steel, and at $0{ }^{\circ} \mathrm{C}$ for those of 12GN2MFAYu steel, $\sigma_{0}^{\mathrm{d}}$ turned out to be higher than $\sigma_{0}^{\text {st }}$. Therefore, the experimental points are not given on the ordinate axis. The derived stresses at specified temperature were used at determination of ratios $\sigma^{\mathrm{d}} / \sigma_{0}^{\mathrm{st}}$ and $\sigma^{\mathrm{st}} /$ $\sigma_{0}^{\text {st }}$. Therefore, for any temperature the relative value of critical stress at static loading is equal to a unity. Analysis of the results, given in the Figure, showed that mainly a linear dependence is observed between static $\sigma^{\text {st }}$ and breaking dynamic $\sigma^{\mathrm{d}}$ components of crit-

Limit stresses in butt welded joints of 09G2 and 12GN2MFAYu steels at different temperatures $\left(20--80^{\circ} \mathrm{C}\right)$

\begin{tabular}{|c|c|c|c|}
\hline Temperature, ${ }^{\circ} \mathrm{C}$ & $\sigma^{\mathrm{st}}, \mathrm{MPa}$ & $\sigma^{\mathrm{d}}, \mathrm{MPa}$ & $\sigma_{\mathrm{cr}}, \mathrm{MPa}$ \\
\hline (20)0 & $\begin{array}{ll}(799) & 1056 \\
(0) & 1045 \\
(363) & 525 \\
& 0 \\
\end{array}$ & $\begin{array}{ll}(0) & 0 \\
(848) & 0 \\
(475) & 671 \\
& 1264 \\
\end{array}$ & $\begin{array}{ll}(799) & 1056 \\
(848) & 1045 \\
(838) & 1196 \\
& 1264 \\
\end{array}$ \\
\hline$(-20)-40$ & $\begin{array}{ll}(749) & 1160 \\
(525) & 517 \\
(0) & 0 \\
& (369)\end{array}$ & $\begin{array}{ll}(0) & 0 \\
(75) & 618 \\
(459) & 1144 \\
(224) & \end{array}$ & $\begin{array}{ll}(749) & 1160 \\
(600) & 1135 \\
(459) & 1144 \\
(593) & \end{array}$ \\
\hline$(-60)-80$ & $\begin{array}{ll}(752) & 942 \\
(350) & 453 \\
(463) & 0 \\
(0) & \end{array}$ & $\begin{array}{ll}(0) & 0 \\
(110) & 81 \\
(47) & 658 \\
(295) & \end{array}$ & $\begin{array}{ll}(752) & 942 \\
(460) & 734 \\
(510) & 658 \\
(295) & \end{array}$ \\
\hline
\end{tabular}

Note. Data pertaining to welded joints of steel 09G2, are given in brackets. 

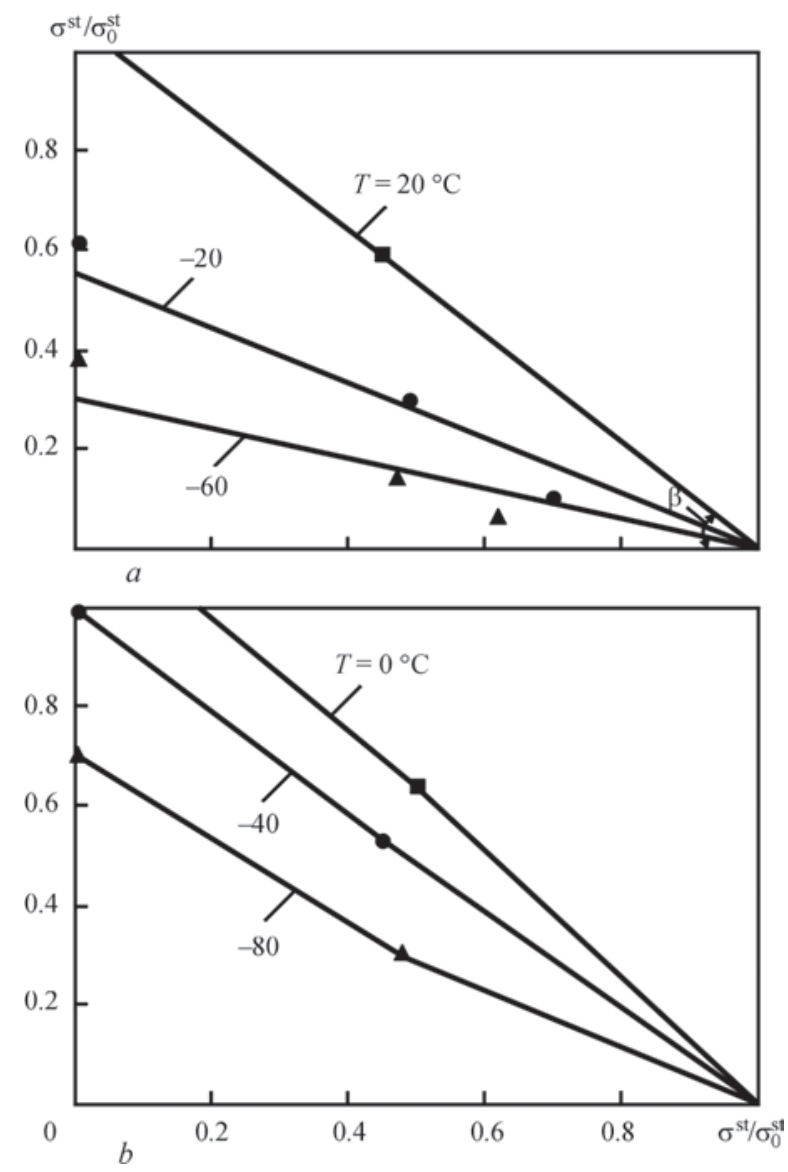

Figure 2. Diagrams of limit stresses of welded joints of 09G2 (a) and 12GN2MFAYu (b) steels under the conditions of combined loading at room and low temperatures

ical stress $\sigma_{\mathrm{cr}}$, except for the results of testing 09G2 steel welded joints at $-60{ }^{\circ} \mathrm{C}$. With increase of static stresses, limit dynamic stresses decrease, and critical stresses increase. A certain lowering of $\sigma_{c r}$ is observed for welded joints of 09G2 steel only at room temperature and at $0{ }^{\circ} \mathrm{C}$ for those of $12 \mathrm{GN} 2 \mathrm{MFAYu}$ steel. It can be noted that if by static stresses we mean residual stresses, then the admissible level of dynamic loads can always be assessed by the derived limit stress diagrams. Moreover, in absence of impact drop-hammers with high impact energy, it is possible to determine

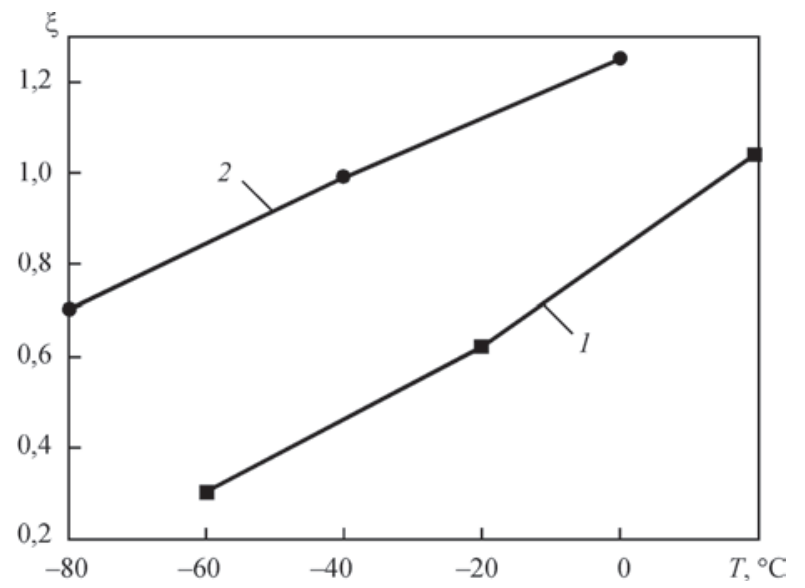

Figure 3. Temperature dependence of the coefficient of proportionality of welded joints of 09G2 (1) and 12GN2MFAYu (2) steels the breaking stress at dynamic loading by the results of testing at static and combined loading.

Points of LSD intersection with axes of ordinates and abscissas correspond to relative values of $\sigma_{0}^{\mathrm{d}}$ and $\sigma_{0}^{\text {st }}$, respectively. In this case, the tangent of the angle of LSD inclination to the abscissa axis at specified temperature, is defined as

$$
\operatorname{tg} \beta=\xi=\frac{\sigma_{0}^{\mathrm{d}}}{\sigma_{0}^{\text {st }}}=\frac{\sigma^{\mathrm{d}}}{\sigma_{0}^{\text {st }}-\sigma^{\mathrm{st}}},
$$

and critical stress at combined loading is

$$
\sigma_{\mathrm{cr}}=\sigma_{0}^{\mathrm{d}}+(1-\xi) \sigma^{\mathrm{st}}
$$

where $\xi$ is the coefficient of proportionality, depending on the ratio of stresses, induced by static and dynamic loads at combined loading of welded joints.

Analysis of the Figure showed that the angle of LSD inclination largely depends on temperature. Relative $\sigma / \sigma_{0}^{\mathrm{dt}}$ value decreases noticeably with temperature lowering, but critical stress changes only slightly here. $\xi$ dependence on temperature for the studied welded joints is shown in Figure 3. One can see that it decreases with testing temperature lowering. Here, the value of the coefficient of proportionality for butt joint of 09G2 steel (curve 1) is essentially lower, that is indicative of higher crack resistance of $12 \mathrm{GN} 2 \mathrm{MFAYu}$ steel welded joint that is confirmed by operating practice of these steels application.

In those cases, when dynamic loads are random, and are not taken into account in strength analysis, we will use static component $\sigma^{\text {st }}$ of critical stress $\sigma_{c r}$ by analogy with the method of evaluation of load-carrying capacity of a sample, accepted in work [5], as limit stress at combined loading. In this case, we will designate the ratio of dynamic and static stresses at combined loading, numerically characterizing the degree of dynamic overload, as dynamic overload factor $K_{\mathrm{ov}}=\sigma \mathrm{d} /$ $\sigma^{\text {st }}$. Then, the limit static and breaking dynamic stresses at specified temperature and dynamic overload factor, allowing for dependence (2), can be found as

$$
\sigma^{\mathrm{st}}=\frac{\xi}{K_{\mathrm{ov}}+\xi} \sigma_{0}^{\mathrm{st}}
$$

or

$$
\sigma^{\mathrm{d}}=\frac{\xi K_{\mathrm{ov}}}{K_{\mathrm{ov}}+\xi} \sigma_{0}^{\mathrm{st}} .
$$

Derived equations and dependencies, presented in Figure 3, allow determination of LSD of the studied welded joints at any temperature in the considered range, in the absence of direct experimental studies. For this purpose, it is sufficient to assign the value of $K_{\text {ov }}$ and determine $\sigma_{0}^{\text {st }}$ at static loading.

Temperature dependencies of limit static stress $\sigma^{\text {st }}$ for welded joints of steels 09G2 ( $a$ ) and 12GN2MFAYu (b) at certain values of dynamic overloading factor are given in Figure 4. Curve $K_{\mathrm{ov}}=0$ characterizes the dependence of limit stress $\sigma_{0}^{\text {st }}$ on temperature at static loading. All the other curves characterize the results 
of studies at combined loading. At $K_{\mathrm{ov}}=1$ stresses induced by static and dynamic loads, are the same. The same Figure gives temperature dependencies of the studied material yield point at tension $\sigma_{\mathrm{y}}$ and bending $\sigma_{\mathrm{y}}^{\mathrm{b}}$. Yield point $\sigma_{\mathrm{y}}^{\mathrm{b}}$ was determined by threepoint bending of smooth (uncracked) samples, the thickness of which (see Figure 1) is equal to thickness of net-section of the cracked sample. This means that the gradient of nominal stresses of smooth samples and the cracked samples was the same. At room temperature it was 480 and $970 \mathrm{MPa}$ for $09 \mathrm{G} 2$ and 12GNMFAYu steels, respectively. Temperature dependencies of $\sigma_{y}$ and $\sigma_{y}^{\mathrm{b}}$ of the studied materials were established by calculation [4]. Points of intersection of graphs $\sigma^{\text {st }}=f(T)$ at the set dynamic overload factor and $\sigma_{\mathrm{y}}=f(T)$ or $\sigma_{\mathrm{y}}^{\mathrm{b}}=f(T)$ are exactly what determines $T_{\mathrm{cr} 2}$ values. The data given in the Figure show that stresses induced by dynamic load essentially affect both $\sigma^{\text {st }}$ and $T_{\mathrm{cr} 2}$. With increase of $K_{\mathrm{ov}}$ limit stresses in the studied welded joints decrease at static loading, and the second critical brittleness temperature rises.

Welded joint sensitivity to dynamic load can be assessed by the ratio of the value of decrease of static stress $\Delta \sigma=\sigma_{0}^{\text {st }}-\sigma^{\mathrm{st}}$ at the set ratio of dynamic stress to breaking static stress $\sigma_{0}^{\text {st }}$. As an example, Figure 5 gives temperature dependencies of sensitivity of the studied welded joints at $\sigma^{\mathrm{d}}=200 \mathrm{MPa}$. Figure analysis showed that in the studied temperature range the welded joint of 09G2 steel (curve 1) is more sensitive to dynamic load. This difference becomes greater with temperature lowering and at $-60{ }^{\circ} \mathrm{C}$ it increases approximately three times. It follows that during strength analysis at sample testing under combined loading not only static, but also dynamic stresses should be measured and taken into account. In this case, $T_{\mathrm{cr} 2}$ should be more reliably determined by intersection of temperature dependencies of critical maximum stress $\sigma_{\mathrm{cr}}$ and yield point of the considered material. Dynamic factor $K_{\mathrm{d}}=\sigma^{\mathrm{d}} / \sigma_{\mathrm{cr}}$, which is connected by relationship $K_{\mathrm{d}}=K_{\mathrm{ov}} / 1+K_{\mathrm{ov}}$ with dynamic overload factor, was used as loading mode characteristic. Using experimental data (see Table), Figure 6 gives temperature dependencies for welded joints of steels 09G2 (a) and 12GN2MFAYu (b) at certain values of dynamic coefficient. Curve $\sigma_{\mathrm{cr}}=f(T)$ determined at $K_{\mathrm{d}}=0$, characterizes temperature dependence of critical stress, equal to limit stress $\sigma_{0}^{\text {st }}$, derived under the conditions of just static loading, and $K_{\mathrm{d}}=1$ - that at dynamic loading $\sigma_{0}^{\mathrm{d}}$. With known values $\sigma_{0}^{\text {st }}$, $\xi$, and $K_{\mathrm{d}}$, critical stress $\sigma_{\text {cr }}$ for specified temperature can be determined by the following formula:

$$
\sigma_{\mathrm{cr}}=\frac{\xi}{K_{\mathrm{ov}}+\xi\left(1-K_{\mathrm{ov}}\right)} \sigma_{0}^{\mathrm{st}} \text {. }
$$

Dependencies, given in the Figure, show that with $K_{\mathrm{d}}$ increase, critical stresses in the studied welded joints decrease, and the second critical brittleness
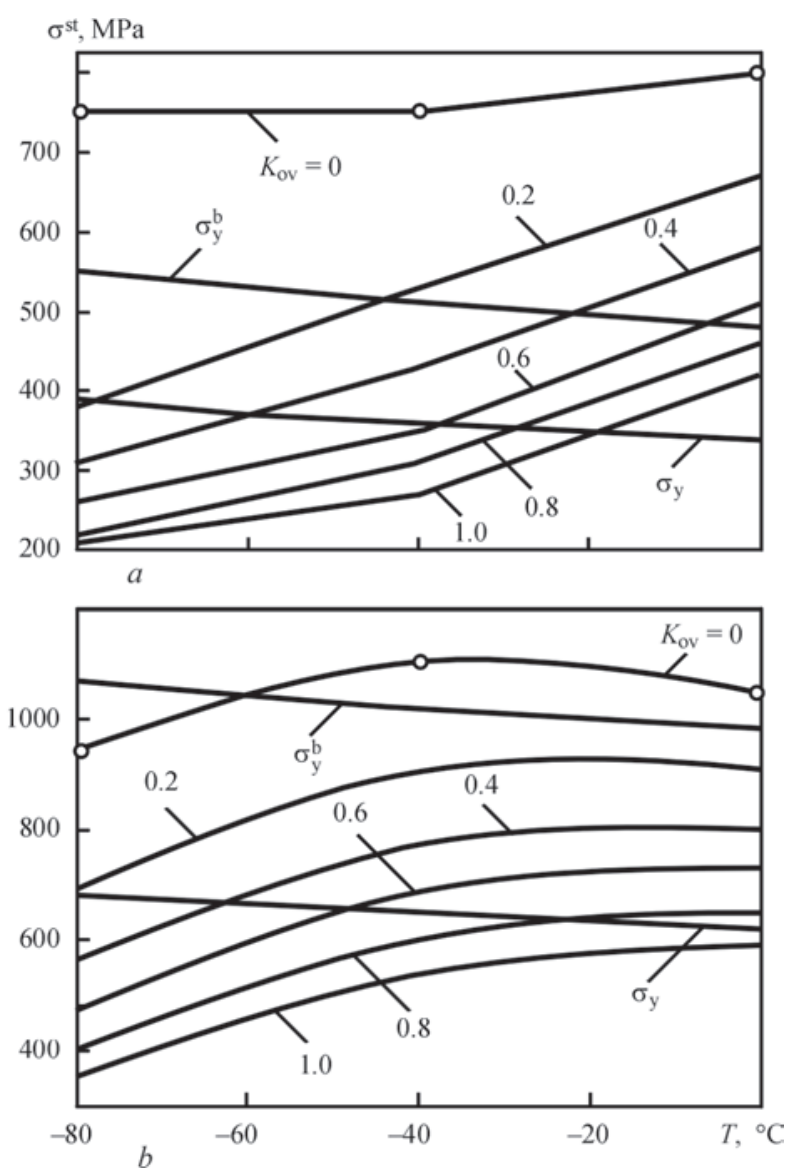

Figure 4. Influence of temperature and dynamic overload factor on limit static stresses in welded samples of 09G2 (a) and 12GN2MFAYu (b) steels: $\sigma^{\mathrm{y}}, \sigma_{\mathrm{y}}^{\mathrm{b}}-$ yield point at tension and bending, respectively

temperature increases, i.e. the nature of variation of maximum stresses and critical brittleness temperature is analogous to those given in Figure 4, except for their absolute values.

Influence of dynamic overload factor (curves 1, 3) and dynamic factor (curves 2, 4) on second critical brittleness temperatures of welded joints of steels 09G2 $(1,2)$ and 12GN2MFAYu $(3,4)$ is show in Figure 7. Points of intersection of temperature dependencies of $\sigma^{\text {st }}$ with $\sigma_{\mathrm{y}}=f(T)$ (Figure 4), and for curves 2, 4 - temperature dependencies of $\sigma_{\text {cr }}$ with $\sigma_{\mathrm{y}}=f(T)$

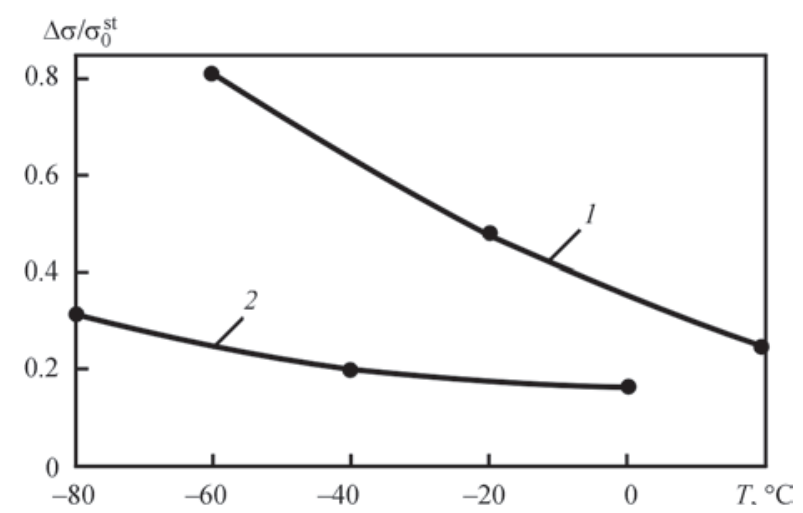

Figure 5. Dependence of sensitivity of welded joints of 09G2 (1) and 12GN2MFAYu (2) steels on temperature at specified value of dynamic stress $\sigma^{\mathrm{d}}=200 \mathrm{MPa}$ 

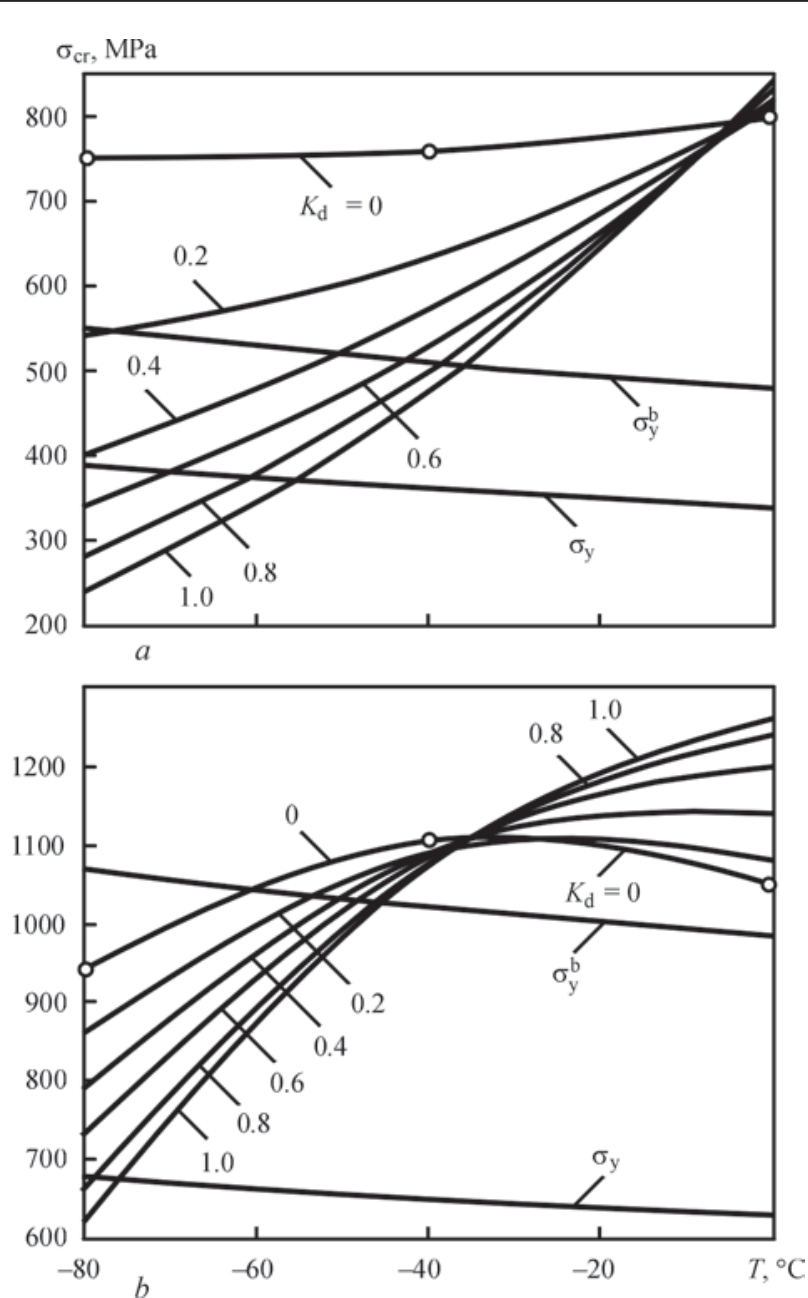

Figure 6. Influence of temperature and dynamic factor on critical stresses in welded samples from 09G2 (a) and 12GN2MFAYu $(b)$ steels

(Figure 6) were used to plot curves 1, 3. Comparison of obtained results shows that $T_{\mathrm{cr} 2}$ is much lower at evaluation of welded joint load level by the dynamic factor, than at its evaluation by dynamic overload factor. With increase of the factors the difference between the second critical brittleness temperatures determined by $\sigma^{\text {st }}$ and $\sigma_{\mathrm{cr}}$, tends to increase. It can be stated that evaluation of second critical brittleness temperatures of the studied welded joints by maximum stresses at combined loading (curves 2, 4) is more valid than that allowing for the impact of just the static stresses. Moreover, one can see that at the same values of $K_{\mathrm{ov}}$ or $K_{\mathrm{d}}$ the second critical brittleness temperatures of welded joints of 12GN2MFAYu steel are essentially lower. For instance, at $K_{\mathrm{ov}}=0.4$, the difference of critical brittleness temperatures between the studied welded joints is equal to $23^{\circ} \mathrm{C}$, and at $K_{\mathrm{d}}=0.8$ it is $39^{\circ} \mathrm{C}$.

Thus, performed investigations of welded joints of steels of different strength, having a defect in the form of a fatigue crack at different ratios of dynamic and static stresses in a broad range of variation of climatic temperatures and presented analysis of the data pro-

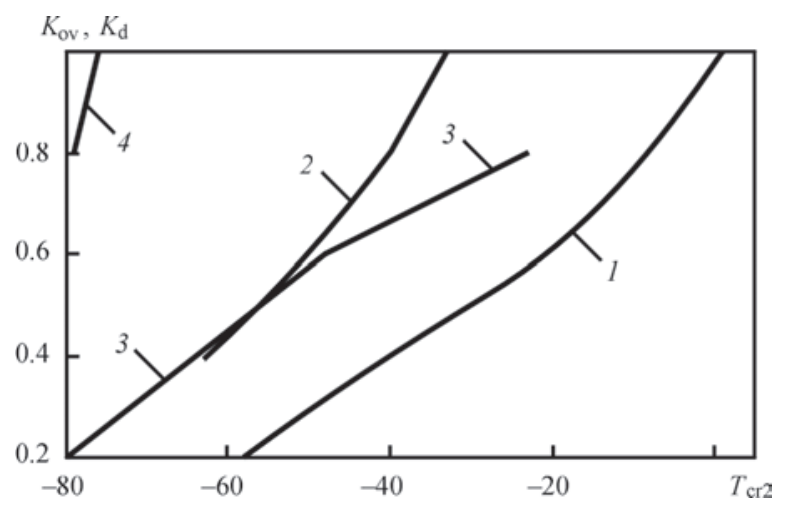

Figure 7. Influence of dynamic overload $(1,3)$ and dynamic (2, 4) factors under combined loading conditions on second critical brittleness temperatures of welded joints of $09 \mathrm{G} 2(1,2)$ and 12GN2MFAYu $(3,4)$ steels

vide a better substantiated approach to determination of strength margins of metal structure elements, produced from the studied materials.

\section{Conclusions}

1. Limit stress and second critical brittleness temperature at combined loading of the studied welded joints depend on the ratio of static and dynamic stresses. At increase of dynamic overload and dynamic factors limit stress decreases, and the second critical brittleness temperature rises.

2. It is shown that ignoring the dynamic stresses leads to lower values of limit stress and overestimated values of second critical brittleness temperature.

3. It is found that second critical brittleness temperatures of welded joints of steel 12GN2MFAYu and their sensitivity to dynamic load are lower in the entire range of studied temperatures.

4. Limit stresses and second brittleness temperature should be determined under the conditions of combined loading at the same dynamic factor, at which metal structure element operates.

1. Grigoriev, R.S., Larionov, V.P., Urzhumtsev, Yu.S. (1987) Methods of increase of serviceability of equipment in North version. Novosibirsk: Nauka. Siberian section.

2. Telushkin, V.D., Vinokurov, V.A., Ryakhin, V.A. et al. (1978) Road-building machines for regions with cold climate. Moscow: Mashinostroenie.

3. Sleptsov, O.I., Shulginov, B.S., Mikhajlov, V.E. et al. (2012) Improvement of strength of welded metal structures of mining and transport engineering under conditions of North. Novosibirsk: Nauka.

4. Makhutov, N.A. (1973) Resistance of structure elements to brittle fracture. Moscow: Mashinostroenie.

5. Trufyakov, V.I. (1973) Fatigue of welded joints. Kiev: Naukova Dumka.

6. (1985) GOST 25.506-85: Methods of mechanical tests of metals. Determination of characteristics of crack resistance (fracture toughness) under static loading. Moscow: Standart.

7. Degtyaryov, V.A. (1982) Units of DSO type for fatigue testing under repeated impact loading with different cycle asymmetry. Problemy Prochnosti, 10, 110-113. 


\title{
INVESTIGATION OF PHYSICAL FEATURES AND TECHNOLOGICAL CAPABILITIES OF CONTINUOUS OPTICAL DISCHARGE
}

\author{
V.D. SHELYAGIN, A.V. BERNATSKY, V.Yu. KHASKIN, I.V. SHUBA and A.V. SIORA \\ E.O. Paton Electric Welding Institute, NASU \\ 11 Kazimir Malevich Str., 03150, Kiev, Ukraine. E-mail: office@paton.kiev.ua
}

\begin{abstract}
In order to study physical features and technological capabilities of continuous optical discharge, a number of laboratory stands and plasmatrons were developed, which were used to determine the ranges of variation of energy, gas-dynamic, chemical and design parameters, providing stability of processing operations. It was found that at the change of power of $\mathrm{CO}_{2}$-laser radiation in the range of $1.5-6.0 \mathrm{~kW}$, power of continuous optical discharge changes linearly, while power of laser radiation, passing through the discharge, can be regulated from 8 to $40 \%$ of $\mathrm{CO}_{2}$-laser radiation power. Shown is the possibility of additional energy input into continuous optical discharge from direct current source. Here, power of additional input can exceed that of laser radiation. It is rational to apply continuous optical discharge, together with laser radiation which passed through it, to produce new materials, nanostructured carbide and diamond films, spheroidizing of refractory materials, surface modification, surfacing and other related technologies. 14 Ref., 1 Table, 3 Figures.
\end{abstract}

Ke y w ord s : continuous optical discharge, $\mathrm{CO}_{2}$-laser radiation, surfacing, heat treatment, experiments, modes, metallography, structure, residual stresses

In 1970 continuous optical discharge (COD) in gas was for the first time obtained experimentally and studied by Yu.P. Raiser [1]. In the first experiments, optical discharge plasma was freely located inside a stationary gas volume in the focal region of continuous $\mathrm{CO}_{2}$-laser radiation. In 1978 there was the first report about development of a plasmatron [2], in which optical discharge stabilization in focused laser radiation is achieved by gas flow longitudinal in the direction of radiation. Possibility of free transfer of laser radiation energy to considerable distance, its concentration in small volumes by optical means, high temperature and degree of ionization in optical discharges open up the prospects for many practical applications. Until recently, however, work on this problem was focused on investigations of COD plasma proper in gases, and just the possibility of application of laser plasmatron in thermal and plasmochemical processes was noted [3-5].

Prospects for COD application were determined by its features and unique characteristics.

First, COD plasma can be generated in the majority of gas mixtures at atmospheric and higher pressure, while known «pure» technologies, based on application of plasma of high and superhigh purity (HF, SHF), are preferably applied at lower (below 100 Torr) pressures of gas mixtures, i.e. in vacuum chambers. At the same time, solution of many applied problems is essentially simplified, or even becomes possible only at development of technologies of plasmochemical synthesis and coating deposition directly under atmospheric conditions. Application of COD plasma, which can exist at atmospheric pressure, in combination with manipulators, opens up the possibility of coating deposition both locally, and on products of practically unlimited dimensions.

Secondly, high pressure of gases, i.e. considerable density of active molecules, in combination with record specific density of laser energy evolution in gas and high plasma temperature (15-20 thou K), create conditions for high-velocity synthesis of materials.

Thirdly, maintaining stable COD plasma does not require any structural elements for energy supply (electrodes, waveguides, resonators, etc.). There are no erosion products that usually contaminate the growing film in the traditional methods of plasmochemical deposition that allows producing chemically pure materials.

Wide acceptance of up to $2-10 \mathrm{~kW}$ laser units in industry and in research organizations stimulated performance of research and appearance of publications in this field [6-14].

The objective of this work is determination of COD physical parameters and technological capabili- 
ties of its application, as well as development of plasmatrons with plasma jet and laser radiation directed downward on the item. Design allowed for published data and results of our own experiments.

Experiments were conducted on different plasmatron models to determine optimum conditions of COD excitation and stable existence at different variations of laser radiation power, gas kind and flow rate, geometrical dimensions of the discharge, point of application of powder and gas precursors to the discharge, etc.

Energy parameters of the discharge were provided by $\mathrm{CO}_{2}$-laser of TRIAGON 12000 model (ROFIN-SINAR Company, Germany). Technological stand was at $7.5 \mathrm{~m}$ distance from laser output window. Reflecting copper mirrors were used to transmit laser radiation by air to the process head, where it was focused by salt $\mathrm{KCl}$ lens with focal distance $F=330 \mathrm{~mm}$. Head conical part ended in a nozzle $27 \mathrm{~mm}$ long with 12 $\mathrm{mm}$ inner diameter. During experiments the lens focal plane was located at $10 \mathrm{~mm}$ distance from nozzle edge, to which plasmatrons of various designs were abutted, by inserting the plasmatron into the nozzle to the depth of $20 \mathrm{~mm}$. COD excitation was performed by short-time insertion of aluminium plate into laser radiation focal zone.

The Table gives the results of experiments on COD ignition and determination of the conditions of its stable existence in commercial argon jet, at variation of laser radiation power level on focusing lens $(P, \mathrm{~kW})$ and gas flow velocity in output nozzle of 12 $\mathrm{mm}$ diameter $(Q, \mathrm{~m} / \mathrm{s})$. At power exceeding $1.5 \mathrm{~kW}$, and argon flow velocity of more than $1.0 \mathrm{~m} / \mathrm{s}, \mathrm{COD}$ is excited and runs in a stable manner. Range of gas flow velocities, more suitable for technological operations, was selected for investigations $(1-40 \mathrm{~m} / \mathrm{s})$.

It is known [10] that at subsonic velocities of gas flow of $0.1-0.6 \mathrm{~m} / \mathrm{s}$ of atmospheric pressure and
1.2-6.0 kW power of $\mathrm{CO}_{2}$-laser radiation, $\mathrm{COD}$ behaves as a solid and the gas flow moving over it, is heated at the discharge periphery and flows around it. COD high-temperature core is localized in the region of laser beam focus, rises along the beam for up to $10 \mathrm{~mm}$ distance and is elongated along the gas flow. Gas discharge temperature gradient decreases with increase of gas flow velocity. Retardation of the flow is observed on COD front, where the higher pressure zone is located and gas flowing around the discharge high-temperature region is realized [10].

Figure 1, a, $c$ shows photos of COD under atmospheric conditions. COD stationary existence envisages equality of $\mathrm{CO}_{2}$-laser radiation energy dissipated in gas and its dissipation due to thermal radiation emission, heat conductivity and heat removal by convective gas flow. Dependence of the coefficient of laser radiation absorption on temperature has a maximum in the region of $17-18$ thou $\mathrm{K}$ at $1 \mathrm{~atm}$ in air, and threshold power is in the range of $1.8-2.0 \mathrm{~kW}$, respectively. In argon at $1 \mathrm{~atm}$ threshold power is about $800 \mathrm{~kW}$, and possible minimum temperature of plasma near the caustic is $12700 \mathrm{~K}$ [10].

Minimum threshold power of COD stable running decreases in the case of application of gas with a low ionization potential, poor heat conductivity and pressure increase. Figure 2 [14] shows experimentally measured isotherms of spatial distribution of plasma temperature of COD excited in air at atmospheric pressure, excited by $\mathrm{CO}_{2}$-laser of $6 \mathrm{~kW}$ power [14]. Beam is directed horizontally from right to left. A certain asymmetry of isotherms is attributable to air flow generated by Archimedean force.

If laser beam of 1.5 to $2.0 \mathrm{~kW}$ power and argon flow with velocity of $0.59 \mathrm{~m} / \mathrm{s}$ are directed vertically downwards, COD takes the shape of a sphere of about $15 \mathrm{~mm}$ diameter, and rises by approximately $1 \mathrm{~cm}$ in-

Values of process parameters, providing COD stable excitation and existence

\begin{tabular}{|c|c|c|c|c|c|c|c|c|c|c|c|}
\hline & 0.147 & 0.294 & 0.442 & 0.589 & 0.884 & 1.179 & 1.47 & 2.21 & 2.047 & 3.684 & 4.42 \\
\hline 1.0 & - & & - & - & & - & - & - & - & - & - \\
\hline 1.5 & - & & +- & +- & + & + & + & + & + & + & + \\
\hline 2.0 & + & & & +- & + & + & + & + & + & + & + \\
\hline 2.5 & & & & +- & + & + & + & + & + & + & + \\
\hline 3.0 & & & & +- & + & + & + & + & + & + & + \\
\hline 3.5 & & & & +- & + & + & + & + & + & + & + \\
\hline 4.0 & & & +- & + & + & + & + & + & + & + \\
\hline 4.5 & & & & +- & + & + & + & + & + & + & + \\
\hline 5.0 & & & +- & + & + & + & + & + & + & + \\
\hline 5.5 & & & & +- & + & + & + & + & + & + & + \\
\hline 6.0
\end{tabular}



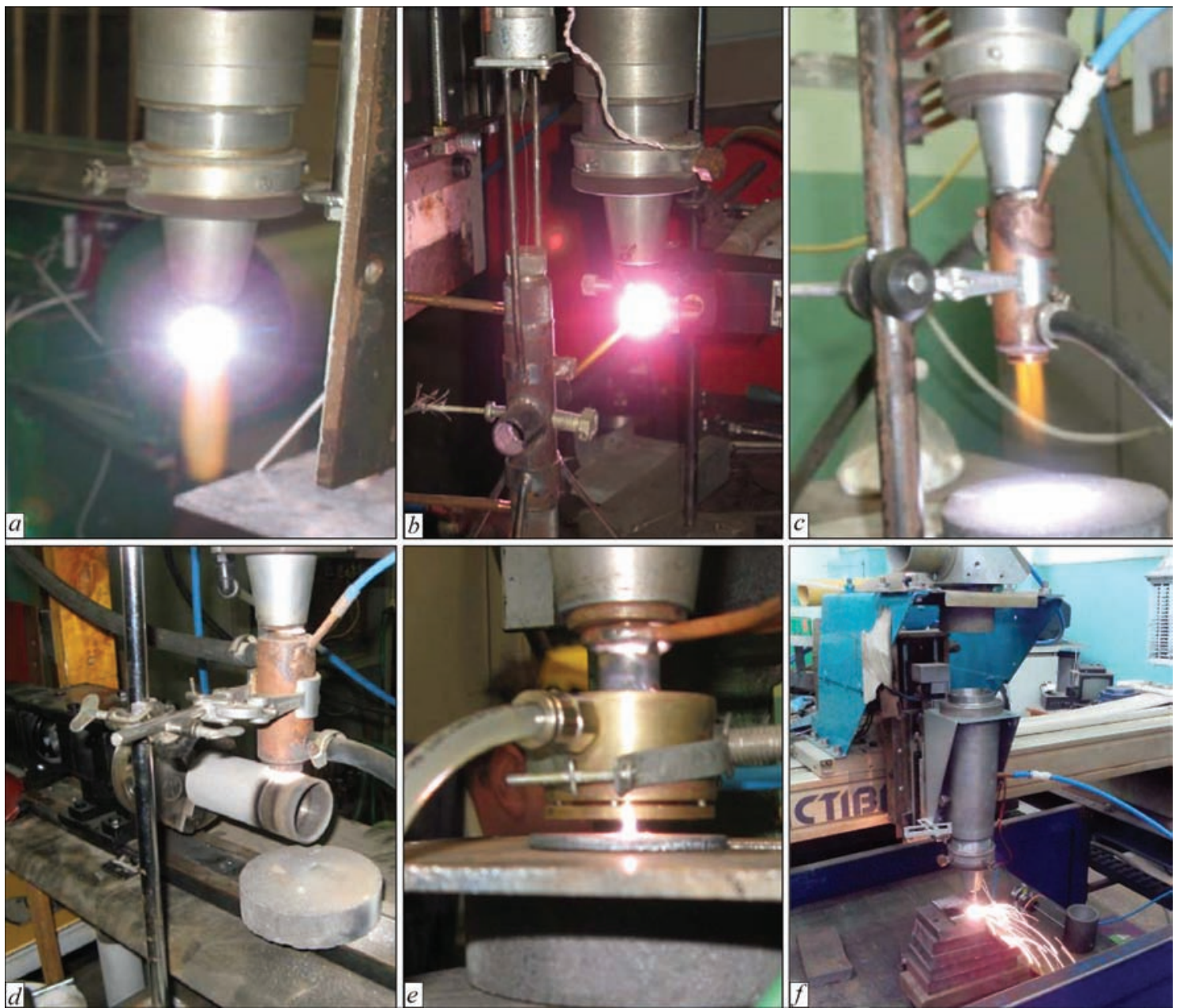

Figure 1. Laboratory stands for investigation of COD technological capabilities: $a-$ COD, running in an argon jet, in atmosphere; $b$ - hybrid interaction of COD and microplasma; $c$ - plasmatron operating on COD base in nitrogen; $d$ - treatment of bodies of revolution with COD; $e$ - hybrid plasmatron with COD pumping by DC arc; $f$ - COD surfacing

versely to the direction of laser radiation propagation; at flow velocity of $1.0 \mathrm{~m} / \mathrm{s}$ COD core is a bright luminous ellipse of $7 \times 17 \mathrm{~mm}$ size, which moves down for $7-8 \mathrm{~mm}$, and at the velocity of $4.42 \mathrm{~m} / \mathrm{s}$ COD moves down for $15 \mathrm{~mm}$ and has the form of a bright white ellipse, the central part of which is of $8 \times 22 \mathrm{~mm}$ size (Figure 1,a).

COD placing inside the plasmatron increases its stability, which depends, at other conditions being equal, on inner diameter of plasmatron channel. In plasmatron with inner diameter of $48 \mathrm{~mm}$ at beam power of $2.0 \mathrm{~kW}$ the discharge is stable at flow velocities of $0.14-3.0 \mathrm{~m} / \mathrm{s}$. In a plasmatron of $22 \mathrm{~mm}$ inner diameter and $115 \mathrm{~mm}$ length, at $2.0 \mathrm{~kW}$ power of laser radiation the discharge is stable at flow velocity in the range of $0.1-10.0 \mathrm{~m} / \mathrm{s}$. At atmospheric pressure and argon flow velocity of $1.0 \mathrm{~m} / \mathrm{s}$, it was not possible to set the upper power limit. In an optical plasmatron, the temperature of the discharge central part is by $1-3$ thou $\mathrm{K}$ higher, than COD temperature in stationary gas.
To enhance COD technological capabilities, at limited power of laser source, experiments were conducted to increase COD power by passing current through the discharge without inserting additional electrodes. Under the conditions of this experiment, COD does not touch plasmatron walls, and the jet

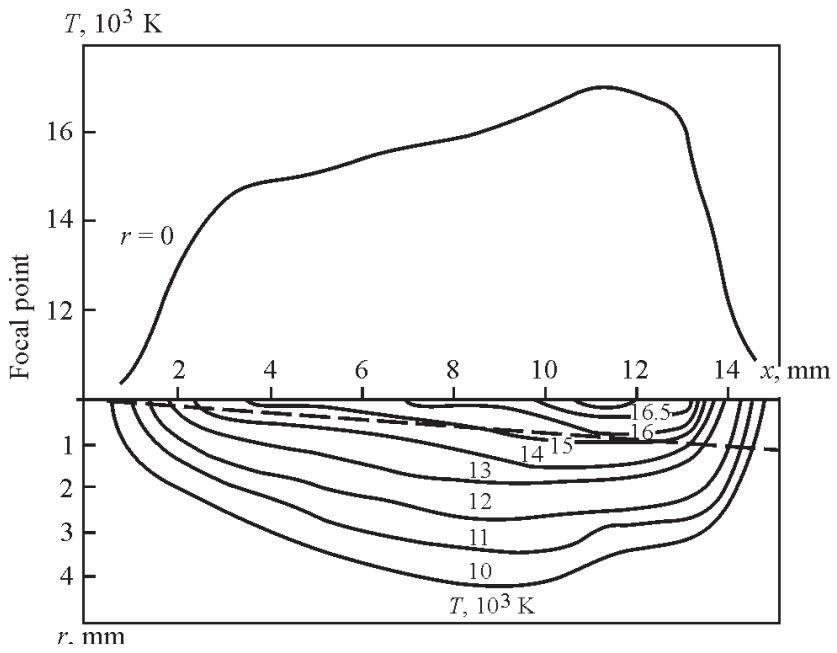

Figure 2. Isotherms of spatial temperature distribution of COD (bottom) and temperature distribution on beam axis (on top) 
formed by plasma discharge, touches the item. Diameter of plasmaforming nozzle was $3 \mathrm{~mm}$, the gap between the nozzle and item was $8 \mathrm{~mm}$. Positive potential of welding source was connected to plasmatron case, and negative potential - to the item. Current of additional discharge was $40 \mathrm{~A}$, voltage was $31 \mathrm{~V}$. About $1240 \mathrm{~W}$ were released in the discharge. Current flows through the cold layer of gas, due to greater mobility of plasma electrons. At polarity change current does not flow. Figure 1, e shows COD additionally preheated by direct current.

Interesting results were obtained at COD intersecting argon plasma flow, generated by arc plasmatron (Figure $1, b$ ). In this device, gaseous and powder precursors can be inserted both into COD plasma region, and into arc plasmatron plasma.

An important task in COD application is realization of laser-plasma technology of gas-phase synthesis of diamond films from multicomponent gas mixtures and deposition of these films on the surface of parts of machines and mechanisms, working surfaces of tools, etc [9]. COD generates dense equilibrium plasma with small temperature gradient in the cross-section of laminar gas flow - these are optimum conditions for decomposition of active components of gas mixtures and increasing the rate of diamond film deposition. Substrate temperature is very important for film deposition rate and its quality. Stabilization of its optimum temperature (about $800 \mathrm{~K}$ ) was performed by different design and energy parameters of the device, namely adjustment of crossover position in the plasmatron; plasma-substrate distance; design of gas and contact coolers; variation of laser power and gas flow velocity. Fraction of laser radiation reaching the substrate can be reduced due to elongation of COD high-temperature component. This requires reducing plasmatron channel diameter and increasing gas flow velocity. Elongation of high-temperature jet in COD will enhance laser beam refraction and power density on the item will decrease. This will allow avoiding overheating of deposited film central part, if power distribution in the beam is a Gaussian one. Qualitative estimates of synthesized films and individual crystals, as well as the spectra of their combined scattering are not given in this paper.

COD unique properties open up broad technological capabilities in the field of welding and related technologies. A laboratory stand was developed for determination of the possibility of changing the dimensions of powder material particles (powder dispersion) under COD impact. The stand consists of plasmatron of MP-4 model and its power source MPU-4M, allowing operation at up to 45 A currents at up to $40 \mathrm{~V}$ voltage. According to technological schematic given in [12], plasmatron was placed so that microplasma jet passed through COD normal to laser radiation axis (Figure 1, $b$ ). Used were powders of 40-60 $\mu \mathrm{m}$ granulation with three types of meltability, namely $\mathrm{Al}_{2} \mathrm{O}_{3}+\mathrm{TiO}_{2}$ refractory powder (melting temperature of about $2200{ }^{\circ} \mathrm{C}$ ), self-fluxing powder PG-12N-02 and PG-AN6 of N-Cr-B-Si system with medium values of meltability (melting temperature of $1000-1200{ }^{\circ} \mathrm{C}$ ), as well as low-melting powder PG19M-01 (melting temperature of $885-1020^{\circ} \mathrm{C}$ ).

During research performance splats were prepared to determine the degree of plasma discharge influence on powder particle. For this purpose powder particles which have flown through COD, shot-through by arc microplasma normal to laser beam axis, were deposited on object plates. Plates with a deposit were examined in optical microscope MBS-9. Investigations showed that refractory powders are poorly melted off by COD in view of the short time of staying in the discharge. Powders with low meltability values lend themselves too readily to COD impact and are prone to complete evaporation. Nickel-based self-fluxing powders with medium meltability values (melting temperature of $1000-1200^{\circ} \mathrm{C}$ ) proved to be the best. A tendency was established of refinement of power particles transported through COD by microplasma jet. Particle size was reduced to $30 \mu \mathrm{m}$ in approximately $20-25 \%$ of the total quantity of powder.

The next step in investigation of COD capabilities in the area of spheroidizing, crushing and refining of powders, was manufacturing a laser plasmatron based on COD (Figure 1, c). Investigation of technological capabilities of laser plasmatron with $3 \mathrm{~mm}$ nozzle diameter showed that the best conditions for its operation are in place at application of $2.0-3.0 \mathrm{~kW}$ radiation power of $\mathrm{CO}_{2}$-laser and flow velocity of plasma gas (argon) of 5-10 l/min. About 1.5-2.5 kW was applied to optical plasma, and $20 \%$ of laser power passed through COD. Optical discharge length was in the range of 15-20 mm, i.e. for 7-10 $\mathrm{mm}$ up and down with respect to focus. Length of plasma jet, leaving the laser plasmatron, was equal to $5-10 \mathrm{~mm}$, depending on gas flow velocity.

A laboratory stand was manufactured on the base of three-axis manipulator to perform experiments on steel sample surfacing by laser beam with simultaneous COD impact (Figure 1, f). It was used to spray samples with $\mathrm{Ni}-\mathrm{Cr}-\mathrm{B}-\mathrm{Si}$ system powders from PG- 

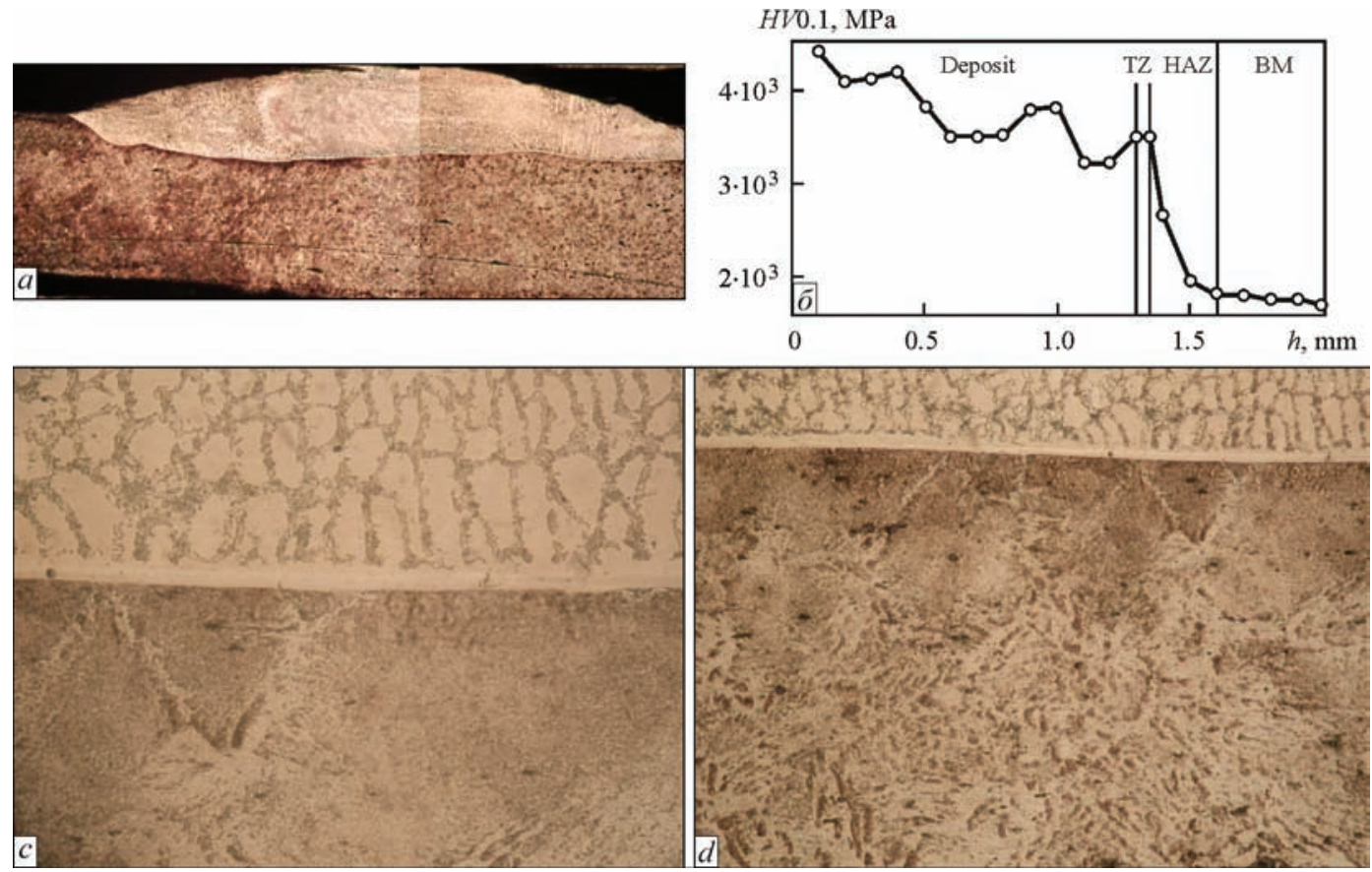

Figure 3. General view of deposited bead $(a, \mathrm{x} 25)$ with distribution of microhardness HV0.1 by depth $h$ of deposited layer $(b)$, transition zone $(c, \times 400)$ and HAZ in base metal $(d, \times 200)$

12N-02 (HRC 40-45) and PG-AN6 (HRC 60-65) alloys [13] by laser and hybrid laser-COD processes. Here, in all the cases laser radiation power was equal to $P=0.7-0.8 \mathrm{~kW}$, COD power was $P_{\mathrm{COD}}=2.0$ $2.2 \mathrm{~kW}$, deposition rate was $40 \mathrm{~m} / \mathrm{h}$, and deposited bead width was $4 \mathrm{~mm}$. Obtained samples were ground for further metallographic and radiographic investigations.

Hybrid laser-COD surfacing enabled produced defectfree layers with finely-dispersed cast structure, consisting of austenite matrix and $\delta$-ferrite, which precipitated along the boundaries of crystallites and cells (Figure 3, a). Quantity of $\delta$-ferrite was 15-25 $\%$ (measurements were performed in «Ferritegehalt-messer $1.053 »$ instrument). Microhardness distribution was measured in the direction from deposited layer surface towards base metal $(100 \mathrm{~g}$ load, $100 \mu \mathrm{m}$ step). These measurements showed greater uniformity of microhardness distribution for laser-COD surfacing than for laser surfacing (Figure 3,b). Transition zone size was equal to about $10 \mu \mathrm{m}$ (Figure 3, $c$ ), and heat-affected zone depth was up to $0.2 \mathrm{~mm}$ (Figure 3, d).

Thermal cycle modification in hybrid laser-COD surfacing promotes elimination of such characteristic defect of deposited layers as microcracks, as well as producing layers of sufficiently high hardness. Here, comparatively small dimensions of the HAZ (200$300 \mu \mathrm{m})$ and transition zone $(10-15 \mu \mathrm{m})$ are indicative of successful energy input.
Analysis of the results of deposition of layers from PG-12N-02 and PG-AN6 alloys of Ni-Cr-B-Si system on steel of St3ps type, made by laser and laser-COD processes, revealed that cracking index decreased from 40-60 to 20-30\%, respectively. Stresses of the Ist kind, measured in deposited layers by X-Ray phase technique, using X-ray diffractometer DRON-2, were also decreased. For PG-12N-02 and PG-AN6 alloys, deposited by the laser process, they were equal to -200 and $-510 \mathrm{MPa}$, respectively, whereas in layers, deposited by hybrid process, they were equal to +120 and $-310 \mathrm{MPa}$, respectively. Change of sign from «-» to $\langle+\rangle$ is indicative of the change of compressive to tensile stresses.

Investigations of heat treatment of samples from stamped steel $20 \mathrm{Kh} 13$ were conducted with minimum surface flashing (to the depth of $0.1-0.3 \mathrm{~mm}$ ) with $\mathrm{CO}_{2}$-laser radiation. Here, laser quenching was performed in the following mode: $P_{\text {las }}=1.5$ and $3.0 \mathrm{~kW}$; $v=60 \mathrm{~m} / \mathrm{h} ; d_{\mathrm{b}}=4-5 \mathrm{~mm} ; Q_{\mathrm{Ar}}=25-30 \mathrm{l} / \mathrm{min}$; and hybrid laser-COD quenching - in the following mode: $P_{\text {las }}=1.5 \mathrm{KW} ; d_{\mathrm{b}}=4-5 \mathrm{~mm} ; P_{\mathrm{pl}}=1.5 \mathrm{~kW} ; d_{\mathrm{pl}}=8 \mathrm{~mm}$; $v=60 \mathrm{~m} / \mathrm{h} ; Q_{\mathrm{Ar}}=25-30 \mathrm{l} / \mathrm{min}$. Produced quenched paths were used to cut out templates of $10 \times 10 \times 5 \mathrm{~mm}$ size, in which internal stresses of the Ist kind were measured in these paths by the method of X-ray phase analysis. Measurements showed that stressed state of the layers strengthened by laser process, was equal to about $470 \mathrm{MPa}$. Application of laser-COD strengthening allows reducing this value to approximately $260 \mathrm{MPa}$. 
The authors believe that additional advantages of COD application at synthesis of polycrystalline diamond films can be achieved by changing the shape of laser radiation intensity from Gaussian to rectangular one.

\section{Conclusions}

1. Investigations of the features of COD existence showed that COD power changes linearly in 1.5$6 \mathrm{~kW}$ range of powers of $\mathrm{CO}_{2}$-laser radiation, which has passed through focusing lens, while laser radiation component, which has passed through COD, can be equal to $10-30 \%$, depending on plasmatron design and values of process mode parameters. This allows using COD simultaneously with laser radiation which has passed through it, in the field of surface treatment technologies.

2. Possibility of applying additional electric power to COD was established.

3. To conduct the processes of surfacing and heat treatment of surfaces, it is rational to combine COD with the action of unfocused laser radiation (up to 2-4 mm diameter). The best results were obtained at COD power of $1.5-2.5 \mathrm{~kW}$ and $0.7-1.5 \mathrm{~kW}$ power of laser radiation, which has reached the substrate.

4. COD influence on the results of laser surfacing and heat treatment of surfaces consists in lowering residual internal stresses by $40-60 \%$ through thermal cycle modification.

1. Generalov, N.A., Zimakov, V.P., Kozlov, G.I. et al. (1971) Experimental investigation of continuously burning optical discharge. ZhETF, 61(1), 1434-1446.
2. Kozlov, G.I. (1978) Laser plasmatron with gas flow. Pisma $v$ ZhETF, 10(4), 586-589.

3. Raizer, Yu.P. (1980) Optical discharges. UFN, 132(3), 549581.

4. Zimakov, V.P., Kuznetsov, V.A., Kedrov, A.Yu. et al. (2009) Gas laser for efficient maintenance of plasma of continuous optical discharge in scientific and technological applications. Kvantovaya Elektronika, 39(9), 797-801.

5. Bolshakov, A.P., Kono, V.I., Vostrikov, V.G. et al. (2008) Examination of plasma optical discharge in multicomponent mixtures of molecular gases. Ibid., 38(2), 165-168.

6. Zimakov, V.P., Kuznetsov, V.A., Kedrov, A.Yu. et al. (2009) Refraction of laser radiation in plasma of continuous optical discharge in gas flow at atmospheric pressure. Optika Atmosfery i Okeana, 22(11), 1023-1028.

7. Franzen, D.L. (1973) Continuous laser-sustained plasmas. J. Appl. Phys., 44, 4, 1727-1732.

8. Kozlov, G.I., Kuznetsov, V.A., Masyukov, V.A. (1979) Continuous optical discharge in molecular gases. ZhTF, 49(11), 2304-2310.

9. Bolshakov, A.P. (2007) Synthesis of polycrystalline diamond films using laser plasmatron: Syn. of Thesis for Cand. of Phys.-Mat. Sci. Moscow: RGB.

10. Raizer, Yu.P. (1996) Continuous optical discharge - maintenance and generation of dense low-temperature plasma by laser radiation. SOZh, 3, 87-94.

11. Kolumbaev, E.B., Lelevkin, V.M. (2002) Numerical analysis of characteristics of optical discharge in air. Vestnik KRSU, 2(2), 76-83.

12. Shelyagin, V.D., Krivtsun, I.V., Borisov, Yu.S. et al. (2005) Laser-arc and laser-plasma of welding and coating technologies. The Paton Welding J., 8, 44-49.

13. Borisov, Yu.S., Khaskin, V.Yu., Vojnarovich, S.G. et al. (2012) Combined laser-microplasma cladding with powders of Ni-Cr-B-Si system alloys. Ibid., 11, 16-22.

14. (1992) Physical encyclopedia. Moscow: Great Russian Encyclopedia. 


\title{
INVESTIGATION OF FORMATION OF WEAR-RESISTANT ALLOY STRUCTURE IN SURFACING USING FLUX-CORED STRIP PL-AN-111
}

\author{
B.V. EFREMENKO, A.G. BELIK, Ya.A. CHEJLYAKH and M. BAKHRAMI ALAMDARLO \\ «Pre-Azov State Technical University» (PSTU) \\ 7 Universitetskaya Str., 87500, Mariupol, Donetsk Region, Ukraine. E-mail: alexbelick@gmail.ua
}

\begin{abstract}
The investigations of temperature-time conditions of formation of microstructure of the alloy produced by electric arc surfacing of austenitic alloy of the type 500Kh40N40S2G1RTs using flux-cored strip PL-AN-111 were carried out. The investigation of structure formation of deposited bead over the height was carried out by modeling in the environment of the software product ProCAST. The modeling results were compared with the real microstructure of wear-resistant layer produced by electric arc surfacing using flux-cored strip PL-AN-111. The microstructure of a deposit was investigated on transverse microsections, etched with $4 \%$ nital for a long time, using the optical microscope Nikon Eclipse M200 and the electron scanning microscope JSM-6510 LV, equipped with the EDS-analyzer of Oxford Instruments Company. The application of finite element modeling allowed establishing that the cooling rate of the bead of $10 \mathrm{~mm}$ height and $25 \mathrm{~mm}$ width, deposited applying the flux-cored strip PL-AN-111 on the plate 09G2S of $15 \mathrm{~mm}$ thickness, varies from 27.8 to $0.6{ }^{\circ} \mathrm{C} / \mathrm{s}$, decreasing with the increase in cooling time and removal from the fusion zone with the base. The crystallization of 500Kh40N40S2G1RTs type alloy takes place in the temperature range of $1332-1195{ }^{\circ} \mathrm{C}$, starting with evolution of the primary carbides $\mathrm{M}_{7} \mathrm{C}_{3}$ and completing by the eutectic «liquid $\rightarrow$ austenite $+\mathrm{M}_{7} \mathrm{C}_{3}$ » transformation. The increase in cooling rate up to $27.8^{\circ} \mathrm{C} / \mathrm{s}$ suppresses the crystallization process of primary carbides $\mathrm{M}_{7} \mathrm{C}_{3}$, as a result of which a gradient structure is formed over the deposited layer height, varying from austenitic non-carbide (near the fusion boundary with the base) to the hypereutectic (in the upper part of the bead). At the cooling rate of $6.6{ }^{\circ} \mathrm{C} / \mathrm{s}$, the primary carbides $\mathrm{M}_{7} \mathrm{C}_{3}$ from the liquid are evolved in the interval of $1332-1274{ }^{\circ} \mathrm{C}$, containing in average $57.6 \% \mathrm{Cr}$ and $2.7 \% \mathrm{Ni}$, which corresponds to the thermodynamically stable state of the alloy of the $500 \mathrm{Kh} 40 \mathrm{~N} 40 \mathrm{~S}-$ 2G1RTs type. 12 Ref., 6 Figures.
\end{abstract}

Ke ywords: flux-cored strip, deposited layer, microstructure, computer modeling, crystallization

The deposition of protective coatings by arc surfacing is one of the most widespread technologies of restoration and surface hardening of machine parts. Among the wide variety of surfacing materials, the high-carbon compositions on an iron-chromium-nickel base, forming solid carbide phases of flux-cored strips PLAN-101, PL-AN-111, PL-AN-150 find application, which are used to strengthen contact surfaces of cones and bowls of charging equipment of blast furnaces [1-4]. The chemical composition of flux-cored strips provides formation of structure in the deposited layer which is resistant to abrasive, gas-abrasive, erosion wear at elevated temperatures, which is promoted by a high corrosion and heat resistance of metal in combination with hardening carbide phases and the appropriate matrix $[5,6]$. Taking into account the complex alloying $\mathrm{Fe}-\mathrm{C}-\mathrm{Cr}-\mathrm{Ni}$ of flux-cored strips and the non-stationary nature of running surfacing processes, the formation of microstructure in the deposited metal can have a heterogeneous nature, leading to a gradient of properties over the height of the bead. As the tribotechnical properties of the deposited metal are determined by its microstructure, the issues of struc- ture formation control become important, especially at the stage of formation of a surfacing primary structure $[7,8]$. For this, it is necessary to know thermokinetic features of crystallization and the character of phase-structural transformations in the alloy of a specific chemical composition, which requires additional investigations, as-applied to the mentioned surfacing materials.

The aim of the work is the investigation of temperature-time conditions for formation of phases and their distribution over the bead height during surfacing of wear-resistant alloy using the flux-cored strip PL-AN-111.

Procedure. The deposited layer, made by electric arc surfacing using the flux-cored wire PL-AN-111, producing the alloy of 500Kh40N40S2G1RTs type, was investigated. The surfacing was carried out on $15 \mathrm{~mm}$ thick sheet of steel 09G2S (GOST 5520) at the following parameters: arc current $-700 \pm 50 \mathrm{~A}$, voltage $-32 \pm 2 \mathrm{~V}$, stickout $-50 \mathrm{~mm}$, surfacing speed $-32 \mathrm{~m} / \mathrm{h}$; feed rate $-41 \mathrm{~m} / \mathrm{h}$.

The thermal and time parameters of crystallization were studied using a computer modeling based on 

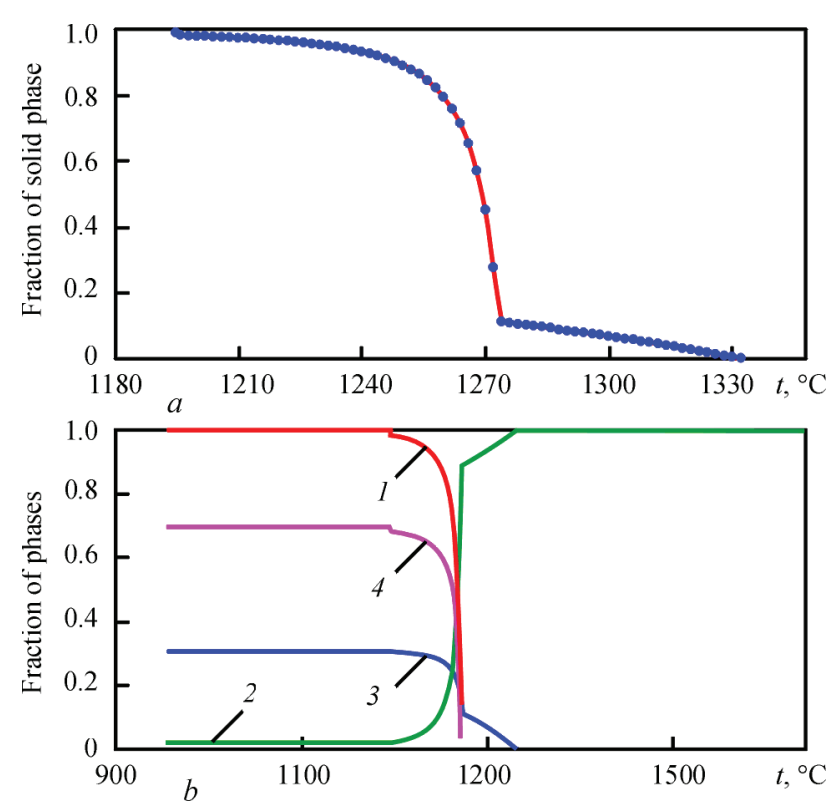

Figure 1. Calculation changes in the total volume fraction of solid phase $(a)$ and separate phases $(b)$ during crystallization of the 500Kh40N40S2G1RTs type alloy depending on the temperature of metal: 1 - solid phase; $2-$ liquid phase; $3-\mathrm{M}_{7} \mathrm{C}_{3} ; 4-$ austenite

the finite element method $[9,10]$. As the formation of deposited metal under certain assumptions can be similar to the crystallization of castings, to design the casting technologies the ProCAST software product was used in this work [11]. The modeling was carried out for the case of surfacing the bead of $10 \mathrm{~mm}$ height and $25 \mathrm{~mm}$ width using the flux-cored strip PL-AN-111, the initial temperature of the deposited metal was accepted as $1800{ }^{\circ} \mathrm{C}$, the cooling was in a calm air. The results of modeling were compared with the deposited metal real microstructure. The sur-

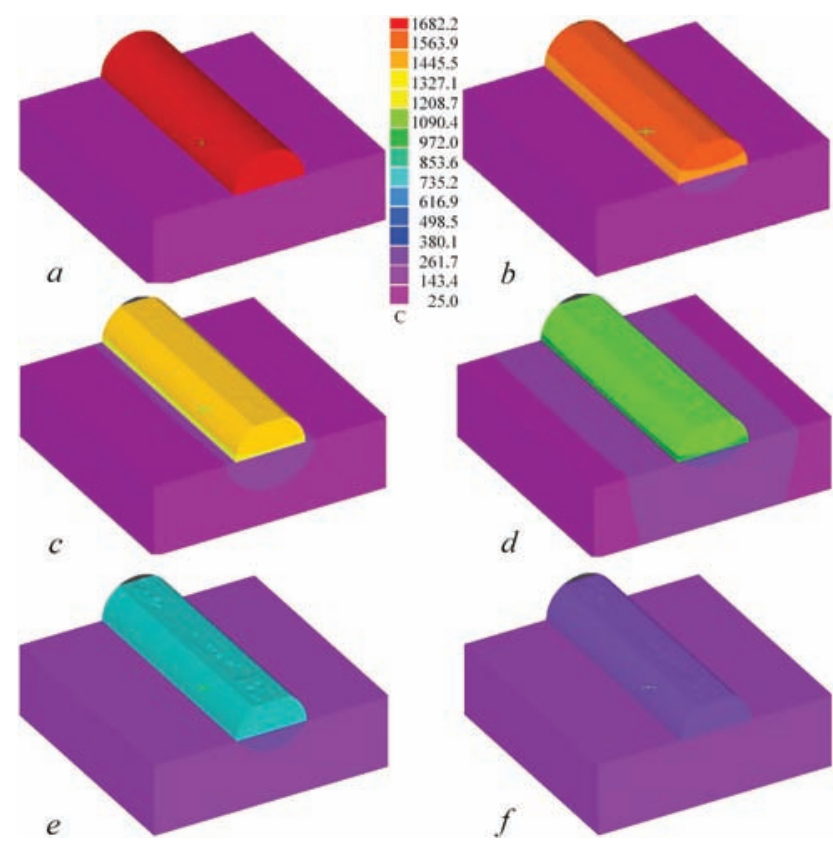

Figure 2. Dynamics of temperature field of the bead during crystallization after surfacing using flux-cored strip PL-AN-111: $a-$ $0 ; b-19 ; c-49 ; d-108 ; e-164 ; f-500 \mathrm{~s}$ facing microstructure was investigated on transverse microsections after long-term etching with $4 \%$ nital, using the optical microscope Eclipse M200 (Nikon) and the scanning electron microscope (SEM) JSM$6510 \mathrm{LV}$ (JEOL). The phase chemical composition was determined with the help of the energy dispersive microanalyzer X-Act (Oxford Instruments). The microhardness was measured by the micro-durometer FM-300 (Future-Tech) at a load of 20-50 g, averaging the values of 5-7 measurements.

Results and discussion. The results of thermodynamic modeling of crystallization of alloy of 500Kh40N40S2G1RTs type are shown in Figure 1. It follows from Figure 1, $a$ that the crystallization proceeds in the temperature range of $1332-1195{ }^{\circ} \mathrm{C}$. In the range of $1332-1274{ }^{\circ} \mathrm{C}$ according to Figure $1, b$ the primary carbides on chromium $\mathrm{M}_{7} \mathrm{C}_{3}$ base, having a rhombohedral lattice of the spatial group Pnma, are precipitated from the liquid. The volume fraction of primary carbides $(Q, \%)$ grows with decrease in temperature $\left(t,{ }^{\circ} \mathrm{C}\right)$ according to the linear dependence:

$$
Q_{\mathrm{M}_{7} \mathrm{C}_{3}}=-0.19 t+248.5 \text {. }
$$

At the moment of completion of primary carbide precipitation, the volume fraction of solid phase amounts to $11 \%$. The formation of remaining fraction of the solid phase is occurring in the range of 1274-1195 ${ }^{\circ} \mathrm{C}$ due to «liquid $\rightarrow$ austenite $+\mathrm{M}_{7} \mathrm{C}_{3}$ " eutectic transformation. The eutectic transformation occurs at the maximum velocity at the temperatures of $1274-1255{ }^{\circ} \mathrm{C}$, when $84 \%$ of solid phase of the alloy is formed; with the transformation exhaustion, its velocity falls sharply. At the moment when crystallization is completed, the following phase composition is fixed in the alloy: $11 \%$ of primary carbides $\mathrm{M}_{7} \mathrm{C}_{3}, 20 \%$ of eutectic carbides $\mathrm{M}_{7} \mathrm{C}_{3}, 69 \%$ of austenite. The alloy of 500Kh40N40S2G1RTs type is a hypereutectic alloy with predominance of an eutectic component. The subsequent solid-phase transformations (diffusion and shear) are almost absent in the alloy, being strongly inhibited due to a high content of chromium and nickel.

Figure 2 shows the results of modeling in the form of dynamics of temperature distribution across the crystallizing bead cross-section. The cooling is accompanied by decrease in the volume of liquid metal, as a result of which, a shrinkage (in the form of a flat area) in the deposit upper part is formed from 9 to 59 seconds after beginning of cooling with a decrease in height of the bead. Based on the results of modeling, the cooling curves of different bead layers were plotted. As follows from Figure 3, the curves can be divided into several regions differing in the average cooling rate. The first region corresponds to the liquid 


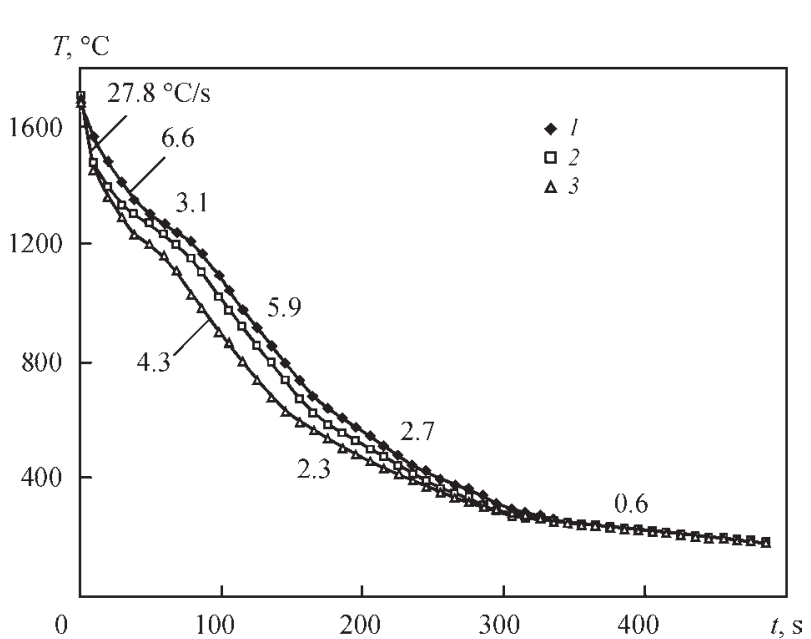

Figure 3. Calculation curves of cooling the bead layers at different distances from the base metal surface: $1-$ surface; $2-0.5$ height; 3 - fusion zone

state (up to $1332{ }^{\circ} \mathrm{C}$ ): here the bead surface is cooling at an average rate of $6.6^{\circ} \mathrm{C} / \mathrm{s}$; in the middle part of the bead and at the fusion boundary the average cooling rate is four times higher, i.e. $27.8^{\circ} \mathrm{C} / \mathrm{s}$. In the second region (in the range of about $1330-1200^{\circ} \mathrm{C}$ ) the bead cooling is delayed: to $3.1^{\circ} \mathrm{C} / \mathrm{s}$ at the surface and to $4.3{ }^{\circ} \mathrm{C} / \mathrm{s}$ in the fusion zone. This is explained by evolution of latent heat of phase transformations in precipitation of primary carbides and formation of austenite-carbide eutectic[12]. The latent heat of crystallization of cast irons amounts to $138.2 \mathrm{~J} / \mathrm{kg}$. After completion of crystallization, the bead cooling is ac-

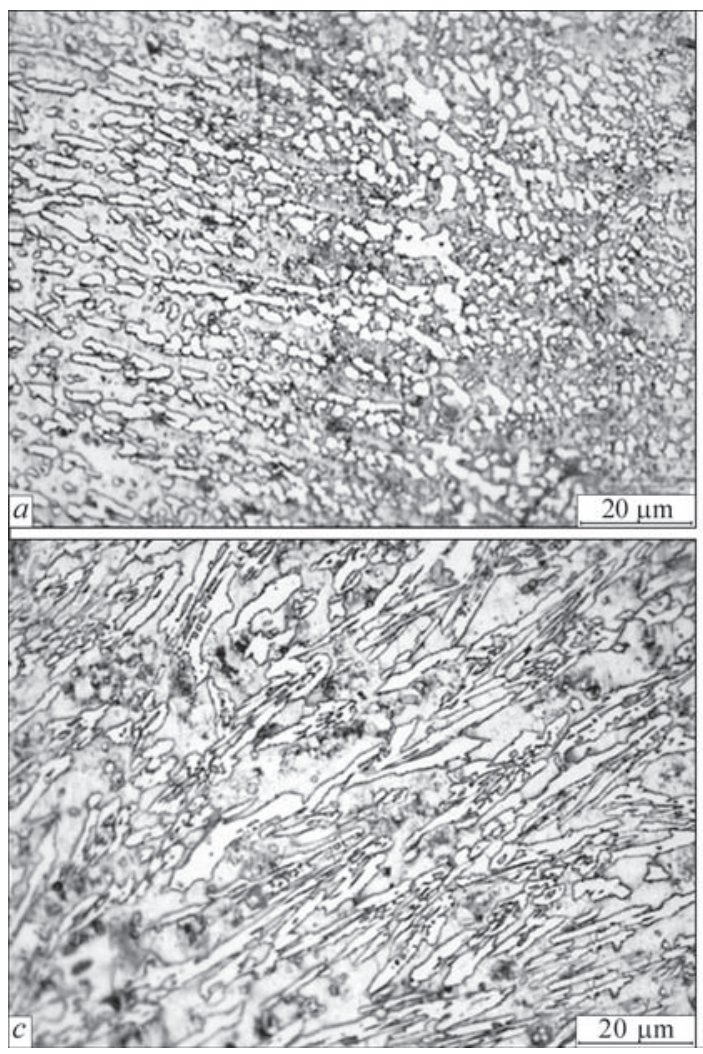

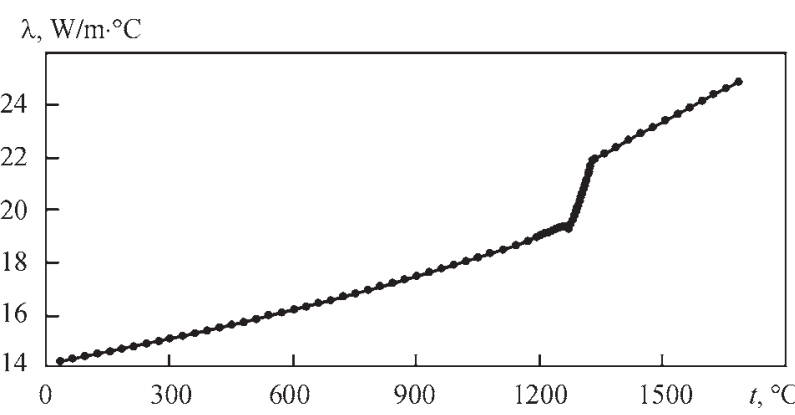

Figure 4. Calculation change of the coefficient of heat conductivity of the 500Kh40N40S2G1RTs type alloy

celerated, reaching $5.9{ }^{\circ} \mathrm{C} / \mathrm{s}$ at $600{ }^{\circ} \mathrm{C}$; this region on the cooling curve lasts almost $100 \mathrm{~s}$.

The cooling of the deposited bead occurs mainly due to heat radiation and heat removal into the base. The last component is limited by the deposit heat conductivity. According to Figure 4, the alloy has a lower heat conductivity, characteristic of high alloys. After completion of the eutectic transformation, the coefficient of heat conductivity $(\lambda)$ of the alloy amounts to $19.3 \mathrm{~W} /\left(\mathrm{m}^{\circ} \mathrm{C}\right)$ and gradually decreases to $14.2 \mathrm{~W} /\left(\mathrm{m} \cdot{ }^{\circ} \mathrm{C}\right)$ at cooling down to $20^{\circ} \mathrm{C}$. A decrease in $\lambda$ causes an equalization of temperature across the section and a decrease in cooling rate of the bead: in the range of $600-300{ }^{\circ} \mathrm{C}$ the deposit cools down at an average rate of $2.5^{\circ} \mathrm{C} / \mathrm{s}$; at the temperatures lower than $300{ }^{\circ} \mathrm{C}$, the cooling rate drops to $0.6^{\circ} \mathrm{C} / \mathrm{s}$.

The modeling results were compared with the real structure of the bead produced by surfacing using the
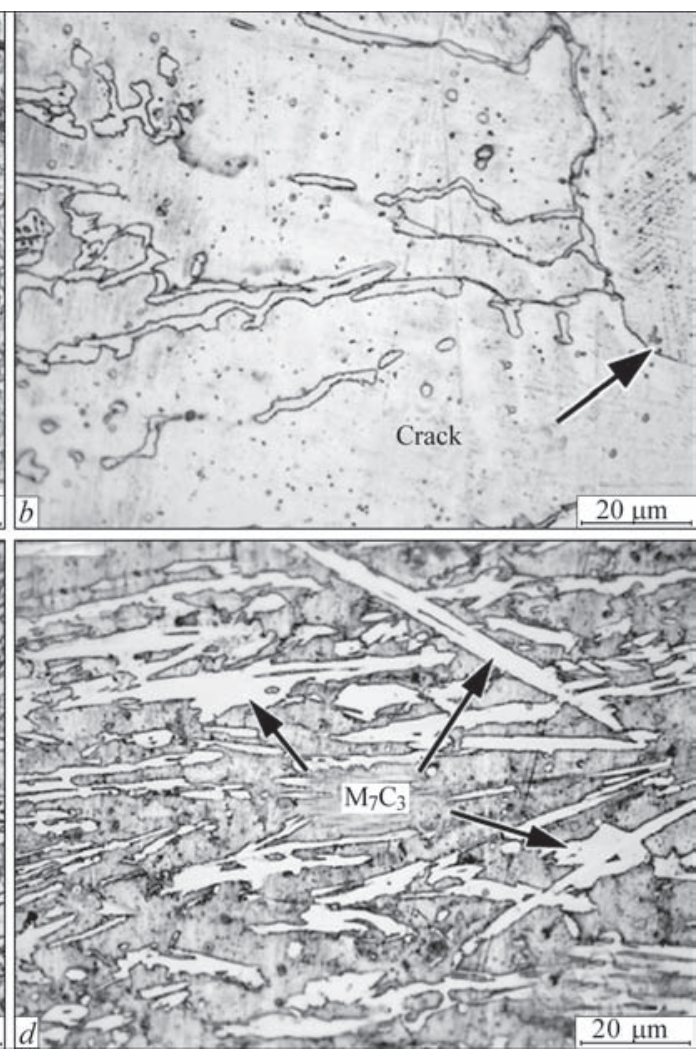

Figure 5. Microstructure of bead, deposited by the flux-cored strip PL-AN-111: zone of fusion with base metal ( $a, b)$; middle (eutectic) zone of bead (c); upper (hypereutectic) zone of bead (d) 
flux-cored strip PL-AN-111. From Figure 5, $a$ it follows that at the boundary with the base the carbide-free layer of solid solution (nickel austenite) with microhardness of 3740-3930 MPa lies in the bead to a depth of up to $20 \mu \mathrm{m}$. As the austenite is characterized by a lower specific volume, the cooling of the near-boundary layer was accompanied by occurrence of tensile stresses in it, which caused the formation of microcracks (Figure 5, $b$ ). After the carbide-free layer the layer with a hypoeutectic microstructure follows, formed by austenitic dendrites and a small amount of eutectic carbides (12-20\%) in the form of a boundary grid.

Further the eutectic structure lies, represented by columnar colonies of eutectic "austenite $+\mathrm{M}_{7} \mathrm{C}_{3}$ ",
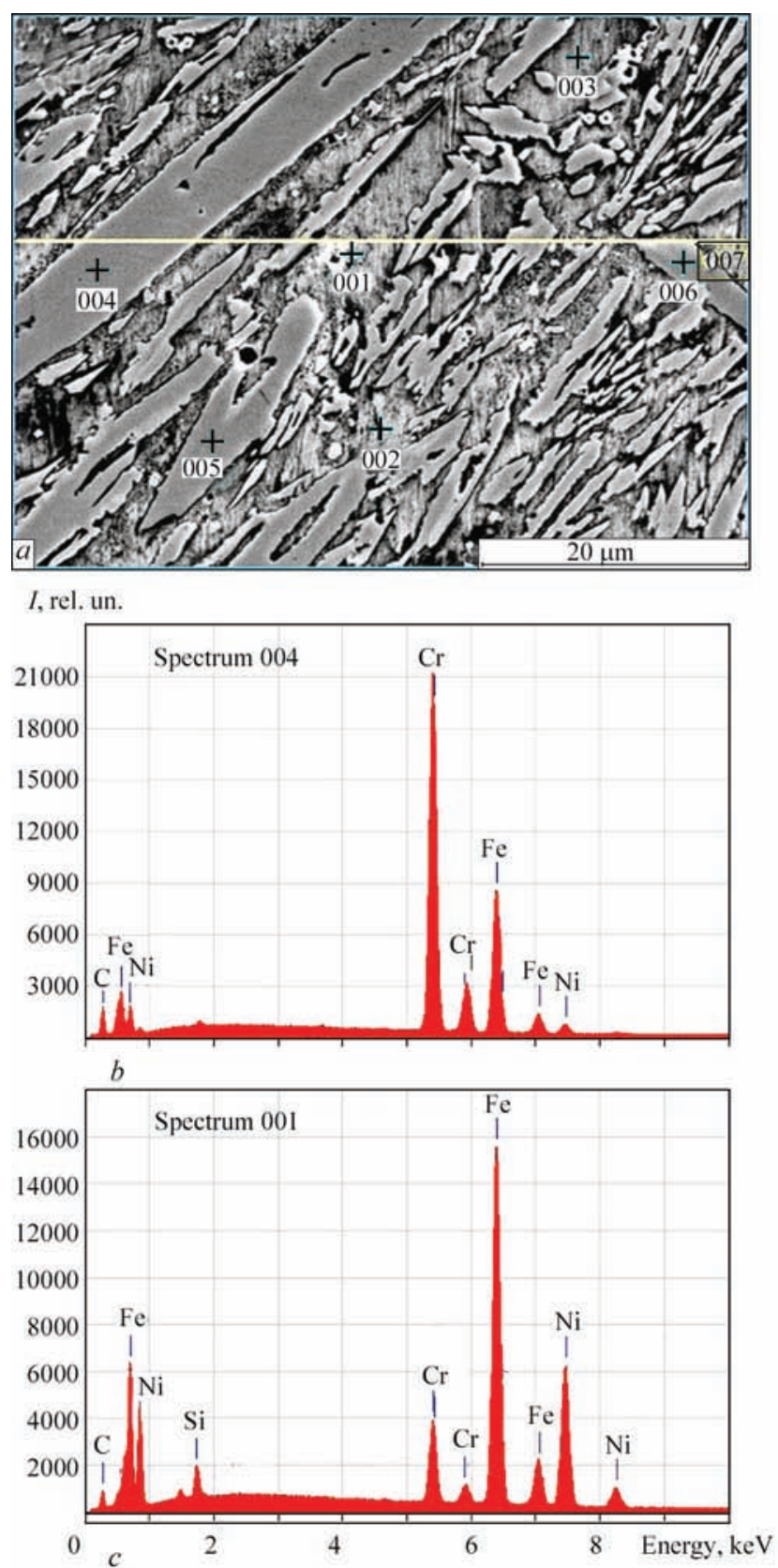

Figure 6. Sections of local micro-X-ray spectral analysis $(a)$ and corresponding spectra obtained from the primary carbide $\mathrm{M}_{7} \mathrm{C}_{3}$ (b) and austenite (c) oriented along the direction of heat removal to the base (Figure 5, c). The microhardness of eutectic colonies varies between $4450-4700 \mathrm{MPa}$. The eutectic consists of elongated carbide fibers separated by thin austenite interlayers; such a structure lies over the half of the bead height.

In the upper part of the bead, alongside with the eutectic, the primary carbides $\mathrm{M}_{7} \mathrm{C}_{3}$ are revealed in the structure in the form of prisms of $2.5-6.3 \mu \mathrm{m}$ width and 40-70 $\mu \mathrm{m}$ length (shown in Figure 5, $d$ with arrows); their microhardness is about $13000 \mathrm{MPa}$. The volume fraction of carbides in the middle (eutectic) part of the bead varies in the range of 33-35\%, in the upper (hypereutectic) part of the bead it is $27-31 \%$, which is close to the value obtained by modeling $(31 \%)$.

The results of metallographic analysis show that in the deposited bead a structural gradient was formed, i.e., the microstructure of the deposited layer as a whole differs significantly from the results of modeling. Only the upper part of the bead corresponds to the thermodynamically equilibrium state of the alloy with the presence of primary carbides $\mathrm{M}_{7} \mathrm{C}_{3}$. The absence of this structural component in the rest of the bead is explained as follows: $a-$ by the share of participation of base metal in deposited metal, which reduced the content of carbide-forming elements $(\mathrm{C}$, $\mathrm{Cr}$ ) in the metal; $b$ - by thermokinetic features of deposit crystallization, at which the crystallization of primary carbides in the near-boundary and middle zones of the bead is suppressed. It was established by the local micro-X-ray spectral analysis (Figure 6, $a, b)$ that the primary carbides $\mathrm{M}_{7} \mathrm{C}_{3}$ contain in average $8.90 \% \mathrm{C}$; $57.63 \% \mathrm{Cr}, 0.05 \% \mathrm{Si} ; 2.70 \% \mathrm{Ni}$; $1.90 \% \mathrm{Mn} ; 28.42 \% \mathrm{Fe}$. Thus, the concentration of chromium in primary carbides is almost one and a half time exceeds its average content in the alloy. Consequently, the formation of primary carbide required both fluctuation enrichment of liquid with chromium in the places of nuclei origination, and also significant diffusion fluxes of chromium atoms to provide the growth of formed carbides. At the rapid cooling of the deposited metal, these processes could be suppressed and eutectic reaction could be kinetically more viable, proceeding with the formation of smaller carbide inclusions or with precipitation of the oversaturated austenite dendrites.

The results of modeling allow establishing the boundary temperature-time conditions for formation of thermodynamically equilibrium structural state of the deposited alloy of 500Kh40N40S2G1RTs type. The intensive heat removal from the weld pool to the base provided cooling of the near-boundary and middle zones at the average velocity of $27.8^{\circ} \mathrm{C} / \mathrm{s}$, which 
inhibited the diffusion of chromium atoms in the liquid; as a result, the process of crystallization in these zones proceeded in the thermodynamically non-equilibrium conditions without formation of primary carbides. In contrast, the cooling of the upper zone proceeded slower $\left(6.6^{\circ} \mathrm{C} / \mathrm{s}\right)$. Firstly, it was connected with the fact that at the time when crystallization began in the upper part of the bead, in the underlayers it was already completed with evolution of latent heat of transformation, which increased the general heat content of surfacing. The preheated upper layer turned out to be screened from the base metal by the previously solidified near-boundary and middle layers; consequently, taking into account the low heat conductivity, which is characteristic to the given alloy, the heat removal from the upper part to the base metal appeared to be difficult. Thus, in this part of deposit and at the cooling rate of $6.6^{\circ} \mathrm{C} / \mathrm{s}$, the favorable kinetic conditions were created to form primary carbides $\mathrm{M}_{7} \mathrm{C}_{3}$, which is confirmed by the results of microstructural examination (Figure 5, d). However, also in this case these carbides have relatively small sizes, which indicates the inhibited kinetics of their growth.

Unlike the primary carbides, the matrix in the upper zone turned to be enriched with iron $(51.94 \%)$ and nickel $(33.03 \%)$ at a low content of chromium $(7.64 \% \mathrm{Cr})$. The rest of elements are: $5.18 \% \mathrm{C}$; $1.67 \% \mathrm{Si} ; 0.50 \% \mathrm{Mn}$ (Figure 6, a, c). The content of nickel in the matrix turned to be lower than the expected value, which is connected with a partial dissolution of nickel in carbides $\mathrm{M}_{7} \mathrm{C}_{3}(2.70 \%)$. The unusually high concentration of nickel in chromium carbides is explained by a general high content of this element in the alloy, which obviously changes the stoichiometry of phases relative to the iron-base chromium-nickel alloys.

\section{Conclusions}

1. The formation of the wear-resistant alloy structure during mechanized electric arc surfacing by the fluxcored strip PL AN-111 applying the finite element modeling was studied, which allowed establishing the sequence of layer-by-layer formation of wear-resistant structure in the deposited layer.

2. It was shown that crystallization of deposited metal is proceeding under non-equilibrium conditions, as a result of which a gradient structure is formed in it, changing from austenitic at the fusion boundary with the base metal to the ledeburite in the upper part of the bead, where primary carbides $\mathrm{M}_{7} \mathrm{C}_{3}$ are formed containing $57.6 \% \mathrm{Cr}$ and an increased amount of nickel (2.7\%).

3. According to the results of modeling, it was established that increase in the cooling rate of the bead up to $27.7{ }^{\circ} \mathrm{C} / \mathrm{s}$ suppresses the crystallization process of primary carbides $\mathrm{M}_{7} \mathrm{C}_{3}$, as a result of which in the deposited layer the hypoeutectic or eutectic structure with a volume fraction of carbides of $33-35 \%$ is formed. With a cooling rate of $6.6{ }^{\circ} \mathrm{C} / \mathrm{s}$, the primary carbides $\mathrm{M}_{7} \mathrm{C}_{3}$ are precipitated from the liquid in the range of $1332-1274{ }^{\circ} \mathrm{C}$, and then eutectic reaction takes place, which corresponds to the thermodynamically stable state of the $500 \mathrm{Kh} 40 \mathrm{~N} 40 \mathrm{~S} 2 \mathrm{G} 1 \mathrm{RT}$ type alloy.

1. Chigarev, V.V., Belik, A.G. (2011) Flux-cored strips for surfacing. Svarochn. Proizvodstvo, 8, 38-44.

2. Zhudra, A.P., Voronchuk, A.P. (2012) Cladding flux-cored strips (Review). The Paton Welding J., 1, 34-38.

3. Chigarev, V.V., Belik, A.G. (2012) Flux-cored strips for surfacing. Welding International, 26, 975-979.

4. Gladky, P.V., Kondratiev, I.A., Yumatova, V.I. et al. (1991) Cladding flux-cored strips: Manual. Kiev: Tekhnika.

5. Malinov, V.L., Chigarev, V.V., Vorobiov, V.V. (2012) New flux-cored strips for surfacing of parts operating under conditions of abrasive and gas-abrasive action. In: Protection of metallurgical machines from failures: Transact. Mariupol: PDTU, Issue 14, 252-258.

6. Shlapak, L.S., Shikhab, T., Prisyazhnyuk, P.N., Yaremiy, I.P. (2016) Structure formation of the chromium carbide-based cermet with copper-nickel-manganese binder. Metallofizika $i$ Novejshie Tekhnologii, 38(7), 969-980.

7. Lin, C.-M., Chang, C.-M., Chen, J.-H. et al. (2010) Microstructure and wear characteristics of high-carbon Cr-based alloy claddings formed by gas tungsten arc welding (GTAW). Surf. and Coat. Technol., 205, 2590-2596.

8. Klimpel, A., Dobrzanski, L.A., Lisiecki, A., Janicki, D. (2005) The study of properties of Ni-WC wires surfaced deposits. $J$. of Materials Processing Technology, 164-165, 1046-1055.

9. Schneider, M.C., Gu, J.P., Beckermann, C. et al. (1997) Modeling of micro- and macrosegregation and Freckle formation in single-crystal nickel-base superalloy directional solidification. Metall. and Mater. Transact. A, 28A, 1517-1531.

10. Murugan, S., Kumar, P.V., Gill, T.P.S. et al. (1999) Numerical modeling and experimental determination of temperature distribution during manual metal arc welding. Sci. and Technol. of Welding \& Joining, 4(6), 357-364.

11. Abdullin, A.D., Ershov, A.A. (2014) End-to-end simulation of casting and metal-forming operations with ProCAST and Qform software. Metallurgist, 58(5), 339-345.

12. Carvill, J. (1993) Mechanical Engineer's Data Handbook, Oxford. 


\title{
FEATURES OF THE STRUCTURE OF PLASMA-ARC COATINGS PRODUCED AT APPLICATION OF FLUX-CORED WIRES WITH A STEEL SHEATH AND FILLER

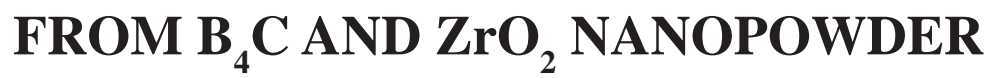

\author{
G.M. GRIGORENKO, L.I. ADEEVA, A.Yu. TUNIK, V.N. KORZHIK and L.M. KAPITANCHUK \\ E.O. Paton Electric Welding Institute, NASU \\ 11 Kazimir Malevich Str., 03150, Kiev, Ukraine. E-mail: office@paton.kiev.ua
}

\begin{abstract}
Features of the structure of coatings made by high-speed plasma-arc spraying of wire with a steel sheath and $\mathrm{B}_{4} \mathrm{C}$ powder filler with addition of nanosized $\mathrm{ZrO}_{2}$ powder were studied. Coatings with low porosity (about $1 \%$ ), lamellar structure and high hardness were produced on a low-carbon steel substrate. Processes of interaction, running in plasma-arc spraying between the sheath, making up $90 \mathrm{wt} . \%$ of the wire, and the filler, were analyzed. Ferrite matrix of the coating is alloyed with boron and carbon, and contains an amorphous phase. It is strengthened by dispersed carbide, borocarbide and oxide particles. Addition of $0.5 \%$ of $\mathrm{ZrO}_{2}$ nanopowder promotes refinement of the coating structure with formation of dispersed borocarbides $\mathrm{Fe}_{3}(\mathrm{~B}, \mathrm{C}), \mathrm{Fe}(\mathrm{B}, \mathrm{C})_{2}$, and oxides of iron $\mathrm{FeO}$ and boron $\mathrm{B}_{3} \mathrm{O}_{5}$. Coating microhardness reaches $6.86 \mathrm{GPa}$ that is 4 times greater than that of the ferrite sheath. Coatings of this class can be applied as wear-resistant ones for protection of equipment from gas-abrasive wear in chemical engineering, in manufacturing parts of pumps, compressors and other items, as well as reconditioning worn parts. 22 Ref., 7 Tables, 7 Figures.
\end{abstract}

Keywords: plasma-arc spaying, flux-cored wire, carbide filler, nanopowders, phase transformation, lamellar structure, dispersed strengthening of coatings, iron boro-carbide, microhardness

Nowadays, high-speed electric arc spraying of wire materials in the flow of products of natural gas combustion with air is one of the progressive methods, which allows producing the highest quality coatings $[1,2]$. Modern mechanical engineering makes ever higher requirements to coating wear resistance, which can be met only on the basis of new approaches. These are requirements of providing high density and strength of the coating, close to those of the compact material, minimum losses at spraying in the case of application of expensive materials and large volumes. Promising for solution of such problems is the process of plasma-arc spraying (PAS) with flux-cored wire at application of argon arc, blown by intensive concomitant air flow, increasing the plasma jet velocity [3-7]. At PAS of coatings, heating of wire material, its melting and formation of finely-dispersed sprayed particles occur both as a result of energy evolving in the arc anode spot, and closed on the wire, and due to energy applied to the wire at its transverse blowing by arc plasma flow. As a result, effectiveness of the process of wire melting rises essentially, compared to, for instance, traditional method of arc spraying [8]. Efficiency and stability of the process will be largely determined by conditions of heat exchange between the wire-anode and heat sources applied to it $[3,9]$. Chemical and phase composition of flux-cored wire charge can be broadly varied, that opens up considerable possibilities for development of new coating systems, and, thus, for further widening the area of their practical application $[10,11]$. Addition of nanosized additives to powder filler composition is one of the promising directions of improving the produced coating quality $[12,13]$.

The objective of this work is investigation of the structure, phase composition and properties of the composite coatings, produced by PAS from flux-cored wires with a steel sheath with fillers from $\mathrm{B}_{4} \mathrm{C}$ and $\mathrm{B}_{4} \mathrm{C}$ with addition of $\mathrm{ZrO}_{2}$ (nanosized) powders. It is promising to use boron carbide as filler for flux-cored wires. Owing to its unique properties (high hardness (49.5 GPa, wear resistance, chemical resistance, etc.), it is becoming widely applied in modern engineering both in its pure form, and in the form of cermets [14]. Boron carbide interaction with the wire sheath is determined by chemical affinity of iron to boron and carbon. As is known, in $\mathrm{Fe}-\mathrm{B}-\mathrm{C}$ system the reaction of interaction at heating in shielding gas medium leads, primarily, to formation of stable iron borides $\mathrm{FeB}, \mathrm{Fe}_{2} \mathrm{~B}$, and then to formation of cementite $\mathrm{Fe}_{3} \mathrm{C}$. Carbon, contained in $\mathrm{Fe}-\mathrm{C}$ melts, demonstrates high interphase activity, relative to $\mathrm{B}_{4} \mathrm{C}$ with formation of boride and boron-carbide phases [15-17]. Fe-B system at rapid cooling $\left(10^{5}-10^{7} \mathrm{C} / \mathrm{s}\right)$ is characterized by 
Table 1. Characteristics of initial materials

\begin{tabular}{|c|c|c|c|}
\hline Material & Particle size (grains), $\mu \mathrm{m}$ & Microhardness $H V$ 0.25, GPa & Phase composition by XSPA data, wt.\% \\
\hline $\mathrm{B}_{4} \mathrm{C}$ & $40-100$ & $29.96 \pm 3.06$ & $92.3 \mathrm{~B}_{4} \mathrm{C}+7.7 \mathrm{C}$ \\
\hline $\mathrm{ZrO}_{2}$ & $(2.6-7.3) 10^{-4}$ & - & $92.2 \mathrm{ZrO}_{2(\mathrm{~m})}+7.8 \mathrm{ZrO}{ }_{2(\mathrm{t})}$ \\
\hline $\mathrm{St08kp}$ & $4-20$ & $1.55 \pm 0.7$ & $100 \alpha-\mathrm{Fe}$ \\
\hline
\end{tabular}

formation of amorphous structures with high hardness of the order of $10 \mathrm{GPa}$. At PAS the processes of interaction run between the lower-melting steel sheath of the wire and refractory $\mathrm{B}_{4} \mathrm{C}$ and $\mathrm{ZrO}_{2}$ powder fillers. These processes lead to formation of new phases of a complex composition. At up to $10 \mathrm{wt} . \% \mathrm{~B}_{4} \mathrm{C}$, a fine-grain matrix structure forms, including dispersed borides, not forming any frame. Such materials are characterized by high strength $\left(\sigma_{t}=700 \mathrm{MPa}\right)[18$, 19]. Particles of nanosized refractory powder of $\mathrm{ZrO}_{2}$ are added to the composition of flux-cored wire filler, in order to create additional crystallization centers at coating formation.

This work is a study of plasma-arc coatings from flux-cored wires, which were deposited on the base from low-carbon, low-alloyed steel with microhardness of $1.90 \pm 0.2 \mathrm{GPa}$.

Investigation procedures and materials. A complex procedure was used in this work, including: metallography - Neophot-32 optical microscope with an attachment for digital photography; durometric analysis - LECO M-400 hardness meter at 0.249 and $0.496 \mathrm{~N}$ loads; X-ray structural phase analysis (XSPA) - DRONUM1 diffractometer with $\mathrm{CuK}_{\alpha}$-monochromatic radiation. Electronic study of the structure and determination of its elementary composition by the method of $\mathrm{X}$-ray spectral microanalysis (XSMA) were conducted in analytical system JAMP-9500F. JAMP-9500F system is fitted with energy-dispersive spectrometer OXFORD EDS INCA Energy 350 for analysis of elements from beryllium to uranium. Energy separating capacity is equal to $\Delta E / E=0.005-0.6 \%$. This attachment allows determination of mass fraction (concentration) of chemical elements in the samples by the method of non-destructive energy-dispersive X-ray analysis. At application of energy-dispersive analysis, probe diameter is $1 \mu \mathrm{m}$, and at Auger-study it is $3 \mathrm{~nm}$. The image of the structure was obtained in secondary electron mode (SEI) at $U=20 \mathrm{kV}$.

Reagents for chemical etching were used to reveal the structure of the studied objects. Structure of ironbased matrix was revealed in Nital reactive ( $4 \%$ alcoholic solution of nitric acid, $\tau=5-30 \mathrm{~s}$, at $\left.t=20^{\circ} \mathrm{C}\right)$, that of boride component - using $10 \%$ alcoholic solution of iodine $\left(\tau=5-15 \mathrm{~s}\right.$, at $\left.t=20^{\circ} \mathrm{C}\right)$.

In $1.8 \mathrm{~mm}$ flux-cored wires a strip from low-carbon steel St08kp (rimmed) $0.3 \mathrm{~mm}$ thick with an overlap butt joint was used as the sheath. Steel structure consisted of equiaxed ferrite grains and thin pearlite interlayers along the grain boundaries.

Powders of boron carbide $\left(100 \% \mathrm{~B}_{4} \mathrm{C}\right)$ and boron carbide with $\mathrm{ZrO}_{2}$ additives $\left(99.5 \% \mathrm{~B}_{4} \mathrm{C}+\right.$ $0.5 \% \mathrm{ZrO}_{2}$ ) were applied as wire fillers to study the influence of additives of zirconia nanopowder on formation of the structure and properties of composite coatings. Coefficient of wire filling was equal to about
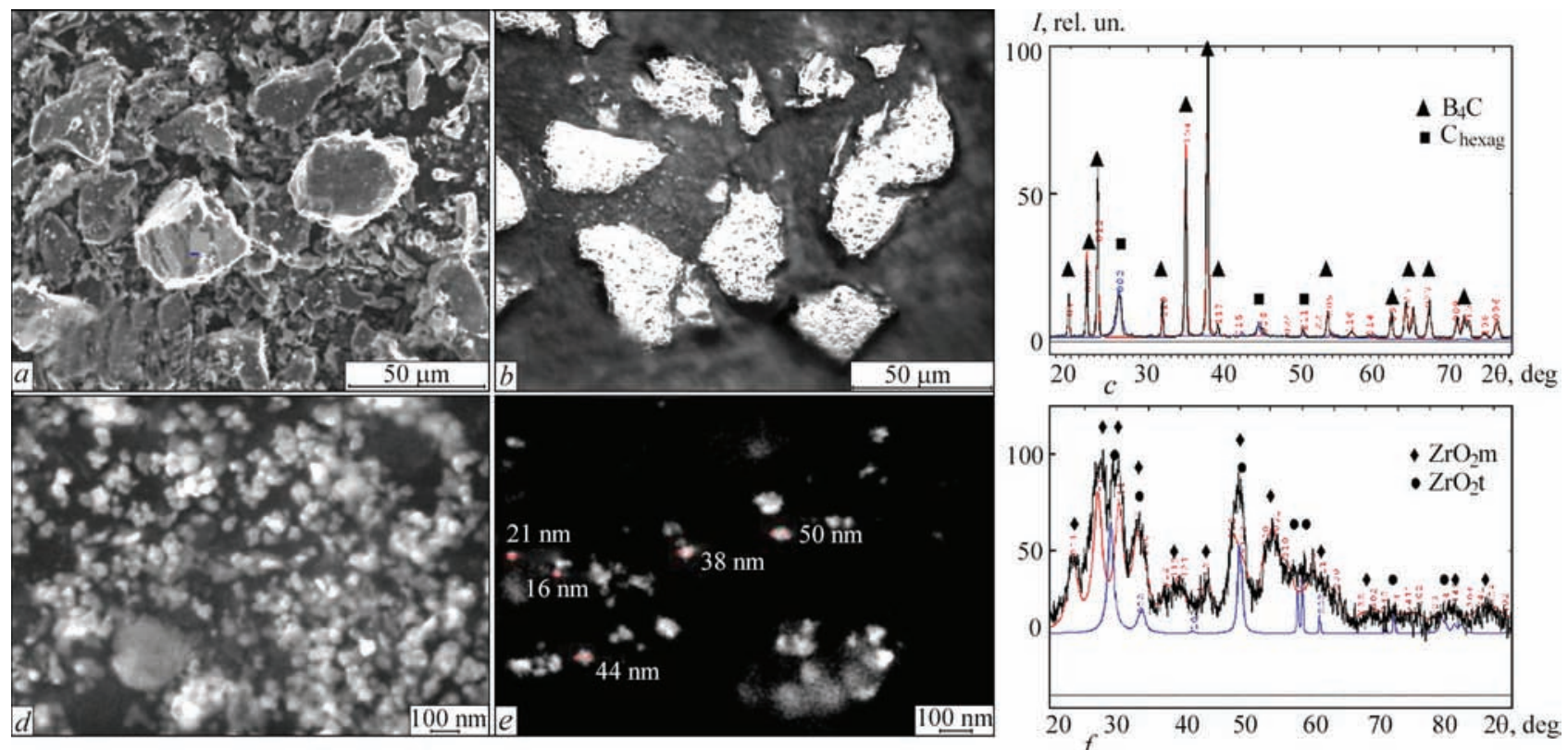

Figure 1. Morphology $(a, d, e)$, microstructure $(b)$ and roentgenograms $(c, f)$ of powder filler particles: $a-c-\mathrm{B}_{4} \mathrm{C} ; d-f-\mathrm{ZrO}_{2}$ 
Table 2. Characteristics of PAS coatings produced from flux-cored wires

\begin{tabular}{|c|c|c|c|c|}
\hline Filler composition, wt. $\%$ & $I, \mathrm{~A}$ & Thickness, $\mu \mathrm{m}$ & Main phase components by XSPA data & Microhardness, GPa \\
\hline $100 \mathrm{~B}_{4} \mathrm{C}$ & 250 & 550 & $\mathrm{Fe}_{3} \mathrm{~B}, \alpha-\mathrm{Fe}$ & $6.76 \pm 1.22$ \\
\hline $99.5 \mathrm{~B}_{4} \mathrm{C}+0.5 \mathrm{ZrO}_{2}$ & 240 & 300 & $\mathrm{Fe}_{3} \mathrm{~B}, \alpha-\mathrm{Fe}$ & $6.86 \pm 2.10$ \\
\hline
\end{tabular}

9 wt.\%. Characteristics of materials, making up the flux-cored wire, are given in Table 1.

$\mathrm{B}_{4} \mathrm{C}$ powder, produced by ingot crushing, consists of particles of irregular fragmentary form of 40-100 $\mu \mathrm{m}$ size (Figure 1, $a, b$ ). Microhardness of powder particles is equal to $21.40-35.00 \mathrm{GPa}$. By the data of XSPA (Figure 1, $c$, Table 1) the main phase of the powder is $\mathrm{B}_{4} \mathrm{C}$ with the following rhombic lattice parameters: $a=0.56078, c=1.20897 \mathrm{~nm}$ and small amount of carbon with the following hexagonal lattice parameters: $a=0.24658, c=0.67849 \mathrm{~nm}$.

Morphological studies of nanopowder particles showed that the size of $\mathrm{ZrO}_{2}$ particles does not exceed $100 \mathrm{~nm}$ (Figure 1, $d, e$ ). XSPA method was used to determine (Figure 1, $f$; Table 1), that zirconia nanopowder $\mathrm{ZrO}_{2}$ consists of two modifications: monoclynic with lattice parameters: $a=0.51382, b=0.51970, c=$ $=0.53078 \mathrm{~nm}$ and tetragonal with parameters of the lattice: $a=0.35997 ; c=0.51692 \mathrm{~nm}$.

Experimental. Coatings from flux-cored wires were produced by PAS method in PLAZER-30 unit in the following modes: $I=240-250 \mathrm{~A} ; U=60 \mathrm{~V}$; $L=175 \mathrm{~mm}, Q_{\text {air }}=110 \mathrm{l} / \mathrm{min}, Q_{\mathrm{Ar}}=7 \mathrm{l} / \mathrm{min}$, wire feed rate $-7 \mathrm{~m} / \mathrm{min}$ [20]. Coating characteristics are given in Table 2.
Coatings produced by PAS from wires with fillers are sound from metallographic viewpoint. They are thinly-lamellar, dense, have no cracks, and adhere well to the base. In the section of the coating with $\mathrm{B}_{4} \mathrm{C}$ filler (Figure 2,a) dark inclusions of a spherical shape of $10-40 \mu \mathrm{m}$ diameter and those of irregular shape of $80 \times 100,90 \times 120 \mu \mathrm{m}$ size are observed, as well as those in the form of lamellas of $15 \times 110,20 \times 120 \mu \mathrm{m}$ size (form factor of 7,6 ). These inclusions are the initial boron carbide, which has not reacted with the steel sheath of the wire. Also observed are thin grey-coloured oxide fringes of $0.1-0.5 \mu \mathrm{m}$ thickness along the lamella boundaries and small oxide particles of 1-10 $\mu \mathrm{m}$ diameter. After etching the section in Nital reagent it was found that the coating structure is predominantly lamellar with lamella size of approximately $20 \times 70,12 \times 320 \mu \mathrm{m}$ (form factor of 3-25). Lamellas of white colour and different shades of grey are observed. White lamellas and spherical particles of $10-30 \mu \mathrm{m}$ diameter, have the highest microhardness of up to $12.5 \mathrm{GPa}$, and are an amorphous component of the coating. XSPA method confirmed the presence of amorphous phase in both the coatings - by recording a «Halo» in the roentgenograms in angular intervals of $39^{\circ} \leq 2 \theta \leq 50^{\circ}$ and $79^{\circ} \leq 2 \theta \leq 85^{\circ}$ (Figure $2, b, d)[21]$.
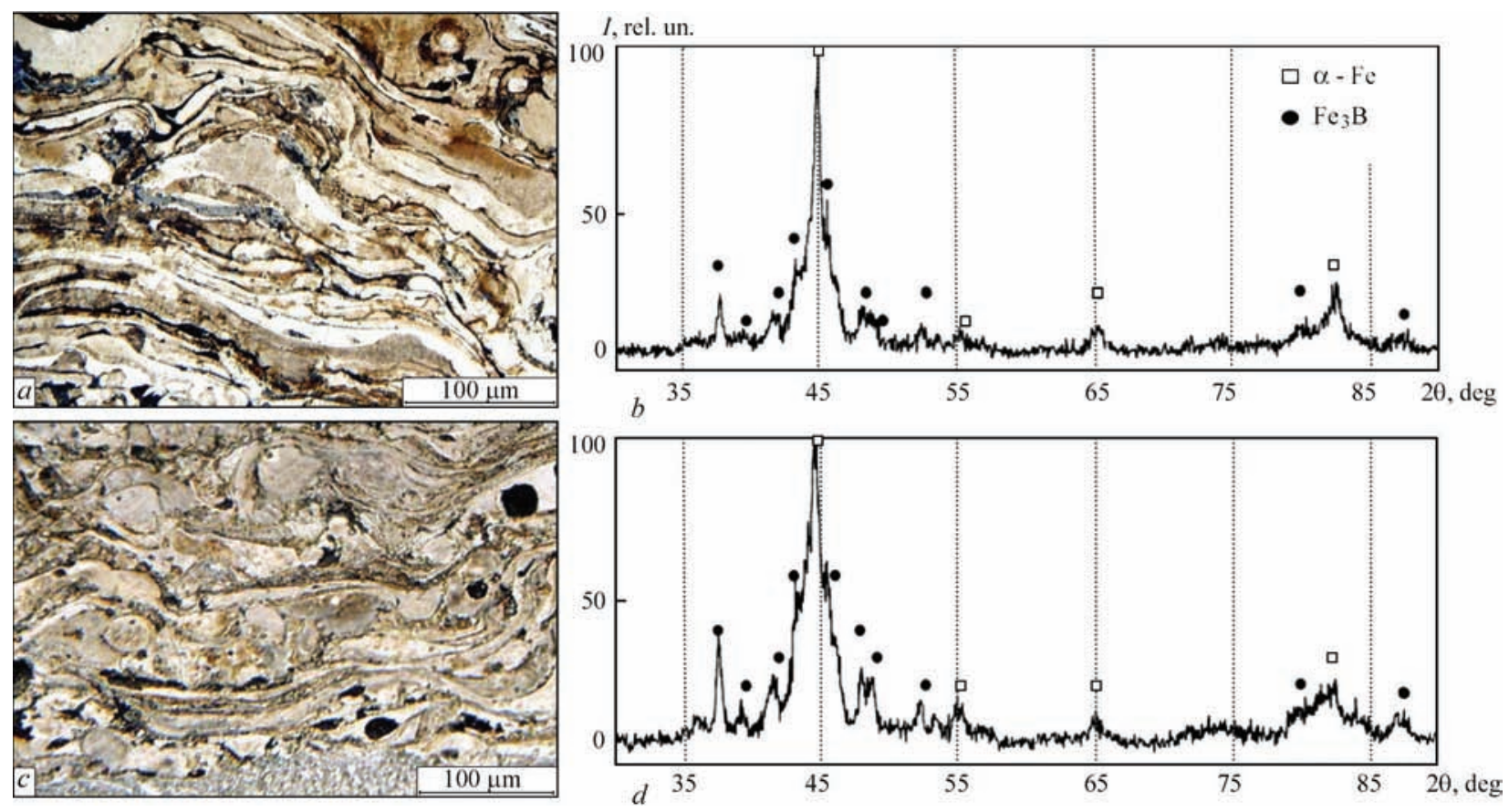

Figure 2. Microstructure $(a, c)$ and roentgenograms $(b, d)$ of plasma coatings produced from flux-cored wires with fillers of: $a, b-$ $\mathrm{B}_{4} \mathrm{C} ; c, d-\mathrm{B}_{4} \mathrm{C}+\mathrm{ZrO}_{2}$ 
At high magnification it is found that grey lamellas consist of finely-dispersed round and platelike inclusions of borides and borocarbides in the iron-based matrix, i.e. they have a two-phase structure. The grey lamella microhardness is equal to $5.71 \pm 1.22$, and that of light-grey ones is $7.89 \pm 1.35 \mathrm{GPa}$, that is attributed to their alloying.

In the coating produced by PAS from wire with $\mathrm{B}_{4} \mathrm{C}+\mathrm{ZrO}_{2}$ filler, the structure also is predominantly lamellar with oxide interlayers along the lamella boundaries (Figure 2,c). Metal particles of a spherical shape of 15-100 $\mu \mathrm{m}$ diameter are rare. Oxide component is recorded in the form of individual particles of round and irregular shape, as well as interlayers along the boundaries of lamellas and round particles. The coating is characterized by different etchability of the structural components. After etching in Nital reagent, particles and lamellas of white, light-grey and grey colour are found. A structure with directional solidification or formation of an acicular-type structure, are recorded in thin lamellas. A cast dendritic structure is characteristic for thicker lamellas, and particularly, for round particles. Coatings are formed by rather large lamellas. Their maximum size reaches $500 \times 30 \mu \mathrm{m}$, and the form factor of the lamellas is 5-17.

Studying the structure reveals white unetchable lamellas of amorphous type with high microhardness that is characteristic for $\mathrm{Fe}-\mathrm{B}$ system, and is indicative of high rates of coating cooling. The quantity of such lamellas is about 15 vol.\%, and their microhardness

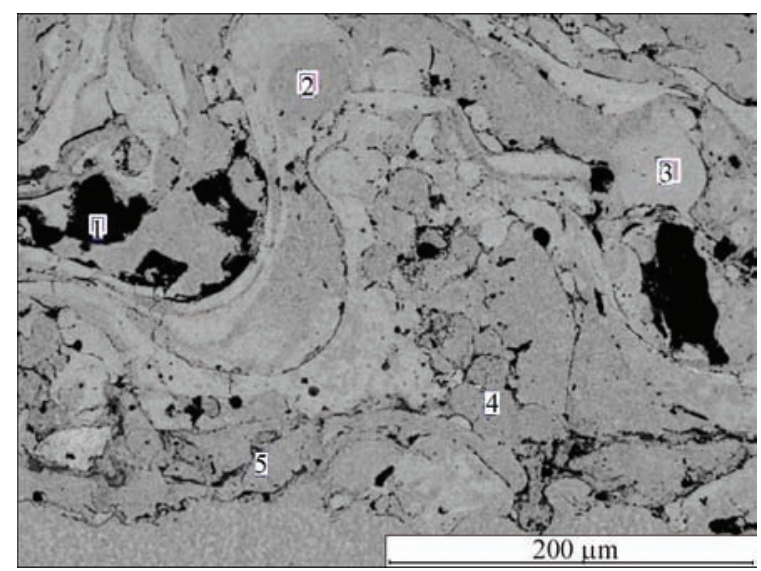

Figure 3. Microstructure of plasma coating produced from wire with $\mathrm{B}_{4} \mathrm{C}+\mathrm{ZrO}_{2}$ filler (REM, BEI mode)

is in the range of 6.44-11.45 GPa. The initial boron carbide is recorded in the structure, which is present, mainly, in the form of globular dark-coloured particles of up to $50 \mu \mathrm{m}$ size. After etching into the boride component, particles of iron boride of $0.5-1.0 \mu \mathrm{m}$ size are observed in the structure. They are uniformly distributed across the entire coating thickness. Microhardness of such areas is equal to 5.49-12.83, and average microhardness of the coating is equal to $6.86 \pm 2.10 \mathrm{GPa}$. This more than 4 times exceeds the microhardness of the steel sheath, which makes up about 90 wt. $\%$ of the wire. Addition of $0.5 \%$ of $\mathrm{ZrO}_{2}$ nanopowder to the composition of the wire filler only slightly increases the coating microhardness. By the data of XSPA and metallographic analysis, the main phases are: iron boride $\left(\mathrm{Fe}_{3} \mathrm{~B}\right)$, and $\alpha$-Fe-based

Table 3. Composition of the studied coating areas (Figure 3)

\begin{tabular}{|c|c|c|c|c|c|}
\hline \multirow{2}{*}{ Studied area } & \multicolumn{5}{|c|}{ Element content, wt./at.\% } \\
\cline { 2 - 6 } & $\mathrm{Fe}$ & $\mathrm{B}$ & $\mathrm{C}$ & $\mathrm{O}$ & $\mathrm{Zr}$ \\
\hline 1 & $4.02 / 0.82$ & $72.56 / 76.95$ & $22.99 / 1.95$ & $0.38 / 0.27$ & $0.03 / 0.00$ \\
\hline 2 & $96.52 / 84.74$ & $2.35 / 10.64$ & $1.13 / 4.62$ & $0.00 / 0.00$ & $0.00 / 0.00$ \\
\hline 3 & $95.91 / 82.48$ & $2.80 / 2.43$ & $1.21 / 4.83$ & $0.08 / 0.25$ & $0.00 / 0.00$ \\
\hline 4 & $97.67 / 89.67$ & $1.38 / 6.54$ & $0.71 / 3.01$ & $0.24 / 0.78$ & $0.00 / 0.00$ \\
\hline 5 & 73.5444 .04 & $0.50 / 1.53$ & $0.75 / 2.09$ & $24.97 / 52.19$ & $0.00 / 0.00$ \\
\hline
\end{tabular}

Table 4. Composition of the studied coating areas (Figure 4)

\begin{tabular}{|c|c|c|c|c|c|}
\hline \multirow{2}{*}{ Studied area } & \multicolumn{5}{|c|}{ Element content, wt./at.\% } \\
\cline { 2 - 6 } & $\mathrm{Fe}$ & $\mathrm{B}$ & $\mathrm{C}$ & $\mathrm{O}$ & $\mathrm{Zr}$ \\
\hline \multirow{2}{*}{1} & $96.33 / 84.24$ & $2.37 / 10.72$ & $1.12 / 4.54$ & $0.14 / 0.43$ & $0.00 / 0.00$ \\
\cline { 2 - 6 } & 82.80 & 9.40 & 1.40 & 6.50 & - \\
\hline \multirow{2}{*}{2} & $96.69 / 86.71$ & $1.98 / 9.18$ & $0.89 / 3.72$ & $0.00 / 0.00$ & $0.00 / 0.00$ \\
\cline { 2 - 6 } & 85.3 & 7.20 & 0.70 & 6.80 & $0.27 / 0.89$ \\
\hline 3 & $98.46 / 93.68$ & $0.26 / 1.28$ & $0.90 / 4.00$ & $0.15 / 0.50$ & $0.00 / 0.00$ \\
\hline 4 & $97.91 / 93.05$ & $0.64 / 3.13$ & $0.61 / 2.70$ & $0.21 / 0.15$ & $2.24 / 0.29$ \\
\hline \multirow{2}{*}{5} & $6.04 / 1.29$ & $68.24 / 75.28$ & $23.11 / 22.95$ & 4.50 & - \\
\hline & 2.40 & 67.60 & 25.50 & $0.18 / 0.13$ & $0.08 / 0.01$ \\
\hline 7 & $3.32 / 0.68$ & $75.39 / 79.35$ & $20.89 / 19.79$ & $0.15 / 0.12$ & $5.70 / 0.78$ \\
\hline
\end{tabular}




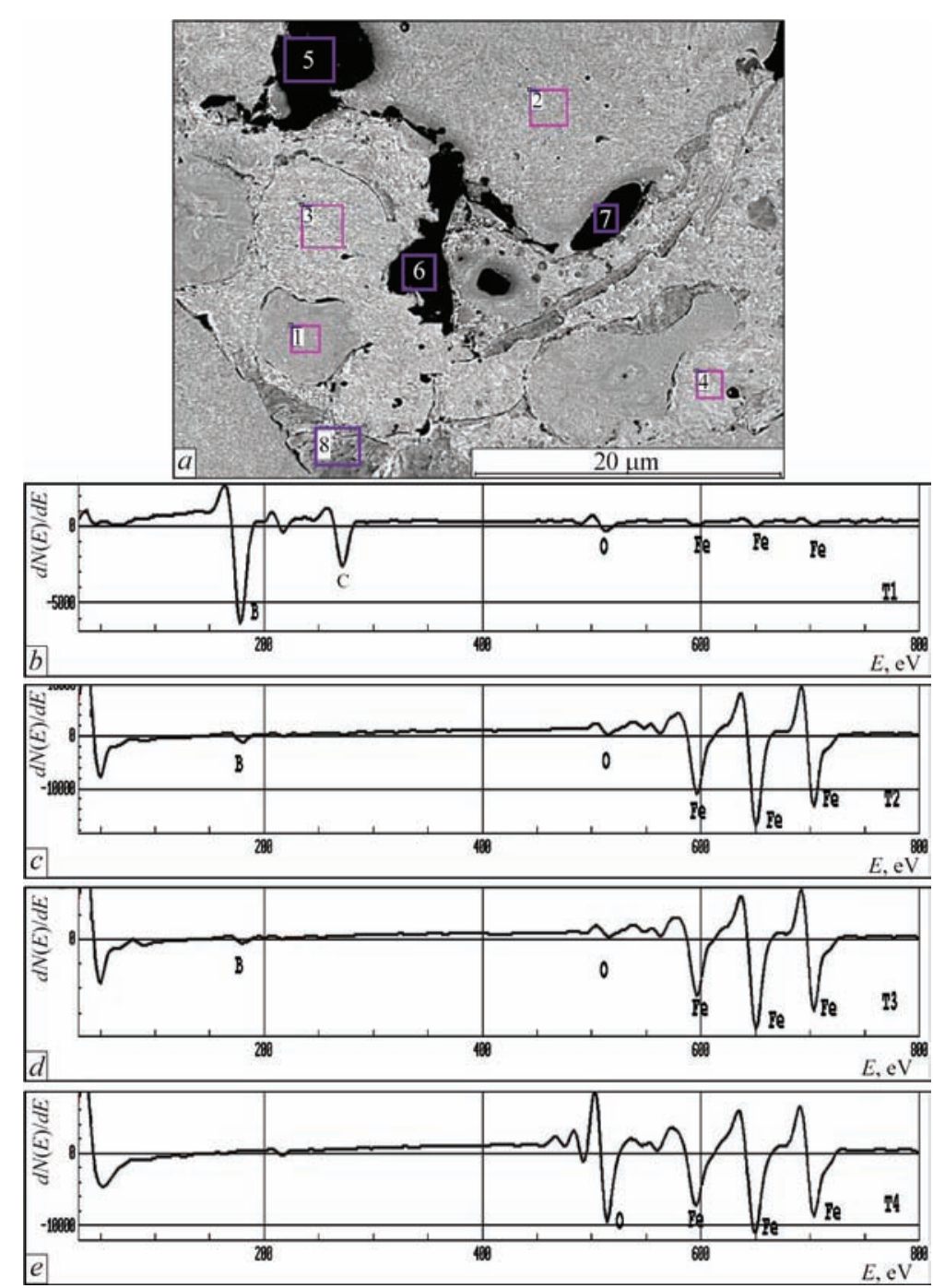

Figure 4. Microstructure $(a)$ and Auger-spectrometry data $(b-e)$ of areas 5, 1, 2, 8 of plasma coating produced from wire with $\mathrm{B}_{4} \mathrm{C}+$ $\mathrm{ZrO}_{2}$ filler, respectively

solid solution with larger parameter of BCC lattice, as well as boron carbide and iron oxide $(\mathrm{FeO})$. Metastable $\mathrm{Fe}_{3} \mathrm{~B}$ phase was found in $\mathrm{Fe}-\mathrm{B}$ system at rapid solidification at $10^{-3}{ }^{\circ} \mathrm{C} / \mathrm{s}$. The phase has orthorhombic lattice with parameters $a=0.543 ; b=0.666$; $c=0.445 \mathrm{~nm}$ [22]. Parameters of this phase found in the coating, are somewhat different from the data of ASTM card file: $a=0.536 ; b=0.668 ; c=0.446 \mathrm{~nm}$ that is probably related to boride alloying by carbon, i.e. formation of borocementite.

Additional investigations were conducted using XSMA and Auger-spectroscopy methods, in order to study the influence of $\mathrm{ZrO}_{2}$ nanopowder additives on formation of coating structure. Studied sections of the coating do not have a strict lamellar structure (Figure 3). Lamellas are bent, and their orientation is chaotic. In addition, rounded particles are found. Dark inclusions in the coating are boron carbide particles. Ferrite matrix, as a result of interaction with boron carbide at spraying, contains an increased quantity of boron and carbon. Coating areas, most doped with these elements, cannot be etched. They are white-coloured and smooth in optic photos. By the data of XSMA such particles and lamellas contain, wt.\%: 2.1-3.6 B, and 1.1-1.8 C (Tables 3, 4: Figure 3, ar. 2, 3 and Figure 4, ar. 1). Deeper etched areas (light-grey lamellas in optic photos) contain 1.4-2.0 B and 0.7$0.8 \mathrm{C}$. These areas are more doped with boron, than with carbon (Tables 3, 4; Figure 3, ar. 4 and Figure 4, ar. 2). Studies of these areas performed in Auger-spectrometer, confirm the high concentration of boron and carbon in them (Table 4, Figure 4). Oxide lamella (Figure 4, ar. 8) is iron oxide FeO. The most heavily etched areas (grey-coloured lamellas in optic photos) contain wt.\%: 0.3-0.6 B and 0.4-0.9 C (Table 4; Figure 4 , ar. 3,4$)$.

Having studied element distribution in the characteristic radiation of $\mathrm{Fe}, \mathrm{B}, \mathrm{O}$ and $\mathrm{C}$, we can conclude that the greatest amount of boron and carbon is contained in boron carbide areas. The wire sheath from carbon steel, the share of which in the coating is about $90 \%$, initially contains 0.08 wt.\% C. By anal- 
Table 5. Composition of studied areas of the coating (Figure 5)

\begin{tabular}{|c|c|c|c|c|c|}
\hline \multirow{2}{*}{ Studied area } & \multicolumn{5}{|c|}{ Element content, wt./at.\% } \\
\hline & $\mathrm{Fe}$ & $\mathrm{B}$ & $\mathrm{C}$ & $\mathrm{O}$ & $\mathrm{Zr}$ \\
\hline \multicolumn{6}{|c|}{ Figure $5, a$} \\
\hline 1 & $89.80 / 64.10$ & $8.33 / 30.71$ & $1.36 / 4.52$ & $0.12 / 0.31$ & - \\
\hline 2 & $67.81 / 29.62$ & $26.37 / 59.52$ & $5.10 / 10.37$ & $0.16 / 0.25$ & - \\
\hline 3 & $8.19 / 1.74$ & $67.73 / 74.53$ & $23.60 / 23.38$ & $0.47 / 0.35$ & - \\
\hline 4 & $65.36 / 27.31$ & $25.91 / 55.93$ & $8.30 / 16.13$ & $0.43 / 0.63$ & - \\
\hline 5 & $87.53 / 59.54$ & $9.31 / 32.71$ & $1.88 / 5.93$ & $0.52 / 1.23$ & - \\
\hline 6 & $94.65 / 79.47$ & $3.30 / 14.33$ & $1.34 / 5.22$ & $0.15 / 0.44$ & - \\
\hline \multicolumn{6}{|c|}{ Figure $5, b$} \\
\hline 1 & $16.87 / 4.19$ & $55.23 / 70.81$ & $20.35 / 23.48$ & $0.35 / 0.30$ & $6.13 / 0.93$ \\
\hline 2 & $92.38 / 70.91$ & $5.83 / 23.11$ & $1.54 / 5.50$ & $0.07 / 0.19$ & $0.00 / 0.00$ \\
\hline 3 & $98.36 / 93.57$ & $0.45 / 2.21$ & $0.81 / 3.60$ & $0.00 / 0.00$ & $0.08 / 0.04$ \\
\hline 4 & $57.28 / 21.87$ & $27.68 / 54.59$ & $12.84 / 22.79$ & $0.17 / 0.23$ & $1.70 / 0.40$ \\
\hline 5 & $90.13 / 64.42$ & $7.94 / 29.31$ & $1.85 / 6.16$ & $0.00 / 0.00$ & $0.00 / 0.00$ \\
\hline
\end{tabular}

ysis results, all the lamellas in the coating have excess amount of boron and carbon. Enrichment of all the matrix components by these elements is the result of $\mathrm{B}_{4} \mathrm{C}$ interaction with the wire sheath in spraying. $\mathrm{Zr}$ traces were found in matrix areas analyzed using XSMA method (Table 4; Figure 4, ar. 4). Recorded in the structure is the initial boron carbide, which is mainly present in the form of small-sized particles. At spraying, as a result of interaction with the plasma jet, boron carbide particles lose boron because of interaction with iron and boride formation. By the data of XSMA and Auger-spectrometry, boron carbide particles, remaining in the coating, correspond to the composition of $\mathrm{B}_{2.5}-\mathrm{B}_{4} \mathrm{C}$ (Tables 3-5; Figures 3-5). Zirconium in the amount of 2.2-5.7 wt.\% was found in the most disintegrated boron carbide particles (Table 4). This is attributable to reaction of interaction between $\mathrm{ZrO}_{2}$ and $\mathrm{B}_{4} \mathrm{C}$, which leads to zirconium recovery. $\mathrm{A}$ fringe with a changed structure $0.8-1.5 \mu \mathrm{m}$ thick, enriched with $\mathrm{B}$ and $\mathrm{C}$, is found around such particles (Table 5; Figure 5, $a$, ar. 1, 4-6 and Figure 5, b, ar. 2, 5). Such a fringe is absent around boron carbide of the initial composition - $\mathrm{B}_{4} \mathrm{C}$ (Figure 4, ar. 6).

Figure 5, $a$ and Table 5 give the structure and chemical composition of the matrix, located around partially disintegrated particle of boron carbide $\left(\mathrm{B}_{3} \mathrm{C}\right)$. Nanosized particles of iron diboride $-\mathrm{FeB}_{2}$, enriched with $5.1-8.3$ wt.\% $\mathrm{C}$, are visible in the direct vicinity of the carbide to the depth of $0.1 \mu \mathrm{m}$ (Figure 5, $a$, ar. 2, 4). Among the known iron borides, iron diboride features high hardness of 29-30 GPa. Beyond this zone, to the depth of $1.5 \mu \mathrm{m}$, the matrix structure is modified, becoming smooth. At $0.4-0.9 \mu \mathrm{m}$ distance from boron carbide (Figure 5, $a$, ar. 5, 6), B and C content in the matrix decreases and is equal to 9.3-3.3 and $1.9-1.3 \mathrm{wt} . \%$, respectively. The more intensive the carbide dissolution, the wider is the zone around it, enriched in these elements. Boron carbide fringe of
$\mathrm{B}_{2.5} \mathrm{C}$ composition increased up to $2-3 \mu \mathrm{m}$ (Table 5; Figure $5, b)$. It is alloyed with boron and carbon to a greater degree than is the coating matrix as a whole. In the ferritic matrix the average boron content is equal to approximately 1.5 , and that of carbon is approximately $1.0 \mathrm{wt} . \%$. At analysis of the composition of boron carbide in the matrix area adjacent to it, 6.1 and 1.7 wt. $\% \mathrm{Zr}$ and an increased oxygen content were recorded (Table 5; Figure 5, b, ar. 1, 4). Nanosized particles of iron diboride formed in this area of the matrix, $\mathrm{ZrO}_{2}$ nanoparticles participating in their formation.

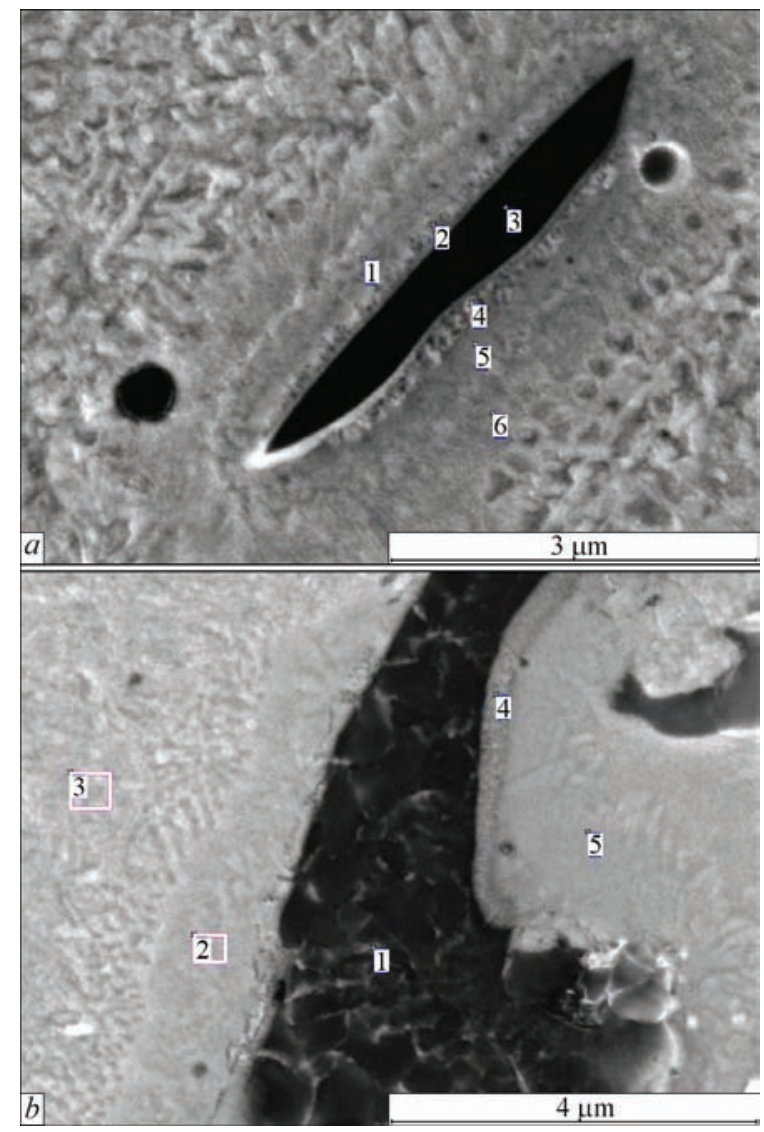

Figure 5. Matrix microstructure around $\mathrm{B}_{4} \mathrm{C}$ inclusions (REM, BEI mode) 


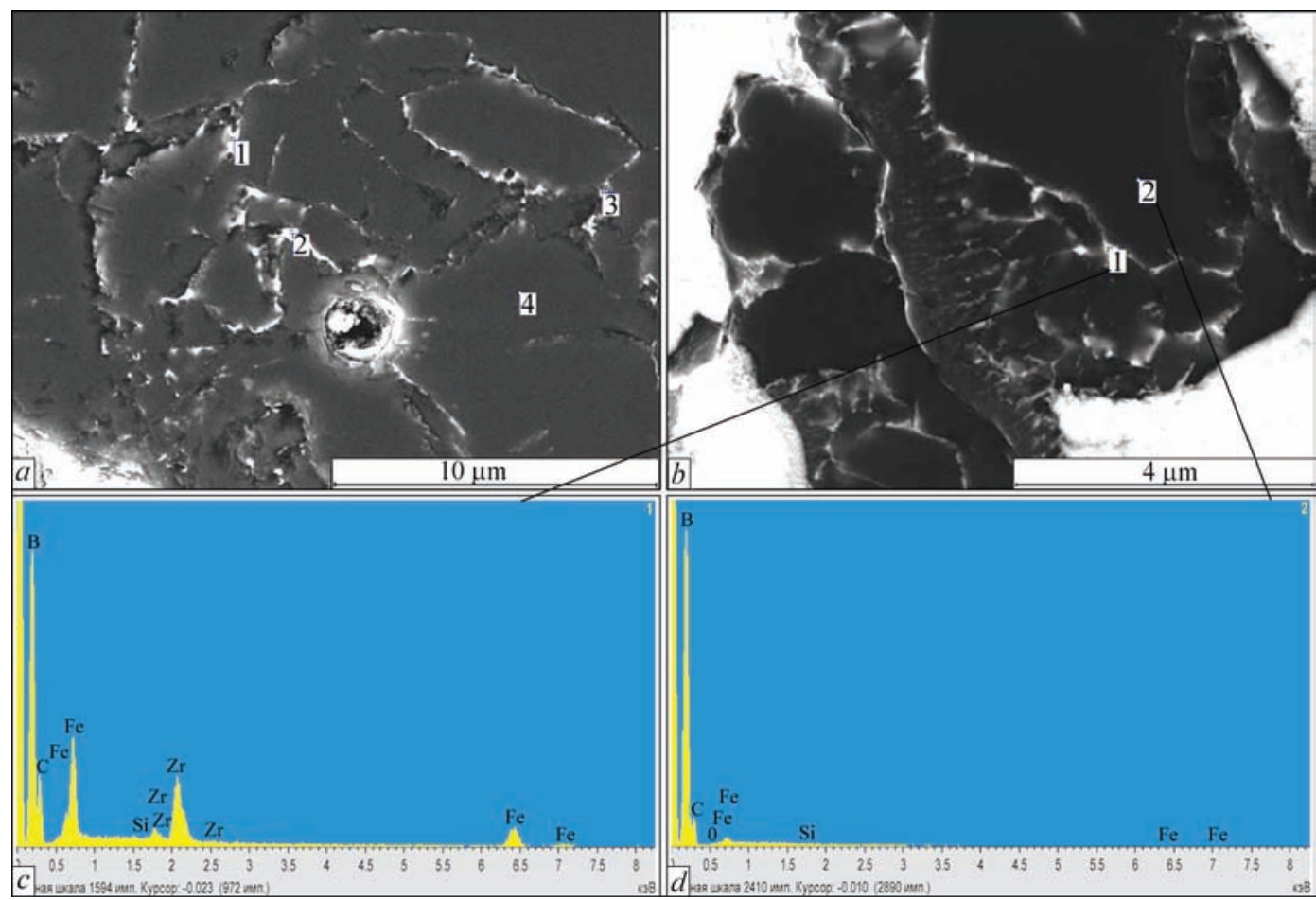

Figure 6. Microstructure $(a, b)$ of boron carbide inclusions in the coating (REM, BEI mode) and spectra of areas $1(c)$ and $2(d)$

When studying the structure of boron carbides in the coating, their grain structure is recorded (Figure 6). Segregations of the following elements were found along the boundaries of boron carbide grains, wt.\%: 0.25-1.6 Zr; 22.0-52.0 Fe; 0.4-0.7 [O] (Table 6; Figure 6, $a$, ar. 1-4), compared to the grain bulk, where no enrichment with these elements was observed. This is clearly recorded in XSMA spectra, obtained from these areas (Figure 6, b, ar. 1, 2). These segregations are the result of interaction of powder filler components $\left(\mathrm{ZrO}_{2}\right.$ and $\left.\mathrm{B}_{4} \mathrm{C}\right)$ at spraying.

Chemical composition of nonmetallic components of the coating was determined by XSMA and Auger-spectrometry methods. The oxide component is

Table 6. Composition of studied coating areas (Figure 6)

\begin{tabular}{|c|c|c|c|c|c|}
\hline \multirow{2}{*}{ Studied area } & \multicolumn{5}{|c|}{ Element content, wt./at.\% } \\
\hline & $\mathrm{Fe}$ & B & $\mathrm{C}$ & $\mathrm{O}$ & $\mathrm{Zr}$ \\
\hline \multicolumn{6}{|c|}{ Figure $6, a$} \\
\hline 1 & $37.11 / 10.81$ & $47.33 / 70.66$ & $12.96 / 17.41$ & $0.56 / 0.57$ & $1.59 / 0.28$ \\
\hline 2 & $52.04 / 18.26$ & $36.27 / 65.34$ & $9.53 / 15.46$ & $0.21 / 0.26$ & $1.40 / 0.30$ \\
\hline 3 & $26.29 / 7.07$ & $50.77 / 67.77$ & $20.15 / 24.20$ & $0.69 / 0.63$ & $0.32 / 0.05$ \\
\hline 4 & $0.90 / 1.27$ & $75.68 / 78.72$ & $22.26 / 20.84$ & $0.00 / 0.00$ & $0.00 / 0.00$ \\
\hline \multicolumn{6}{|c|}{ Figure $6, b$} \\
\hline 1 & $21.86 / 0.25$ & $52.15 / 71.71$ & $16.55 / 20.49$ & $0.39 / 0.36$ & $0.25 / 1.38$ \\
\hline 2 & $1.63 / 0.07$ & $74.67 / 77.66$ & $23.37 / 21.87$ & $0.15 / 0.11$ & $0.07 / 0.01$ \\
\hline
\end{tabular}

Table 7. Composition of studied coating areas (Figure 7)

\begin{tabular}{|c|c|c|c|c|c|c|}
\hline \multirow{2}{*}{ Studied area } & \multicolumn{6}{|c|}{ Element content, wt./at.\% } \\
\hline & $\mathrm{Fe}$ & B & $\mathrm{C}$ & $\mathrm{O}$ & $\mathrm{Mn}$ & $\mathrm{Zr}$ \\
\hline \multicolumn{7}{|c|}{ Figure $7, a$} \\
\hline 1 & $78.53 / 45.56$ & $11.43 / 34.25$ & $0.92 / 2.48$ & $8.63 / 17.48$ & $0.21 / 0.12$ & $0.28 / 0.10$ \\
\hline 2 & $65.41 / 33.74$ & $12.74 / 33.94$ & $0.28 / 0.68$ & $15.73 / 28.31$ & $4.29 / 2.25$ & $0.76 / 0.24$ \\
\hline 3 & $32.75 / 11.02$ & $19.28 / 33.52$ & $0.75 / 1.17$ & $45.67 / 53.66$ & $0.86 / 0.29$ & $0.29 / 0.06$ \\
\hline 4 & $95.90 / 83.70$ & $1.92 / 8.66$ & $1.35 / 5.48$ & $0.54 / 1.64$ & $0.00 / 0.00$ & $0.00 / 0.00$ \\
\hline \multicolumn{7}{|c|}{ Figure $7, b$} \\
\hline 1 & $73.02 / 42.34$ & $3.86 / 11.55$ & $0.95 / 2.57$ & $21.23 / 42.96$ & $0.91 / 0.53$ & - \\
\hline 2 & $85.48 / 61.53$ & $1.26 / 4.68$ & $0.59 / 1.97$ & $12.64 / 31.76$ & $0.00 / 0.00$ & - \\
\hline 3 & $61.55 / 30.72$ & $4.26 / 10.98$ & $0.67 / 1.55$ & $32.14 / 55.99$ & $1.27 / 0.64$ & - \\
\hline 4 & $78.92 / 48.63$ & $8.43 / 26.83$ & $0.06 / 0.18$ & $10.37 / 22.30$ & $1.18 / 0.74$ & - \\
\hline
\end{tabular}


recorded in the form of fine oxide lamellas $(5 \times 18 \mu \mathrm{m}$, form factor of 3.5), individual particles of round or irregular shape of up to $10 \mu \mathrm{m}$ size, as well as interlayers along the lamellas boundaries, predominantly $0.1-0.3 \mu \mathrm{m}$ thick. As was noted above, small oxide lamellas in the coating correspond to $\mathrm{FeO}$ composition (Figure 4, Table 4). In fine globular inclusions of oxide type, of up to $1 \mu \mathrm{m}$ size (Table 7, Figure 7, $a$, ar. 1,2) the amount of boron exceeds that of oxygen, and they, essentially, are iron boro-oxide. Some of these inclusions are boron oxide, alloyed by iron (Table 7, Figure 7, a, ar. 3). Zirconium is often found in fine non-metallic inclusions in a small amount of $0.3-0.8$ wt.\%. It is obvious that at spraying $\mathrm{ZrO}_{2}$ nanopowder interacts with the forming particles of iron boro-oxide and boron oxide. $\mathrm{ZrO}_{2}$ particles in the coating matrix promote its fine-grain crystallization. As shown by investigations, the composition of oxide inclusions is non-uniform. So, globular iron oxide of $1.4 \mu \mathrm{m}$ diameter at $0.13,0.3$ and $0.5 \mu \mathrm{m}$ distance from the center contains $1.3 ; 3.9$; and 4.3 boron, and 12.6 ; 21.0 and $32.0 \mathrm{wt} . \%$ oxygen, respectively (Table 7; Figure 7, $b$, ar. 1-3), i.e. the amount of these elements increases from the center to the edge of $\mathrm{FeO}$ nonmetallic inclusion, alloyed with boron. Having analyzed many oxide inclusions, we can conclude that their composition is complex: $\mathrm{FeO}$ iron oxide is alloyed with boron, and boron oxide contains iron. Here, dispersed particles of boron oxide are more common, than those of iron oxide. They have a globular shape of the diameter from $100 \mathrm{~nm}$ up to several $\mu \mathrm{m}$, and are particles strengthening the matrix.

Conducted comprehensive studies allowed determination of the following composition of the coatings: iron boro-carbides $\left(\mathrm{Fe}_{3}(\mathrm{~B}, \mathrm{C}) ; \mathrm{Fe}(\mathrm{B}, \mathrm{C})_{2}\right) ; \alpha$-Fe with increased lattice parameters, as a result of alloying by boron and carbon; amorphous phase; boron carbide of variable composition $\left(\mathrm{B}_{2.5} \mathrm{C}-\mathrm{B}_{4} \mathrm{C}\right)$; Fe boro-oxide; $\mathrm{Fe}$ and $\mathrm{B}$ oxides.

In conclusion it can be noted that owing to broad variation of filler composition, flux-cored wires are a promising material for PAS of protective wear-resistant coatings. Defect-free coatings with lamellar structure and low porosity (about $1 \%$ ), are produced from flux-cored wires with fillers of $\mathrm{B}_{4} \mathrm{C}$ and $\mathrm{B}_{4} \mathrm{C}$ with addition of nanosized $\mathrm{ZrO}_{2}$ powder. A dispersion-strengthened ferrite matrix of the coating forms as a result of interaction with the wire ferrite sheath. High hardness of the coatings is due to the following main structural factors:

- alloying of $\alpha$-Fe based matrix by boron and carbon, owing to considerable dissociation of $\mathrm{B}_{4} \mathrm{C}$ at spraying, and, as a result, formation of amorphous structures;

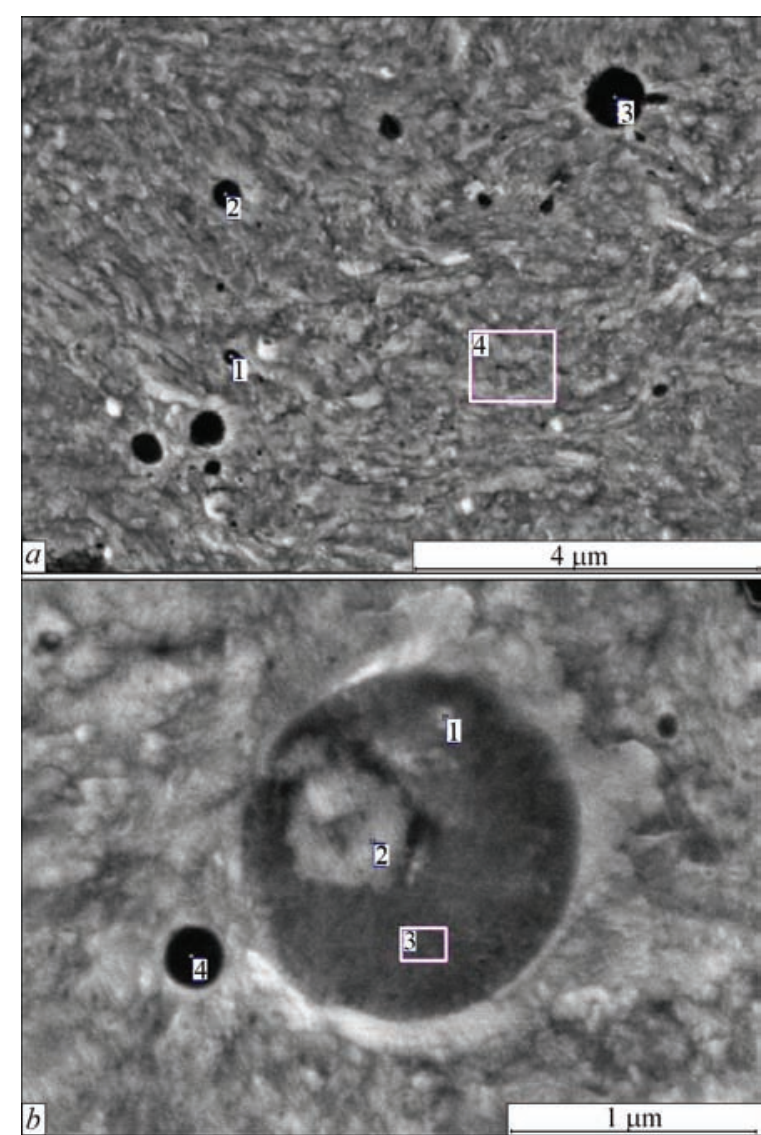

Figure 7. Microstructure of nonmetallic inclusions in the coating (REM, BEI mode)

- strengthening of coating matrix by uniformly distributed dispersed particles of $\mathrm{Fe}_{3}\left(\mathrm{~B}_{2} \mathrm{C}\right), \mathrm{Fe}(\mathrm{B}, \mathrm{C})_{2}$ iron boro-carbides, iron boro-oxide and iron and boron oxides;

- strengthening by small, non-decomposed particles of boron carbide of a variable composition of $\mathrm{B}_{4} \mathrm{C}-\mathrm{B}_{2.5} \mathrm{C}$.

During spraying, $\mathrm{ZrO}_{2}$ nanopowder additive reacts with $\mathrm{B}_{4} \mathrm{C}$, enriching its boundaries, and participates in formation of nanosized particles of iron diboride, dispersed oxides of iron $(\mathrm{FeO})$ and boron $\left(\mathrm{B}_{3} \mathrm{O}_{5}\right)$. Addition of $\mathrm{ZrO}_{2}$ powder promotes refinement of the lamella structure, here coating microhardness is equal to $6.86+2.1 \mathrm{GPa}$, that is 4 times higher than that of the ferrite wire sheath.

Thus, PAS of the wire with steel sheath and powder filler of $\mathrm{B}_{4} \mathrm{C}$ and $\mathrm{B}_{4} \mathrm{C}+0.5 \mathrm{ZrO}_{2}$ resulted in producing a coating with uniform distribution of dispersed strengthening particles in the ferrite matrix. Coatings of this class can be applied as wear-resistant ones for protection from gas-abrasive wear of equipment in chemical engineering, in manufacture of parts of pumps, compressors and other products, as well as reconditioning worn parts.

1. Khromov, V.N., Vertsov, V.G., Korovin, A.Ya. et al. (2001) From subsonic to supersonic spraying of coatings in resto- 
ration and strengthening of machine parts (Review). Svarochn Proizvodstvo, 2, 39-47.

2. Kharlamov, Yu.A. (2000) Thermal spraying of coatings and ecological compatibility of production, service and repair of machines. Tyazholoe Mashinostroenie, 2, 10-13.

3. Wielage, B., Rupprecht, C., Pokhmurska, H. (2011) Peculiarities of thermal spraying of coatings using flux-cored wire (Review). The Paton Welding J., 10, 21-25.

4. Kharlamov, M.Yu., Krivtsun, I.V., Korzhik, V.N. et al. (2007) Mathematical model of arc plasma generated by plasmatron with anode wire. Ibid., 12, 9-14.

5. Kharlamov, M.Yu., Krivtsun, I.V., Korzhik, V.N. et al. (2011) Heating and melting of anode wire in plasma arc spraying. Ibid., 5, 2-7.

6. Wielage, B., Rupprecht, C., Bruhl, M. et al. (2008) Thermisches Spritzen - Potentiale, Entwicklungen, Maerkte. Thermal Spray Bulletin, 1, DVS-Verlag, 30-36.

7. Petrov, S.V., Karp, I.N. (1993) Plasma air-gas spraying. Kiev: Naukova Dumka.

8. Kudinov, V.V., Bobrov, G.V. (1992) Spraying deposition of coatings. Theory, technology and equipment. Moscow: Metallurgiya.

9. Kharlamov, M.Yu., Krivtsun, I.V., Korzhik, V.N. et al. (2011) Formation of liquid metal film at the tip of wire-anode in plasma-arc spraying. The Paton Welding J., 12, 2-6.

10. Borisov, Yu.S., Koziakov, I.A., Korzhik, V.N. (1996) Structure and properties of thermal coatings produced using fluxcored wires of $\mathrm{Fe}-\mathrm{Cr}-\mathrm{B}, \mathrm{Fe}-\mathrm{Cr}-\mathrm{B}-\mathrm{C}$ system. Avtomatich. Svarka, 5, 21-24.

11. Pokhmursky, V.I., Student, M.M., Gvozdetsky, V.M. et al. (2011) Flux-cored wires of FMI series for coating deposition by electric arc spraying (Review). Ibid., 9, 44-48.

12. Korotaev, A.D., Borisov, D.P., Moshkov, V.Yu. et al. (2005) Nanostructured and nanocomposite superhard coatings. Phys. Mesomech., 8(5-6), 93-104.
13. Vityaz, P.A., Ilyushchenko, A.F., Khejfets, M.L. (2011) Technologies of structural nanostructured materials and coatings. Ed. by P.A. Vityaz. Minsk: Belarus. Navuka.

14. Makarenko, G.N., Marrej, E.V. (1975) Hard materials based on boron carbide. High-temperature carbides. Kiev: Naukova Dumka, 133-136.

15. Panasyuk, A.D., Fomenko, V.S., Glebova, G.G. (1986) Resistance of nonmetallic materials in melts: Refer. Book. Kiev: Naukova Dumka.

16. Serebryakova, V.I., Neronov, V.A., Peshev, P.D. (1991) High-temperature borides. Moscow: Metallurgiya.

17. Grigorenko, G.M., Borisova, A.L., Borisov, Yu.S. et al. (2003) Investigation of interphase interaction of ferrotitanium with boron carbide in powder mixtures for thermal coating deposition. Sovremennaya Elektrometallurgiya, 1, 28-31.

18. Tkachenko, V.F., Kogan, Yu.I. (1978) Peculiarities of structure and mechanical properties of sintered materials $\mathrm{Fe}-\mathrm{B}_{4} \mathrm{C}$. Poroshk. Metallurgiya, 5, 69-71.

19. Nevar, N.F., Fasevich, Yu.N., Senkov, V.M., Pavlovich, G.V. (2005) Boron-containing alloy, its characteristics and industrial application. Litiyo i Metallurgiya, 2-2, 174-178.

20. Korzhik, V.N., Korob, M.F. (2012) Mechanized line PLAZER 30PL-W for plasma-arc wire spraying of coatings. Svarshchik, 86(4), 13-16.

21. Grigorenko, G.M., Korzhik, V.N., Adeeva, L.I. et al. (2016) Specifics of metallurgical processes in plasma-arc spraying of coatings produced from flux-cored wire with steel sheath and fillers $\mathrm{B}_{4} \mathrm{C}$ and $\mathrm{B}_{4} \mathrm{C}+\mathrm{ZrO}_{2}$. Visnyk PDTU. Ser. Tekhnichni Nauky, 32, 125-138.

22. Chien, C.L., Musser, D., Gyorgy, E.M. et al. (1979) Magnetic properties of amorphous $\mathrm{Fe}_{x} \mathrm{~B}_{100-x}(72 \leq x \leq 86)$ and crystalline $\mathrm{Fe}_{3}$ B. Phys. Rev. (Condens. Matter), 20(1), 283-295.

Received 07.04.2017 


\title{
EFFECT OF STRUCTURE ON PROPERTIES OF $\mathrm{Al}_{2} \mathrm{O}_{3}$ AND Al (OR Ti) MECHANICAL MIXTURE COATINGS PRODUCED BY MULTICHAMBER DETONATION SPRAYING METHOD
}

\author{
L.I. MARKASHOVA, Yu.N. TYURIN, O.V. KOLISNICHENKO, E.N. BERDNIKOVA, \\ O.S. KUSHNAREVA, E.V. POLOVETSKY and E.P. TITKOV \\ E.O. Paton Electric Welding Institute, NASU \\ 11 Kazimir Malevich Str., 03150, Kiev, Ukraine. E-mail: office@paton.kiev.ua
}

\begin{abstract}
Effect of structure and phase composition of cermet coatings of $\mathrm{Al}_{2} \mathrm{O}_{3}-\mathrm{Ti}(\mathrm{Al})$ system produced using a unit for multichamber detonation spraying was investigated. Analysis of structure peculiarities of investigated coatings was performed applying optical metallography, analytical scanning as well as transmission microdiffraction electron microscopy. It is shown that dispersion of grain and subgrain structures as well as distribution of forming hardening phases of dispersion size make the most significant contribution in the indices of strength, ductility and crack resistance of the investigated coatings. 21 Ref., 2 Tables, 7 Figures.
\end{abstract}

Keywords : cermet coatings, multichamber detonation spraying, aluminum oxide, structure, phase composition, dislocation density, hardening, fracture toughness, local internal stresses, crack resistance

Modern industry, namely aircraft, automobile, power machine building, chemical industry, etc. uses the products, serviceability of which depends on surface quality characteristics. For example, these are piston heads and surfaces of combustion chambers, end sealings of gas turbine units, end sealings on output shafts of mining machines, surfaces of rolls and cylinders for paper industry, spinning nozzles, bars for guiding and processing of raw yarns, sealing surfaces of stop valves, etc. A relevant task is a rise of safety and life of such products, service properties of which are determined by properties of their working surfaces and allow using them for operation under extreme conditions (high temperature and pressure, intensive friction wear, alternate load, etc.). There is a number of different engineering solutions (thermal and thermal-chemical treatment, coating deposition, hardening surface treatment et al.). They provide necessary properties of functional surface layers depending on the requirements to final products under different operation conditions. These engineering methods differ to significant extent on their nature as well as effect on products and its structural-sensitive properties.

One of the most widespread and at the same time perspective methods for increase the service properties and life of the products is deposition on their surface of coatings using various spraying technologies [1-4]. E. O. Paton Electric Welding Institute of the NAS of Ukraine has developed a technology and equipment for multichamber detonation spraying
(MDS). It results in formation of high-quality coatings with high coefficient of material application and productivity. Among the peculiarities of the present technology are presence of several specially profiled detonation chambers and increased detonation frequency $(20 \mathrm{~Hz})$ of combustible mixture, which virtually level the negative effect related with discreteness of detonation spraying methods [5].

Essential direction of application of multichamber detonation method is spraying of aluminum oxide $\left(\mathrm{Al}_{2} \mathrm{O}_{3}\right)$ powders with different additives for obtaining cermet coatings [6]. Investigation of cermet coatings with different phase compositions is very important from point of view of getting a complex of physical-mechanical properties that make their application perspective in different fields of engineering. The interest to $\mathrm{Al}_{2} \mathrm{O}_{3}-\mathrm{Al}\left(\mathrm{Al}_{2} \mathrm{O}_{3}-\mathrm{Ti}\right)$ cermet is provoked by the fact that it can provide a combination of high hardness, strength and refractory property typical for aluminum oxide with ductility and heat conductivity typical for $\mathrm{Al}(\mathrm{Ti})$.

Now, however, information on effect of various MDS technological parameters on structure-phase state of sprayed in such a way coatings and, respectively, on their service properties is insufficiently reliable and unambiguous.

Aim of the present work is evaluation of effect of composition of sprayed mechanical mixture of $\mathrm{Al}_{2} \mathrm{O}_{3}+\mathrm{Al}$ and $\mathrm{Al}_{2} \mathrm{O}_{3}+\mathrm{Ti}$ powders on structure and phase composition of the coatings produced with 

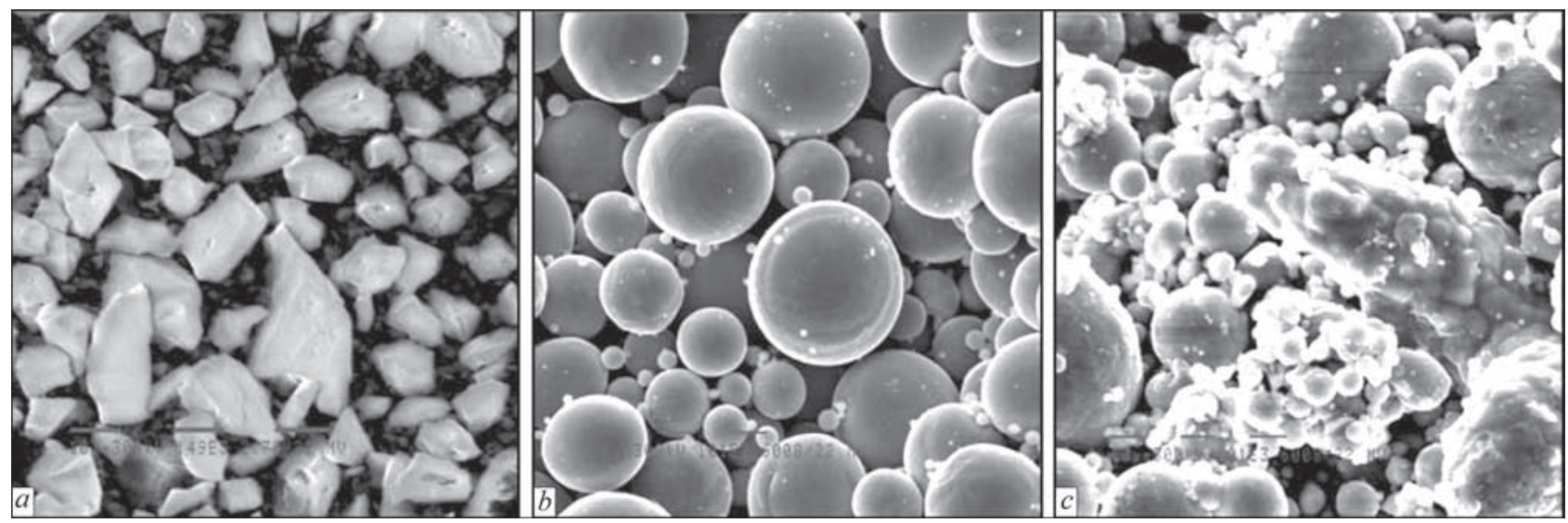

Figure 1. Appearance of sprayed powders: initial powder $\mathrm{Al}_{2} \mathrm{O}_{3}(a, \mathrm{x} 1490)$; additive of $\mathrm{Ti}(b, \times 1010)$ and $\mathrm{Al}(c, \times 1010)$ powders
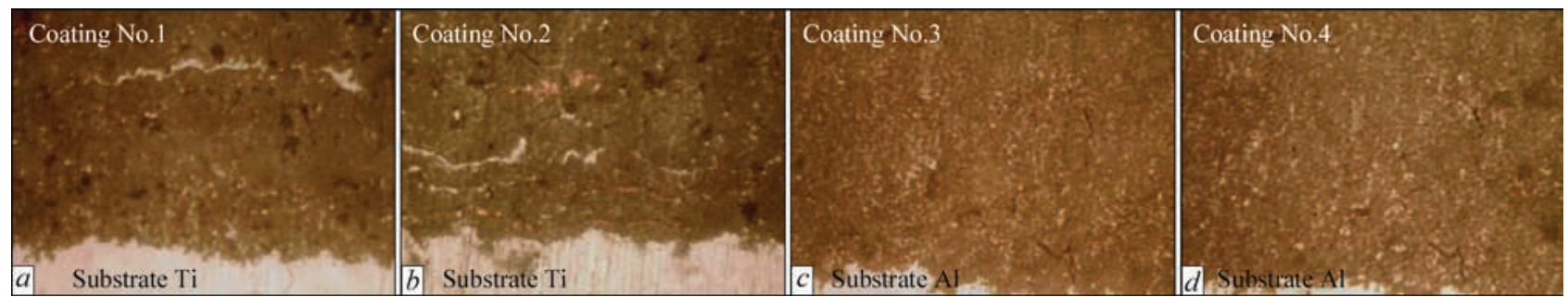

Figure 2. Microstructure (x800) of coatings: $\mathrm{Al}_{2} \mathrm{O}_{3}+3 \% \mathrm{Ti}(a) ; \mathrm{Al}_{2} \mathrm{O}_{3}+5 \% \mathrm{Ti}(b) ; \mathrm{Al}_{2} \mathrm{O}_{3}+3 \% \mathrm{Al}(c) ; \mathrm{Al}_{2} \mathrm{O}_{3}+5 \% \mathrm{Al}(d)$

MDS and structural factors on strength properties and crack resistance of investigated coatings.

Materials and investigation procedures. The coatings were sprayed using mechanical mixture of initial $\mathrm{Al}_{2} \mathrm{O}_{3}$ powder (H.C. Starck Company: AMPERIT $\left.^{\circledR} 740.0\right)$, fraction composition $d_{\mathrm{fr}} \sim 5-22 \mu \mathrm{m}$ with additives ( 3 and $5 \%$ ) of pure powders of $\mathrm{Al}$ and Ti, $d_{\mathrm{fr}} \sim 5-60 \mu \mathrm{m}$ (Figure 1). Detonation spraying mode was the following, i.e. detonation frequency $20 \mathrm{~Hz}$, distance to specimen $55 \mathrm{~mm}$, movement rate $1500 \mathrm{~mm} / \mathrm{min}$ with similar number of passes; relationship of length $(l) /$ diameter $(d)$ of gun shank $l / d=$ $=500 / 16 \mathrm{~mm}$ and combustible gas to oxidizer $(\beta) 5.0$; 5.8 (Table 1). Specimen size was $15 \times 10 \times 3 \mathrm{~mm}$.

Examination of structural-phase state of the coatings (microhardness, volume fraction of pores, phase composition, distribution of dispersed phases, nature of grain, subgrain and dislocation structures, etc.) were carried out at all structural levels using complex

Table 1. Parameters of technological MDS mode

\begin{tabular}{|c|c|c|c|c|}
\hline \multicolumn{3}{|c|}{ Gas flow, $\mathrm{m}^{3} / \mathrm{h}$} & $\beta$ & $\begin{array}{l}\text { Level of } \\
\text { chamber }\end{array}$ \\
\hline \multirow{3}{*}{ Chamber 1} & $\mathrm{O}_{2}$ & $4.4(140)$ & \multirow{3}{*}{5.8} & \multirow{3}{*}{0.82} \\
\hline & Air & $0.14(5)$ & & \\
\hline & $\mathrm{C}_{3} \mathrm{H}_{8}$ & $0.77(60)$ & & \\
\hline \multirow{3}{*}{ Chamber 2} & $\mathrm{O}_{2}$ & 4.0 (125) & \multirow{3}{*}{5.0} & \multirow{3}{*}{1.13} \\
\hline & Air & $0.325(10)$ & & \\
\hline & $\mathrm{C}_{3} \mathrm{H}_{8}$ & $0.82(55)$ & & \\
\hline Feeder & Air & $1(80)$ & - & - \\
\hline
\end{tabular}

technical approach, including optical metallography (Versamet-2, Japan; Leco-M400, USA), analytical scanning electron microscopy (Philips SEM-515, Netherlands), X-ray structural phase analysis (DRON-UM1) as well as transmission microdiffraction electron microscopy (JEM-200CX of JEOL Company with accelerating voltage $200 \mathrm{kV}$, Japan). The results of carried work were experimental data on full complex of structural-phase parameters of coatings in MDS.

Examination results. Four groups of coatings, sprayed on Ti (VT1-0) and Al (AD0) base of up to $250 \mu \mathrm{m}$ thickness $\delta$ (Table 2, Figure 2), were produced. The examinations using optical metallography method showed that porosity of such coatings is at the level of $0.7-2.5 \%$, volume fraction of lamellae $\left(V_{\mathrm{f} /}, \%\right)$ in them makes $1.5-5.0 \%$. At that, the minimum porosity $(\mathrm{P}, \%)$ and the maximum integral microhardness $H V 0.3$ are typical for coatings Nos 1, 2 produced using $\mathrm{Al}_{2} \mathrm{O}_{3}$ powders with 3 and $5 \%$ of Ti additives.

$\mathrm{X}$-ray structural phase analysis of produced coatings determined that application of $\mathrm{Al}_{2} \mathrm{O}_{3}+3 \% \mathrm{Ti}$ (mode No.1) and $\mathrm{Al}_{2} \mathrm{O}_{3}+5 \% \mathrm{Ti}$ (mode No.2) powders promotes formation of coatings with identical phase composition at approximately equivalent content of forming phase constituents, namely $\gamma-\mathrm{Al}_{2} \mathrm{O}_{3}$ (67-69\%); $\alpha-\mathrm{Al}_{2} \mathrm{O}_{3}(18 \%) ; \mathrm{AlTi}_{3}(13-15 \%)$. However, in $\mathrm{Al}_{2} \mathrm{O}_{3}+5 \%$ Ti (mode No.2) coatings the integral microhardness $H V 0.3$ shows $17 \%$ rise (from 
Table 2. Results of investigation of coating structure

\begin{tabular}{|c|c|c|c|c|c|}
\hline No. & Powder (substrate) & $\delta, \mu \mathrm{m}$ & $\mathrm{P}, \%$ & $V_{\mathrm{ff},} \%$ & $H V 0.3, \mathrm{MPa}$ \\
\hline 1 & $\mathrm{Al}_{2} \mathrm{O}_{3}+3 \% \mathrm{Ti}$ & $135-200$ & $1.5-2.0$ & $2.5-3.0$ & $8900-10990$ \\
\hline 2 & $\mathrm{Al}_{2} \mathrm{O}_{3}+5 \% \mathrm{Ti}$ & $100-230$ & $0.7-1.5$ & $4.5-5.0$ & $9660-13770$ \\
\hline 3 & $\mathrm{Al}_{2} \mathrm{O}_{3}+3 \% \mathrm{Al}$ & $115-250$ & $1.7-2.4$ & $1.5-2.5$ & $8900-10520$ \\
\hline 4 & $\mathrm{Al}_{2} \mathrm{O}_{3}+5 \% \mathrm{Al}$ & $90-225$ & $1.9-2.5$ & $1.9-2.5$ & $7900-10250$ \\
\hline
\end{tabular}

8900-10990 to 9660-13770 MPa) in comparison with $\mathrm{Al}_{2} \mathrm{O}_{3}+3 \%$ Ti coating (mode No.1), Table 2 .

Spraying of $\mathrm{Al}_{2} \mathrm{O}_{3}+3 \% \mathrm{Al}$ (mode No. 3) and $\mathrm{Al}_{2} \mathrm{O}_{3}+5 \% \mathrm{Al}$ (mode No.4) powders promotes formation of coatings at $\gamma-\mathrm{Al}_{2} \mathrm{O}_{3}(69 \%) ; \alpha-\mathrm{Al}_{2} \mathrm{O}_{3}(15 \%)$; $\mathrm{Al}(16 \%)$ content and approximately similar level of the integral microhardness HV0.3 (Table 2).

As a result it was determined that (3 and $5 \%$ ) Ti additive in comparison with ( 3 and $5 \%$ ) Al coatings results in changes of the structural-phase composition and microhardness ( $H V 0.3)$ of the coatings. Interaction of $\mathrm{Al}_{2} \mathrm{O}_{3}$ and $\mathrm{Ti}$ in formation of coating layer under conditions of detonation spraying leads to formation of intermetallic phase $\mathrm{AlTi}_{3}$ that possibly stipulates rise (1.2-1.3 times) of the integral microhardness $H V 0.3$ of such coatings.
Results of electron-microscopic transmission examinations allowed investigating the peculiarities of fine structure of the coatings, i.e. change of density and nature of dislocation distribution in different structural constituents (in the internal volumes and along structural boundaries); nature of forming substructure, its parameters; size of phase precipitation particles; effective distances between the forming phases, etc. In this connection the following was determined for the coatings with the most favorable (high microhardness, minimum porosity et al.) structural-phase variations, namely $\mathrm{Al}_{2} \mathrm{O}_{3}+5 \% \mathrm{Ti}$ (mode No.2, Figure 3) and for comparison $-\mathrm{Al}_{2} \mathrm{O}_{3}+5 \% \mathrm{Al}$ (mode No.4, Figure 4).

In the case of application of $\mathrm{Al}_{2} \mathrm{O}_{3}+5 \% \mathrm{Ti}$ (mode No.2, Figure 4, a), the size of phase precipitation particles $\left(d_{\mathrm{p}}=100 \mathrm{~nm}\right)$ in the surface layers of the coatings

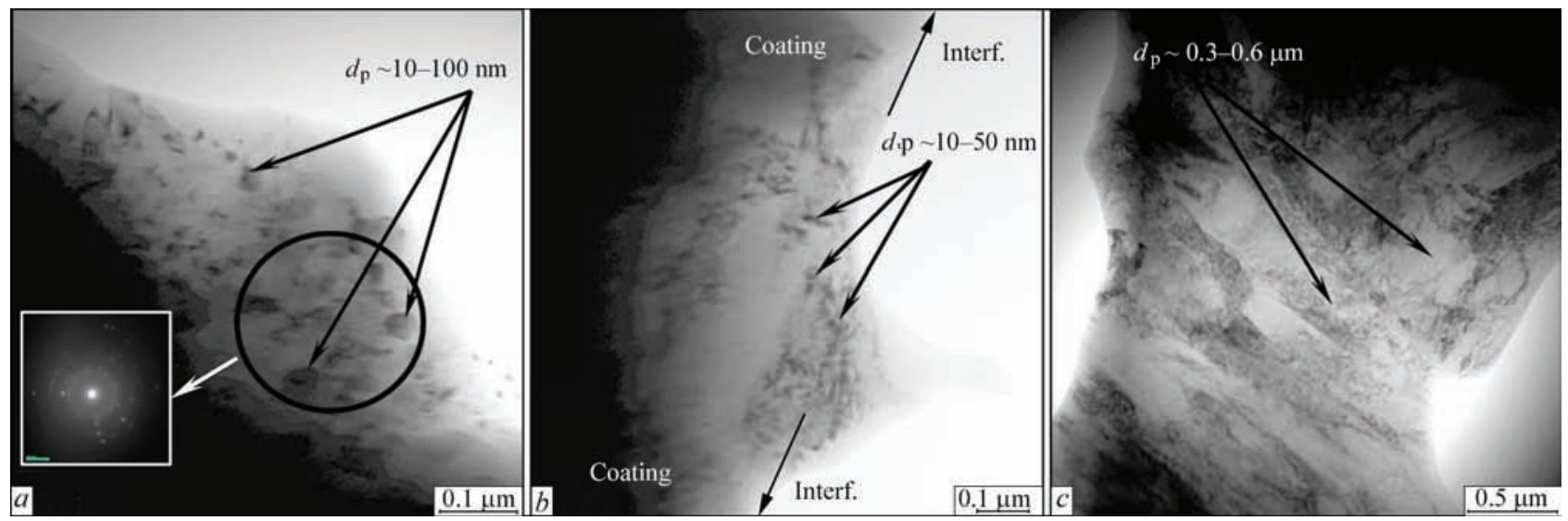

Figure 3. Fine structure of coating No.2 $\left(\mathrm{Al}_{2} \mathrm{O}_{3}+5 \%\right.$ Ti) sprayed on titanium base at $\delta \sim 150-200 \mu \mathrm{m}$ depth from interf. (a), in zone of interface (interf.) of coating-substrate $(b)$ and substrate material $(c)(\mathrm{O}$ - place of examination)
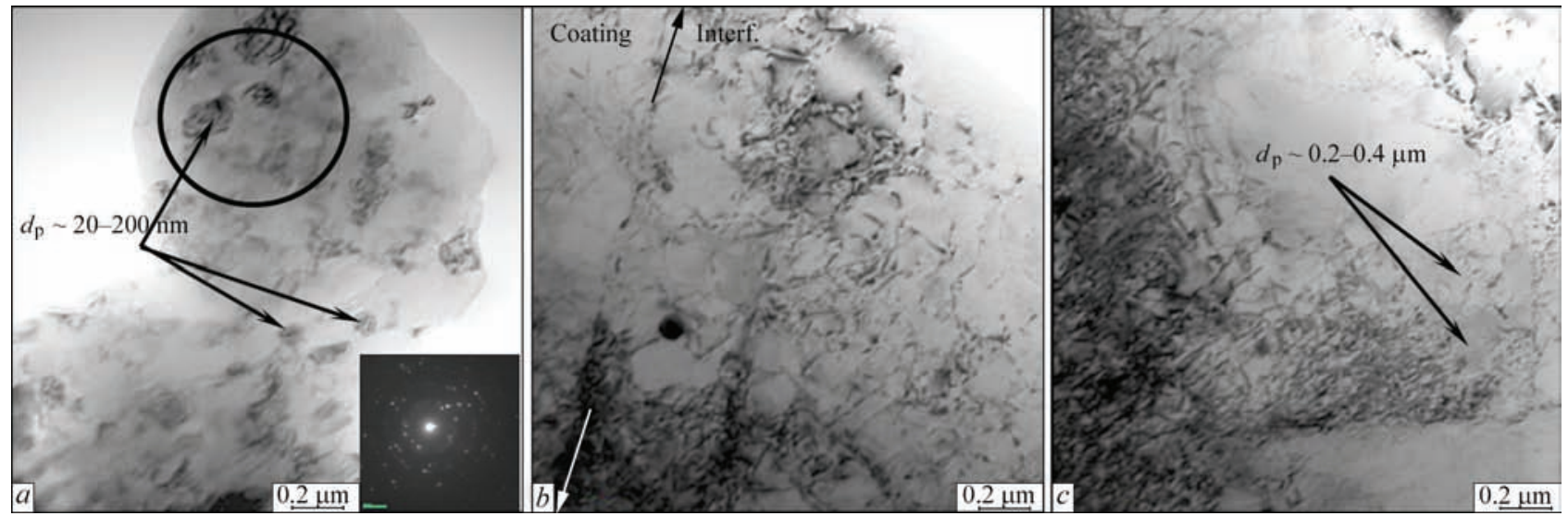

Figure 4. Fine structure of coating No.4 ( $\left.\mathrm{Al}_{2} \mathrm{O}_{3}+5 \% \mathrm{Al}\right)$ sprayed on titanium base at $\delta \sim 200 \mu \mathrm{m}$ depth from interface (interf.) (a), in zone of interface (interf.) of coating-substrate $(b)$ and substrate material (c) 

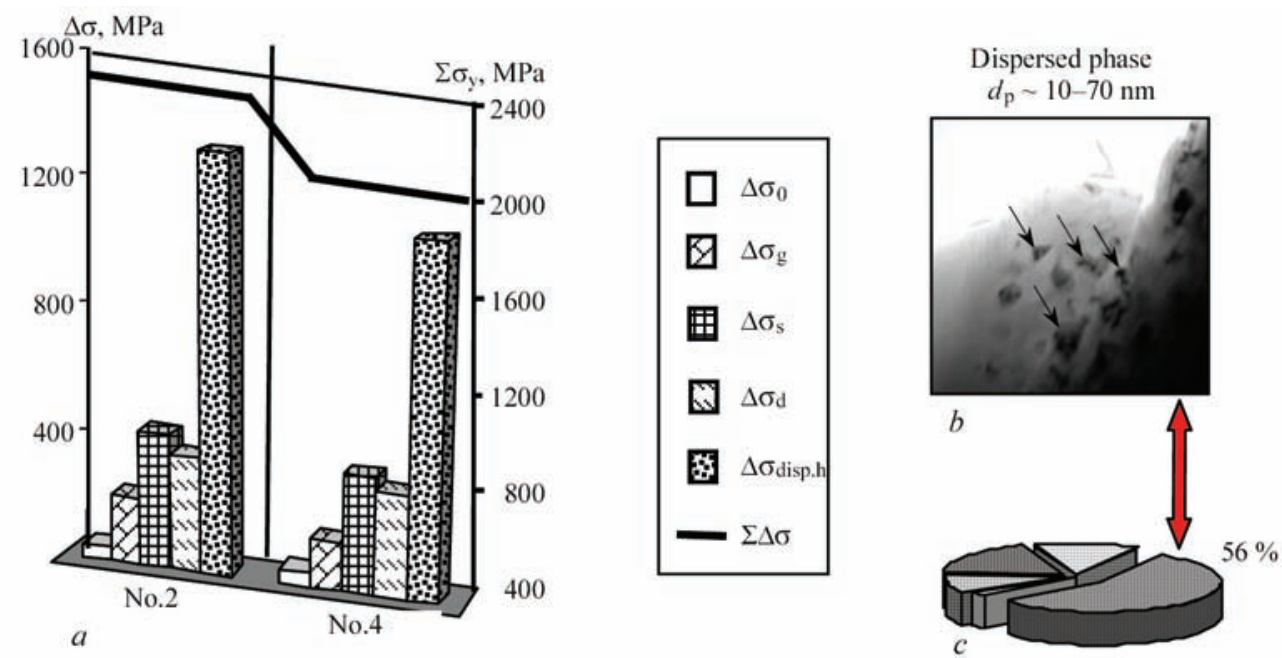

Figure 5. Histograms $(a)$ showing differential contribution of grain $\left(\Delta \sigma_{g}\right)$, subgrain $\left(\Delta \sigma_{s}\right)$, dispersion $\left(\Delta \sigma_{\text {disp.h }}\right)$ and dislocation $\left(\Delta \sigma_{\mathrm{d}}\right)$ hardening in variation of integral value of $\Sigma \Delta \sigma_{\mathrm{y}}$ in material of coatings sprayed on different modes: $\mathrm{Al}_{2} \mathrm{O}_{3}+5 \%$ Ti (mode No.2 - Ti base) and $\mathrm{Al}_{2} \mathrm{O}_{3}+5 \% \mathrm{Al}$ (mode No.4 - $\mathrm{Al}$ base) and contribution of dispersed particle phase formations $(b, c)$ in total $\Sigma \Delta \sigma_{\mathrm{y}}$ level

reduces 2 times in comparison with $\mathrm{Al}_{2} \mathrm{O}_{3}+5 \% \mathrm{Al}$ coatings (mode No.4, Figure $3, a$ ). Also, there is virtually $2.0-2.3$ times decrease of a distance $\left(\lambda_{\mathrm{p}}\right)$ between the forming dispersed phases (to $\lambda_{p}=10-30 \mathrm{~nm}$ ), that characterizes increase of the volume fraction in a forming phase matrix. Refinement (1.4 times) of substructure (values of subgrain $d_{\mathrm{s}} 0.1 \sim 0.4 \mu \mathrm{m}$ ) at increase of dislocation density $(\rho)$ is observed as well on outer surface of the coatings from $\rho \sim 2-3 \cdot 10^{9} \mathrm{~cm}^{-2}$ (mode No.4) to $\rho \sim 3-5 \cdot 10^{9} \mathrm{~cm}^{-2}$ (mode No.2). At that dislocation density at the coatings interface makes $\rho$ 5-6.10 $\mathrm{cm}^{-2}$ (Figure 3, b, c) and $\rho \sim 6-7 \cdot 10^{10} \mathrm{~cm}^{-2}$ (Figure 4, b, c).

Analytical evaluations of coating service properties. Carried complex of experimental examinations at all structural levels allows performing analytical evaluations of specific (differential) contribution of different structural-phase constituents, forming in the examined coatings, on variation of mechanical properties and determine structural factors having principal effect on nature and distribution of local internal stresses $\left(\tau_{1 / \text { in }}\right)$. They are potential sources of nucleation and propagation of cracks in structural microareas [7-9].

Analytical evaluations of hardening were carried out according to equation including known dependencies of Hall-Petch and Orowan et al. [10-16]:

$$
\Sigma \Delta \sigma_{\mathrm{y}}=\Delta \sigma_{0}+\Delta \sigma_{\mathrm{s} . \mathrm{s}}+\Delta \sigma_{\mathrm{g}}+\Delta \sigma_{\mathrm{s}}+\Delta \sigma_{\mathrm{d}}+\Delta \sigma_{\text {disp.h }},
$$

where $\Delta \sigma_{0}$ is the resistance of metal lattice to free dislocation movement (lattice friction stress or PeierlsNabarro stress); $\Delta \sigma_{\text {s.s }}$ is the solid solution hardening with alloying elements and additives (solid solution hardening); $\Delta \sigma_{\mathrm{g}}, \Delta \sigma_{\mathrm{s}}$ is the hardening due to change of grain and subgrain size (Hall-Petch dependences, grain boundary and substructural hardening); $\Delta \sigma_{\mathrm{d}}$ is the dislocation hardening caused by interdislocation interaction; $\Delta \sigma_{\text {disp.h }}$ is the hardening due to dispersed particles by Orowan (dispersion hardening).

It is shown as a result that in the case of application of $\mathrm{Al}_{2} \mathrm{O}_{3}+5 \%$ Ti (mode No.2) and $\mathrm{Al}_{2} \mathrm{O}_{3}+$ $5 \% \mathrm{Al}$ (mode No.4), the integral values of hardening $\left(\Sigma \sigma_{\mathrm{y}}\right)$ for coatings make $\Sigma \sigma_{\mathrm{y}}=2370 \mathrm{MPa}$ and $\Sigma \sigma_{\mathrm{y}}=$ $2050 \mathrm{MPa}$ (Figure 5,a). In the both cases the maximum contribution (up to $56 \%$ ) in $\Sigma \sigma_{\mathrm{y}}$ value is made by coating matrix hardening due to dispersed particles of phase precipitations (dispersion hardening by Orowan): $\Delta_{\text {disp.h }}=1334 \mathrm{MPa}$ (mode No.2) and $\Delta \sigma_{\text {disp.h }}=1070 \mathrm{MPa}$ (mode No.4), Figure 5, b, c). At that contribution of grain $\left(\Delta \sigma_{\mathrm{g}}\right)$, subgrain $\left(\Delta \sigma_{\mathrm{s}}\right)$ and dislocation $\left(\Delta \sigma_{\alpha}\right)$ hardening for examined coatings makes $8-10 \%\left(\Delta \sigma_{\mathrm{g}}=90-200 \mathrm{MPa}\right) ; 12-20 \%\left(\Delta \sigma_{\mathrm{s}}=\right.$ $100-500 \mathrm{MPa})$ and $^{\mathrm{s}} 10-15 \%\left(\Delta \sigma_{\mathrm{d}}=180-200 \mathrm{MPa}\right)$, respectively, Figure 5, c.

The calculation values of fracture toughness index $K_{1 c}$ evaluated on dependence [17]: $K_{1 c}=\left(2 E \sigma_{\mathrm{y}} \delta_{k}\right)^{1 / 2}$, where $\mathrm{E}$ is the Young's modulus; $\sigma_{\mathrm{y}}$ is the calculation value of hardening; $\delta_{c}$ is the value of critical crack opening (according to data of substructure parameters) as well as comparison of $K_{1 c}$ and $\sigma_{\mathrm{y}}$ showed the following, Figure 6.

In the case of application of $\mathrm{Al}_{2} \mathrm{O}_{3}+5 \%$ Ti powder (mode No.2), $\mathrm{K}_{1 \mathrm{c}}$ index (Figure 6, a) insignificantly $(7-10 \%)$ reduces that results in quasi-brittle intergrain fracture of coating material, Figure $7, b$. In the case with $\mathrm{Al}_{2} \mathrm{O}_{3}+5 \% \mathrm{Al}$ powder (mode No.4) there is a fracture nature with tough constituent (pits of disperse sizes 1-2 $\mu \mathrm{m}$ (see Figure $6, c$ )) that should provide crack resistance of produced coatings.

Calculation-analytical estimations of the level of local internal stresses $\left(\tau_{1 / \text { in }}\right)$ allowed evaluating crack resistance of examined coatings taking into account nature of the dislocation structure, which is clearly 
observed at transmission examination of fine structure using thin foil ion thinning procedure [18].

Evaluation of $\tau_{\text {l/in }}$ exactly based on the dislocation theory of crystalline solid bodies, binding the processes of local internal stresses formation with nucleation and rearrangement of the dislocation structure $[7,19$ 21] was taken following the analysis of the different approaches to determination of mechanisms of crack nucleation and material fracture. The field of internal stresses, developed by dislocation structure (dislocation density $\rho$ ) and peculiarities of formation of $\tau_{\text {lin, }}$, namely sources of nucleation and propagation of cracks (their level, extension, interaction with structural peculiarities of the coatings) were determined on dependence [20]:

$$
\tau_{1 / \text { in }}=G b h \rho /[\pi(1-v)],
$$

where $G$ is the shear modulus; $\mathrm{b}$ is the Burgers vector; $h$ is the foil thickness equal $2 \cdot 10^{-5} \mathrm{~cm}$; $v$ is the Poisson's ratio; $\rho$ is the dislocation density.

It is shown that all investigated modes of MDS provide formation of low level (without rapid gradients) of local internal stresses (Figure 7). The maximum $\tau_{1 / \text { in }}$ are observed at coating-substrate interface in the case of application of $\mathrm{Al}_{2} \mathrm{O}_{3}+5 \% \mathrm{Ti}$ powders (mode No.2, Figure 7, $b$ ). At that their level does not exceed $600 \mathrm{MPa}$ (or $\tau_{1 / \text { in }}=0.14 \tau_{\text {theor }}$ from the level of theoretical shear strength of material). This provides sound coatings with low susceptibility to crack formation and, respectively, optimum service characteristics.

Thus, the results of experimental-analytical evaluations of the service properties of coatings determined
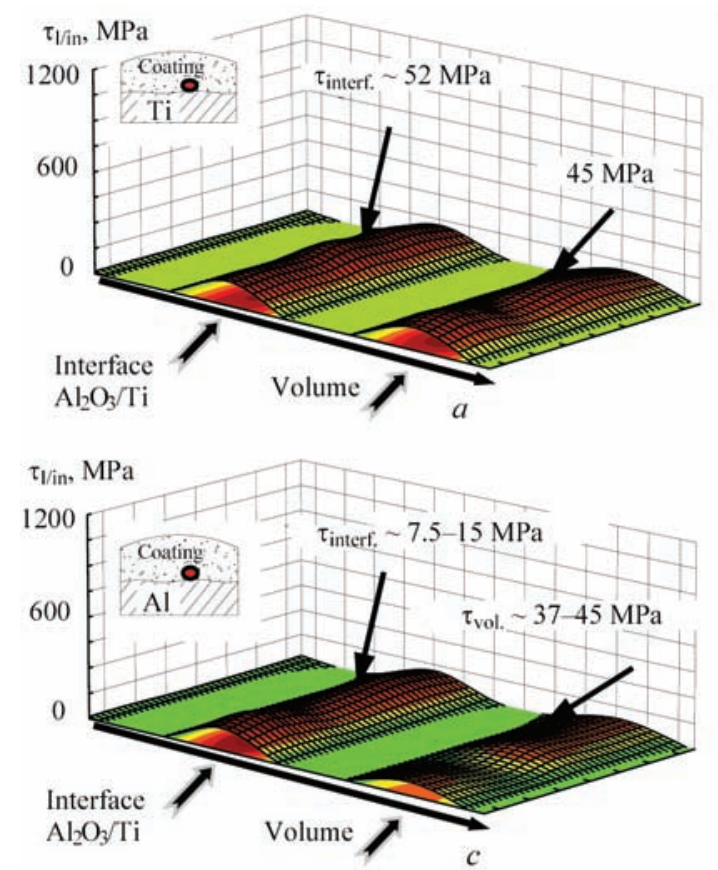
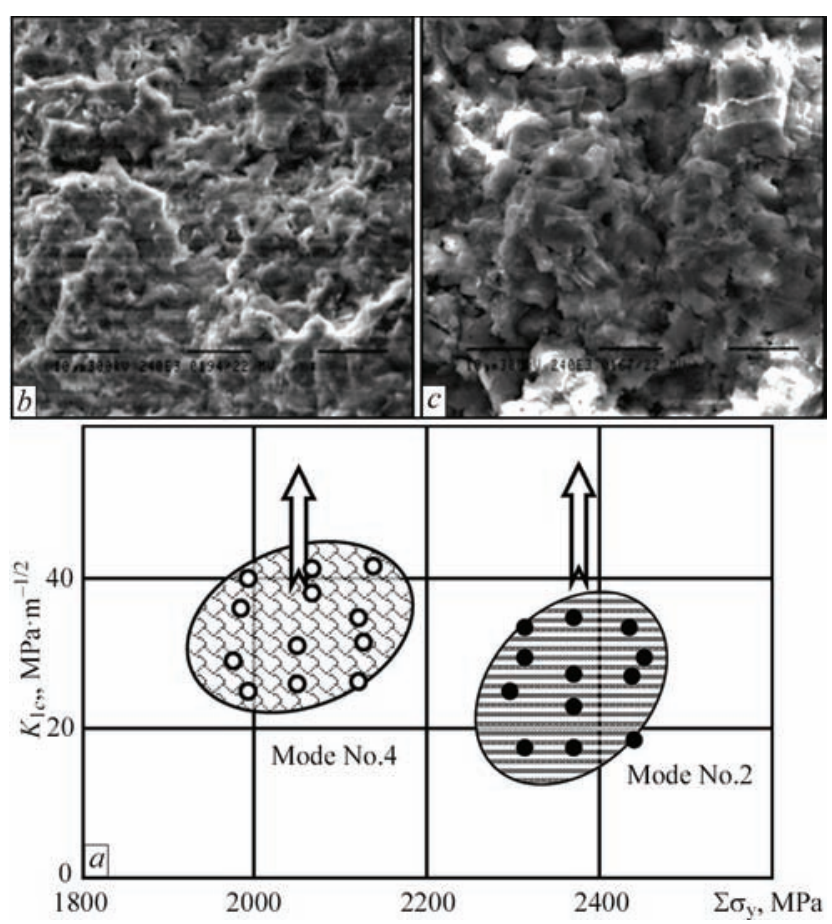

Figure 6. Change of calculation values of strength $\left(\Sigma \sigma_{y}\right)$ and fracture toughness $\left(K_{1 c}\right)$ of coating material $(a)$ and fracture patterns of tough $(b)$ and quasi-brittle fracture $(c)$ in material of coatings sprayed at different modes: $\mathrm{Al}_{2} \mathrm{O}_{3}+5 \% \mathrm{Ti}$ (mode No.2 - Ti base) and $\mathrm{Al}_{2} \mathrm{O}_{3}+5 \% \mathrm{Al}$ (mode No.4 - $\mathrm{Al}$ base)

that high level of mechanical properties and crack resistance is provided due to fine grain and subgrain structure at uniform distribution of dispersed hardening phases and dislocation density. Rise of coating crack resistance is promoted by absence of the extended dislocation accumulation-concentrators of local internal stresses.
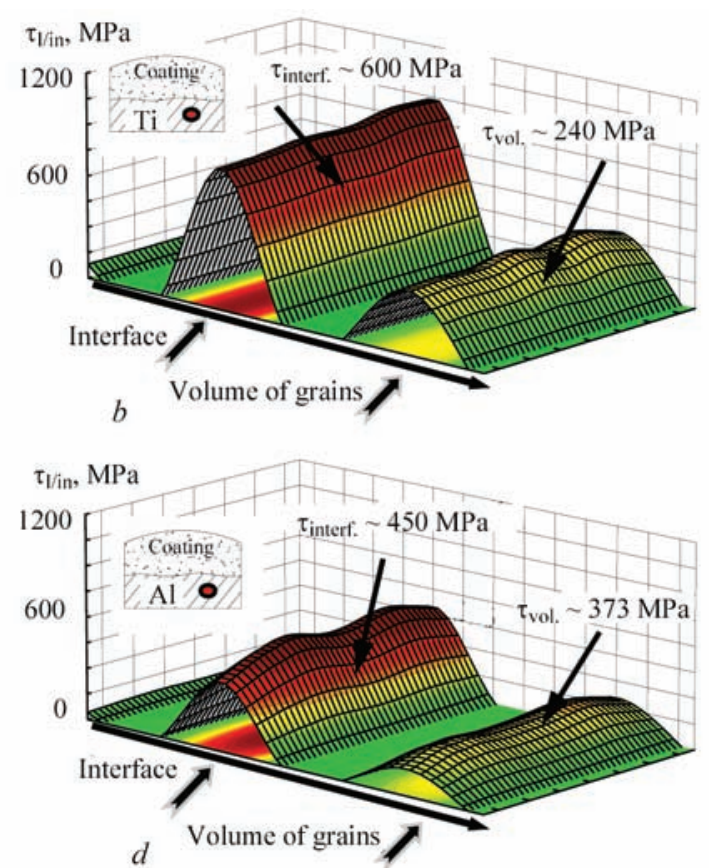

Figure 7. Distribution of local internal stresses $\left(\tau_{1 / \text { in }}\right)$ in material of coatings $(a, c)$ and substrate $(b, d): a, b-\operatorname{coatings~} \mathrm{No}_{2}\left(\mathrm{Al}_{2} \mathrm{O}_{3}+\right.$ $5 \% \mathrm{Ti})$ sprayed on titanium base; $c, d$ - coatings No.4 $\left(\mathrm{Al}_{2} \mathrm{O}_{3}+5 \% \mathrm{Al}\right)$ sprayed on aluminum base 


\section{Conclusions}

The results of complex examination of the coatings, produced by multichamber detonation spraying, at different structural levels (grain, subgrain, dislocation) showed:

- approximately similar content of base phase constituents, such as $\gamma-\mathrm{Al}_{2} \mathrm{O}_{3}(67-69 \%)$ and $\alpha-\mathrm{Al}_{2} \mathrm{O}_{3}$ (18-15\%), the rest are $\mathrm{AlTi}_{3}$ and $\mathrm{Al}$, respectively, in the coatings of initial powder $\mathrm{Al}_{2} \mathrm{O}_{3}$ with additives of ( 3 and $5 \%$ ) of Ti or Al sprayed on different bases (Ti and $\mathrm{Al}$ ). Ti additive ( 3 and $5 \%$ ) promotes formation of intermetallic phase $\mathrm{AlTi}_{3}(18 \%)$.

- $\mathrm{Al}_{2} \mathrm{O}_{3}+5 \% \mathrm{Ti}$ (Ti base) coatings are characterized with the largest (1.2-1.3 times) values of integral microhardness $(H V 0.3=9660-13770 \mathrm{MPa})$, refinement (per 10-15\%) of grain, subgrain structure and size (2 times) of phase precipitation particles, gradients on dislocation density are virtually absent;

- analytical evaluations showed that the most significant contribution in the service properties (strength, fracture toughness, crack resistance) of the examined coatings have uniform distribution of forming hardening phases of dispersed size, refinement of grain and subgrain structures in absence of extended and dense dislocation accumulation-concentrators of local internal stresses.

1. Kulik, A.Ya., Borisov, Yu.S., Mnukhin, A.S. et al. (1985) Thermal spraying of composite powders. Leningrad: Mashinostroenie.

2. Borisov, Yu.S., Borisova, A.L. (1986) Plasma powder coatings. Kyiv: Tekhnika.

3. Bartenev, S.S., Fedko, Yu.P., Grigorov, A.I. (1982) Detonation coatings in machine building. Leningrad: Mashinostroenie.

4. Pawlowski, L. (2008) The science and engineering of thermal spray coatings. $2^{\text {nd }}$ ed. John Wiley $\&$ Sons.

5. Tyurin, Yu.N., Kolisnichenko, O.V., Poleshchuk, M.A. (2009) Cumulative detonation device for thermal spraying of coatings. In: Proc. of $9^{\text {th }}$ Int. Conf. on Films and Coatings-2009, 44-46.
6. Miranda-Hernandez, J.G., Rocha-Rangel, E., Diaz de la Torre, S. (2010) Synthesis, microstructural analysis, mechanical properties of alumina-matrix cermets. J. of Silicate Based on Composite Materials, 62(1), 2-5.

7. Markashova, L.I., Poznyakov, V.D., Berdnikova, E.N. et al. (2014) Effect of structural factors on mechanical properties and crack resistance of welded joints of metals, alloys and composite materials. The Paton Welding J., 6/7, 22-28.

8. Markashova, L.I., Shelyagin, V.D., Kushnareva, O.S. et al. (2014) Structure-phase condition and mechanical properties of surface layers of $38 \mathrm{KhN} 3 \mathrm{MFA}$ steel to be formed under conditions of laser and laser-plasma alloying. In: Proc. of $7^{\text {th }}$ Int. Conf. on Mathematical Modelling and Information Technologies in Welding and Related Processes (15-19 September 2014, Odessa, Ukraine), 43-47.

9. Markashova, L.I., Tyurin, Yu.N., Kolisnichenko, O.V. et al. (2014) Srtucture-phase condition of wear-resistant composite coatings of $\mathrm{Cr}_{3} \mathrm{C}_{2}-\mathrm{NiCr}$ system, deposited using multi-chamber detonation installation. Ibid., 37-42.

10. Suzuki, H. (1967) On yield strength of polycrystalline metals and alloys. In: Structure and mechanical properties of metals. Moscow: Metallurgiya, 255-260.

11. Eshby, I.F. (1972) On Orowan stress. In: Physics of strength and ductility. Moscow: Metallurgiya, 88-107.

12. Goldshtejn, M.I., Litvinov, V.S., Bronfin, B.M. (1986) Metallophysics of high-strength alloys. Moscow: Metallurgiya.

13. Conrad, G. (1973) Model of strain hardening for explanation of grain size effect on metal flow stress. In: Superfine grain in metals. Ed. by L.K. Gordienko. Moscow: Metallurgiya, 206-219.

14. Armstrong, R.V. (1973) Strength properties of metals with superfine grain. Ibid., 11-40.

15. Petch, N.J. (1953) The cleavage strength of polycrystalline. J. Iron and Steel Inst., 173, 25-28.

16. Orowan, E. (1954) Dislocation in metals. New York: AIME.

17. Romaniv, O.N. (1979) Fracture toughness of structural steels. Moscow: Metallurgiya.

18. Darovsky, Yu.F., Markashova, L.I., Abramov, N.P. et al. (1985) Procedure of thinning of specimens of dissimilar welded joints for electron microscopy examinations. Avtomatich. Svarka, 12, 60.

19. Stroh, A.N. (1954) The formation of cracks as a recoil of plastic flow. Proc. of the Roy. Soc. A, 223, 1154, 404-415.

20. Panin, V.E., Likhachev, V.A., Grinyaeva, Yu.V. (1985) Structural levels of deformation of solids. Novosibirsk: Nauka.

21. Conrad, H. (1963) Effect of grain size on the lower yield and flow stress of iron and steel. Acta Metallurgica, 11, 75-77.

Received 06.04.2017 


\title{
STRUCTURE AND PROPERTIES \\ OF ALLOYED POWDERS BASED ON Fe ${ }_{3}$ Al INTERMETALLIC FOR THERMAL SPRAYING PRODUCED USING MECHANOCHEMICAL SYNTHESIS METHOD
}

\author{
Yu.S. BORISOV ${ }^{1}$, A.L. BORISOVA ${ }^{1}$, \\ A.N. BURLACHENKO ${ }^{1}$, T.V. TSYMBALISTAYA ${ }^{1}$ and C. SENDEROWSKI $^{2}$ \\ ${ }^{1}$ E.O. Paton Electric Welding Institute, NASU \\ 11 Kazimir Malevich Str., 03150, Kiev, Ukraine. E-mail: office@paton.kiev.ua \\ ${ }^{2}$ Military University of Technology in Warsaw \\ Warsaw, Poland. E-mail:csenderowski@wat.edu.pl
}

\begin{abstract}
Physical-chemical processes taking place in formation of particles of iron intermetallics based on $\mathrm{Fe}_{3} \mathrm{Al}$ alloyed with $\mathrm{Cr}, \mathrm{Zr}, \mathrm{Mg}$, La and Ti under mechanochemical synthesis conditions were investigated. It is determined that the process of synthesis of alloyed powders passes a range of sequential stages with formation of solid solutions and finishes with formation of single-phase $\mathrm{Fe}_{3} \mathrm{Al}(\mathrm{Cr}, \mathrm{Zr}), \mathrm{Fe}_{3} \mathrm{Al}(\mathrm{Mg}), \mathrm{Fe}_{3} \mathrm{Al}(\mathrm{Mg}, \mathrm{La})$ and $(\mathrm{Fe}, \mathrm{Ti})_{3} \mathrm{Al}$ products with nanodispersed structure (size of CSA $=10-30 \mathrm{~nm}$ ). The powders are designed for deposition of heat-resistant FeAl-coatings using thermal spraying and electric arc metallizing methods. 12 Ref., 2 Tables, 10 Figures.
\end{abstract}

Keywords : iron-based intermetallics, alloying, mechanochemical synthesis, powders, structure, properties, thermal spraying

Intermetallics of transition metals $(\mathrm{Ni}, \mathrm{Fe}, \mathrm{Ti})$ find wide distribution in industry. They are characterized with a complex of such physical, mechanical and corrosion properties as high melting temperature, high heat conductivity, small specific gravity, high strength-to-density relationship, oxidation resistance at high temperatures (up to $1000{ }^{\circ} \mathrm{C}$ and above) including in aggressive sulfur-containing media [1-3].

The special attention is focused on iron-based aluminides. They are considered as substitutes of heat-resistant nickel alloys and their competitiveness is provided by availability and low prices of base component iron [3].

However, the disadvantages of iron aluminides are their low ductility and impact resistance at room temperature, insufficient creep resistance in area of moderate temperatures $[2,3]$. One of the methods for improvement of mechanical and physical-chemical characteristics of $\mathrm{Fe}-\mathrm{Al}$ intermetallics is introduction in their composition of alloying components with formation of ternary compounds as well as transfer of these materials in nanostrucutral state [4-6]. The main reason of low strength of iron-aluminum intermetallics is formation in them of interlayers. The latter consist mainly of $\mathrm{FeAl}_{3}$ binary compounds and, in particular, $\mathrm{Fe}_{2} \mathrm{Al}_{5}$. It is determined that introduction of some metals in $\mathrm{Fe}-\mathrm{Al}$ intermetallic composition can prevent formation of these two phases and provide positive effect on their strength [4].

A method of mechanochemical synthesis (MCS) takes a special place among the methods of iron alu- minides production. This method has no limitations in production of intermetallic compounds of elements with large difference of melting temperatures and densities of initial components, phases with nanometric grain size, stable and metastable phases $[7,8]$. The powders produced using MCS method have chemical and phase homogeneity. One of the ways of their practical application is deposition of iron-aluminum heat-resistant coatings using thermal spraying (TS) methods $[9,10]$.

Present paper studies a production process, structure and properties of alloying powders based on $\mathrm{Fe}_{3} \mathrm{Al}$ intermetallic.

Objects for investigation and experiment procedure. A composition corresponding to $\mathrm{Fe}_{3} \mathrm{Al}$ intermetallic was used as a basis for alloyed powders production, since such combination of components allows receiving a single-phase product in process of MCS without additional heat treatment [11].

The alloying elements were selected based on carried material analysis of multicomponent $\mathrm{Fe}-\mathrm{Al}-\mathrm{X}$ systems as well as available results of investigation of effect of the third element (or several elements) on mechanical, corrosion and other properties of $\mathrm{Fe}-\mathrm{Al}$ system alloys $[4,5,12]$.

Following the reference data [4] the improvement of properties of iron-aluminum alloys at high temperatures can be realized as a result of such mechanisms as formation of $\mathrm{Fe}-\mathrm{Al}-\mathrm{X}$ solid solution with increased hardness, strengthening of $\mathrm{Fe}-\mathrm{Al}$ alloy with dispersed 

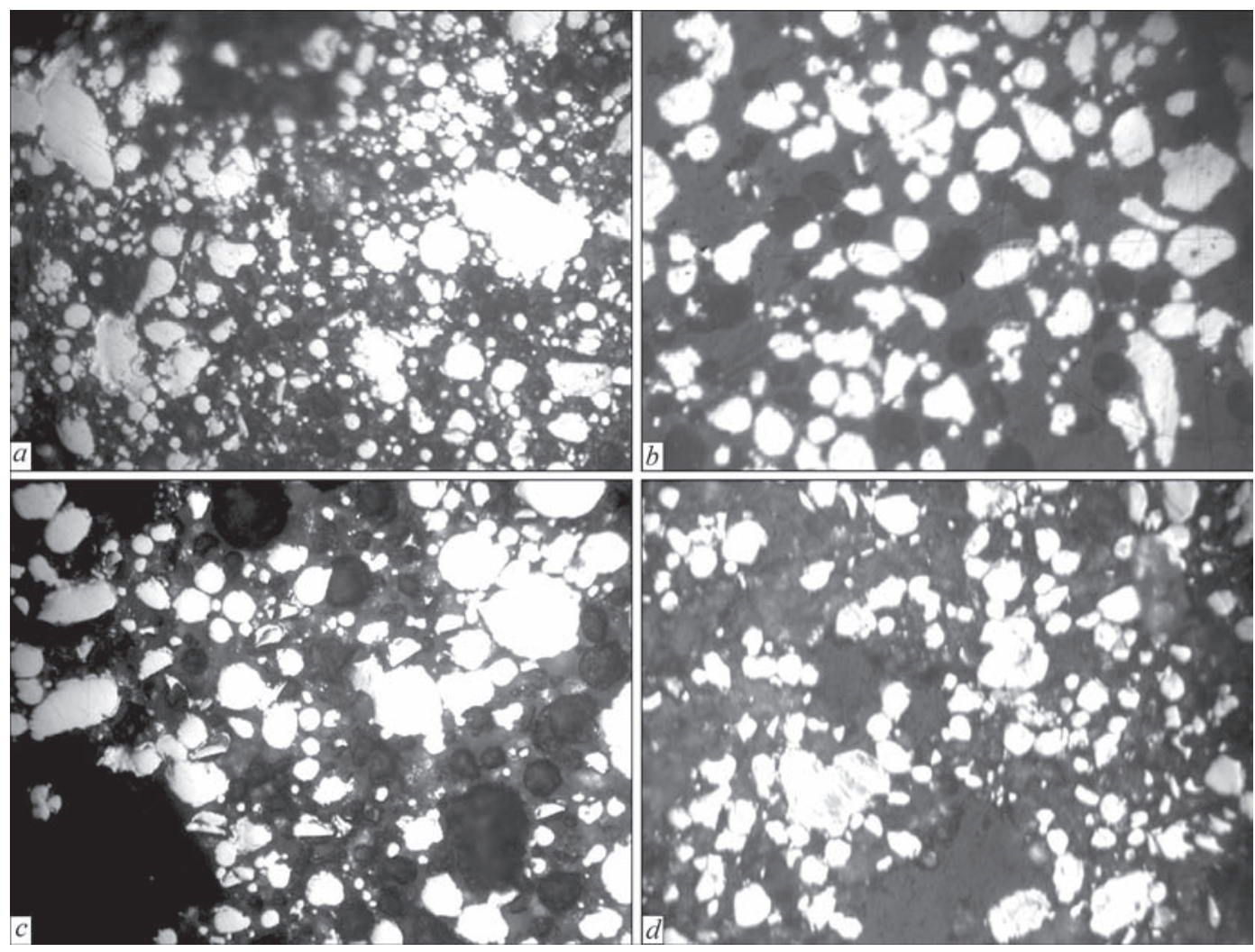

Figure 1. Microstructure $(\times 400)$ of particles of aluminum alloy powders: $\mathrm{A} 11.5 \mathrm{Cr} 1 \mathrm{Zr}(a), \mathrm{A} 15 \mathrm{Mg}(b), \mathrm{A} 15 \mathrm{Mg} 1 \mathrm{La}(c), \mathrm{Ti} 35 \mathrm{Al}(d)$

precipitations or development of ordered structure in $\mathrm{Fe}-\mathrm{Al}-\mathrm{X}$ compound.

«Solid solution strengthening» is carried out in the wide ranges of concentrations in the case of $\mathrm{Fe}-\mathrm{Al}-\mathrm{Cr}$ system.

Strengthening with incoherent precipitations is realized in $\mathrm{Fe}-\mathrm{Al}-\mathrm{X}$ systems, where solubility in solid state of the third element in $\mathrm{Fe}-\mathrm{Al}$ phases is limited (for example, in $\mathrm{Fe}-\mathrm{Al}-\mathrm{X}$ systems, where $\mathrm{X}$ is the Ti, $\mathrm{Zr}, \mathrm{Nb}$ and $\mathrm{Ta}$ ). A significant strengthening effect can be generated by coherent precipitations, for example in Fe-Al-Ni system.

Titanium is of the highest interest as an alloying element. Its application allows realizing several mechanisms of iron intermetallic strengthening, namely structure ordering, strengthening with dispersed inclusions, formation of coherent microstructures. Titanium differs by significant solubility in solid state in $\mathrm{Fe}-\mathrm{Al}$ phases that results in $\mathrm{Fe}_{3} \mathrm{Al}$ structure stabilizing in relation to $\mathrm{FeAl}$ structure at high temperatures. Strengthening with dispersed precipitations of hexagonal Laves phase $(\mathrm{Fe}, \mathrm{Al})_{2} \mathrm{Ti}$ or $\tau_{2}$ cubic phase of $\mathrm{Mg}_{23} \mathrm{Th}_{6}$ type can take place in addition to strengthening due to structure ordering in $\mathrm{Fe}-\mathrm{Al}-\mathrm{Ti}$ system. Besides, there is a specific range of composition in $\mathrm{Fe}-\mathrm{Al}-\mathrm{Ti}$ system where coherent structures [4] are formed. Such elements as chromium and zirconium with possibility of solid solution strengthening as well as magnesium and lanthanum, where strengthening with incoherent compounds can be expected, were used in present work in addition to titanium for alloying of $\mathrm{Fe}_{3} \mathrm{Al}$ intermetallic based powder.

Powders of iron and aluminum alloys: (wt.\%) $\mathrm{A} 11.5 \mathrm{Cr} 1 \mathrm{Zr}, \mathrm{Al} 5 \mathrm{Mg}$ and $\mathrm{Al} \mathrm{Mg} 1 \mathrm{La}$, produced using melt nitrogen sputtering as well as powder of Ti35Al (T65Yu35) intermetallic, produced by calcium-hydrate recovery of oxides, were used as initial materials.

Shape of the particles of aluminum alloy powders produced by melt nitrogen sputtering as well as method of calcium-hydrate recovery is close to spherical one and their structure differs by homogeneity and absence of inner pores (Figure 1). Fraction of 40$100 \mu \mathrm{m}$ size was used for feeding the powder mixture in MCS process.

Method of X-ray structural phase analysis (XSPA) determined that all initial aluminum alloys, except for titanium-aluminum, has a material structure representing itself aluminum lattice with insignificant variation of its parameter. This can indicate presence in them of solid solutions based on aluminum (Figure 2, $a-c$, Table 1). In the case of titanium-aluminum intermetallic (Figure 2,d) one phase, namely TiAl $(\gamma$-phase), was found in the powder.

MCS process was performed in planetary-type mill «Aktivator 2SL». Relationship of mass of balls to mass of powder made 10:1. The central axis of mill triboreactor was rotated with $100 \mathrm{rmp}$ rate, drums rotated around their axis with $1500 \mathrm{rmp}$ rate. Parts of the drum and milling agents were manufactured of steel ShKh 15 . MCS process was performed in air medium. Surface-active substances (SAS), namely oleic acid was 

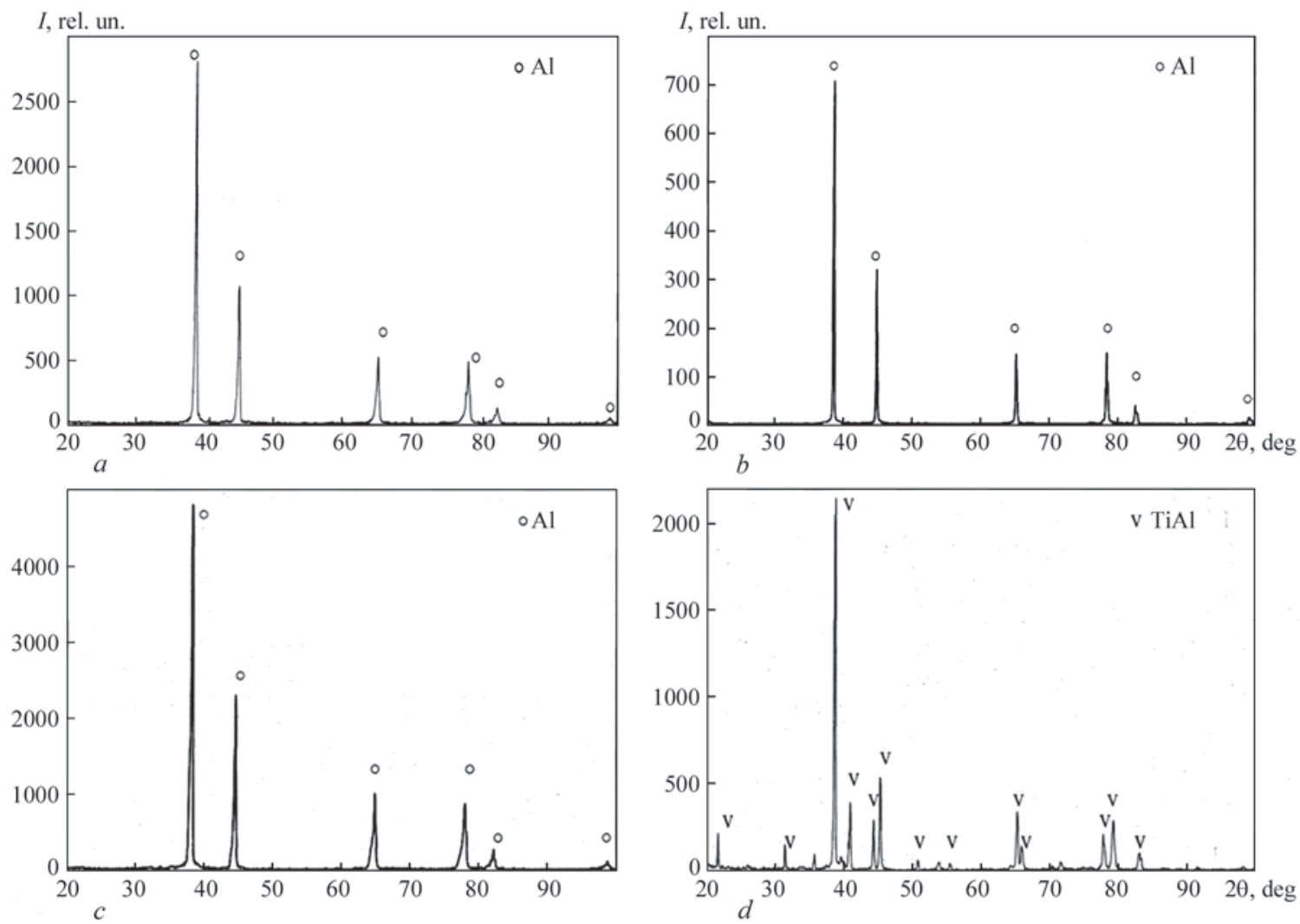

Figure 2. X-ray patterns of powders of aluminum alloys: $a-\mathrm{A} 11.5 \mathrm{Cr} 1 \mathrm{Zr} ; b-\mathrm{A} 15 \mathrm{Mg} ; c-\mathrm{Al} 5 \mathrm{Mg} 1 \mathrm{La} ; d-\mathrm{Ti} 35 \mathrm{Al}$

added to the mixture to prevent pickup of processed charge on the milling agents and drum wall as well as intensification of process of new phases synthesis.

Amount of aluminum alloy powder, introduced in the mixture with iron powder was selected for the purpose of formation in MCS of $\mathrm{Fe}_{3}(\mathrm{Al}, \mathrm{X})$ intermetallics in the case of $\mathrm{AlCrZr}$, AlMg and AlMgLa that corresponds to $14 \mathrm{wt} . \%$ of Al-alloy and (Fe, $\mathrm{Ti})_{3} \mathrm{Al}$ in the case of TiAl intermetallic. In the latter variant amount of introduced TiAl made $39.2 \mathrm{wt} . \%$.

Results and discussion. Structural and phase transformations, taking place in process of MCS, were examined on powder particles taken out of the drum with determined time intervals.

The metallographic examinations of powder mixtures showed that similar to non-alloyed powders of $\mathrm{Fe}-\mathrm{Al}$ system [9], there is breaking of coarse particles and formation of conglomerates consisting of initial components at MCS process initial stages. Refinement of the formed conglomerates takes place next and in $5 \mathrm{~h}$ of processing the particles obtain awakward, chipped shape of $<40 \mu \mathrm{m}$ particle size (Figure 3 ).
Examination of grain-size composition of the powders, carried using a device for dispersion determination ASOD-300, showed that $1.5 \mathrm{~h}$ processing promotes refinement up to $<30 \mu \mathrm{m}$ size of more than $50 \%$ of particle weight, and approximately $76 \%$ of particles have size $<20 \mu \mathrm{m}$ (Figure 4 ) after $5 \mathrm{~h}$.

Examination of appearance of powder-products of MCS on scanning electron microscope (Figure 5) showed that coarse as well as most of fine $(<20 \mu \mathrm{m})$ particles represent themselves the conglomerates consisting of 1-2 $\mu \mathrm{m}$ size particles.

Examination of internal structure in all powders, produced by MCS method, determined the particles of three types, namely insufficiently dense particles of conglomerate type with distinguished intergrain boundaries (Figure 6, a); particles with dense lamellar structure, but non-uniform on coloring, and, probably, on composition (Figure 6,b) and monolithic, homogeneous on composition particles (Figure 6,c).

Particles of the first type prevail in the powders at the initial ( $0.5-1.5 \mathrm{~h}$ of processing) stages of synthesis. MCS products after five hours processing consist

Table 1. Characteristics of initial powders

\begin{tabular}{|c|c|c|c|}
\hline Initial powder & Composition, wt. $\%$ & Microhardness, $\mathrm{MPa}$ & Phase composition, lattice parameter \\
\hline PZhR & $99 \mathrm{Fe} ; 0.05 \mathrm{C} ; 0.05 \mathrm{Si}$ & $1500 \pm 230$ & Fe \\
\hline $\mathrm{A} 11.5 \mathrm{Cr} 1 \mathrm{Zr}$ & $97.5 \mathrm{Al} ; 1.5 \mathrm{C} ; 1.0 \mathrm{Zr}$ & $3550 \pm 470$ & Solid solution Cr and Zr в Al, $a=0.4052 \mathrm{~nm}$ \\
\hline $\mathrm{A} 15 \mathrm{Mg}$ & $95.0 \mathrm{Al} ; 5.0 \mathrm{Mg}$ & $4920 \pm 510$ & Solid solution Mg in Al, $a=0.4072 \mathrm{~nm}$ \\
\hline $\mathrm{Al} 5 \mathrm{Mg} 1 \mathrm{La}$ & $94.0 \mathrm{Al} ; 5.0 \mathrm{Mg} ; 1.0 \mathrm{La}$ & $5780 \pm 1220$ & Solid solution Mg and La in Al, $a=0.4068 \mathrm{~nm}$ \\
\hline Ti35Al & $62.5 \mathrm{Ti} ; 37.5 \mathrm{Al}$ & $4400 \pm 1400$ & TiAl, $a=0.3986 \mathrm{~nm} ; c=0.4085 \mathrm{~nm}$ \\
\hline \multicolumn{2}{|l}{} \\
\hline
\end{tabular}



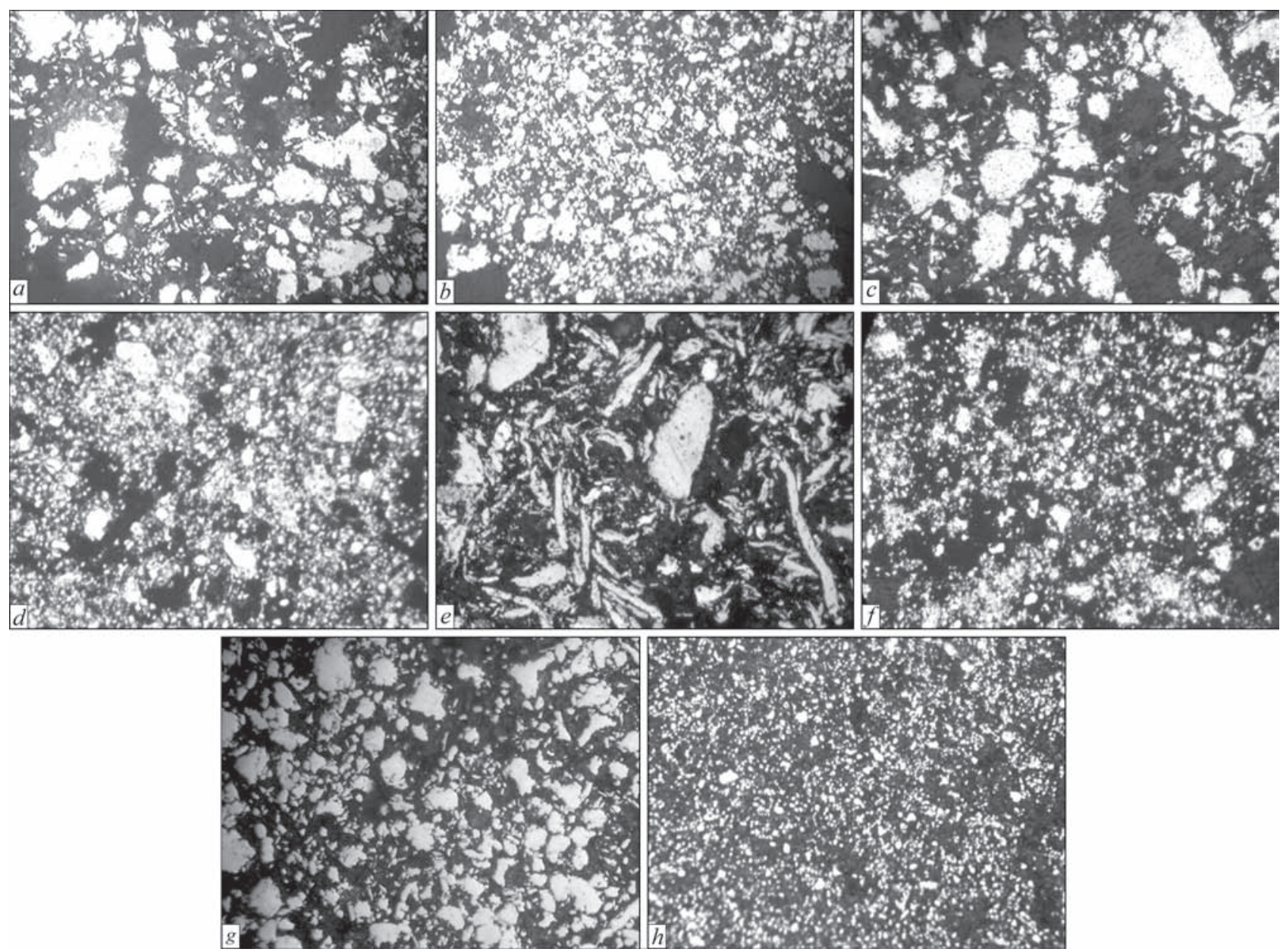

Figure 3. Microstructure $(\times 400)$ of particles of alloyed powders produced from charge: $86 \mathrm{Fe}+14 \mathrm{Al1} .5 \mathrm{Cr} 1 \mathrm{Zr}(a, b), 86 \mathrm{Fe}+14 \mathrm{Al} 5 \mathrm{Mg}$ $(c, d), 86 \mathrm{Fe}+14 \mathrm{Al} 5 \mathrm{Mg} 1 \mathrm{La}(e, f), 60.8 \mathrm{Fe}+39.2 \mathrm{TiAl}(g, h)$, in planetary mill during $0.5(a, c, e, g)$ and $5.0 \mathrm{~h}(b, d, f, h)$

of monolithic, homogeneous on structure and composition particles.

Method of X-ray structural phase analysis (Figure 7, Table 2) determined that MCS process after $5 \mathrm{~h}$ of processing forms the particles in the mixtures of iron with aluminum alloys $\mathrm{AlCrZr}, \mathrm{AlMg}$ and $\mathrm{AlMgLa}$. These particles represent themselves solid solutions of alloying elements in $\mathrm{Fe}_{3} \mathrm{Al}$ intermetallic lattice.

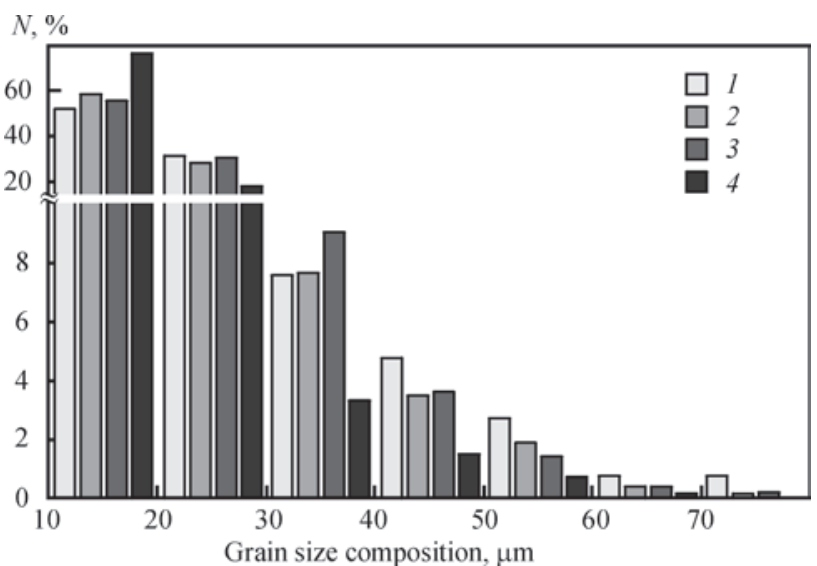

Figure 4. Histogram of distribution $(N)$ of size of particles of MCS powder-products of $\mathrm{Fe}_{3} \mathrm{Al}$ composition depending on processing time: $1-0.5 ; 2-1.5 ; 3-3.0 ; 4-50 \mathrm{~h}$
Complex iron-titanium aluminide $-(\mathrm{FeTi})_{3} \mathrm{Al}$ [12] is formed in the case of MCS in the mixture of iron with titanium-aluminum intermetallic.

Microdurometer examinations of the MCS produced products showed that increase of their microhardness takes place in process of powder processing. At that the maximum growth of microhardness value takes place at powder mixture processing during first $1.5 \mathrm{~h}$ (Table 2, Figure 8). It is related with change of structure dispersion that is indicated by decrease of particle size and area of coherent dissipation.

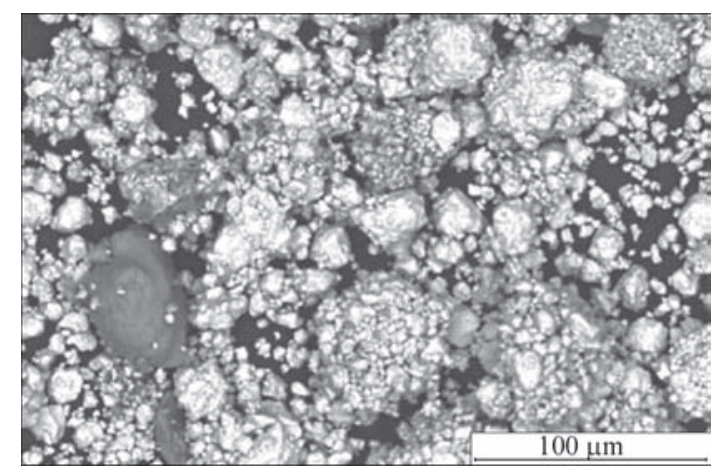

Figure 5. Appearance of particles of MCS powder-product perceived after five hours processing of $\mathrm{Fe}+\mathrm{TiAl}$ charge in planetary mill 

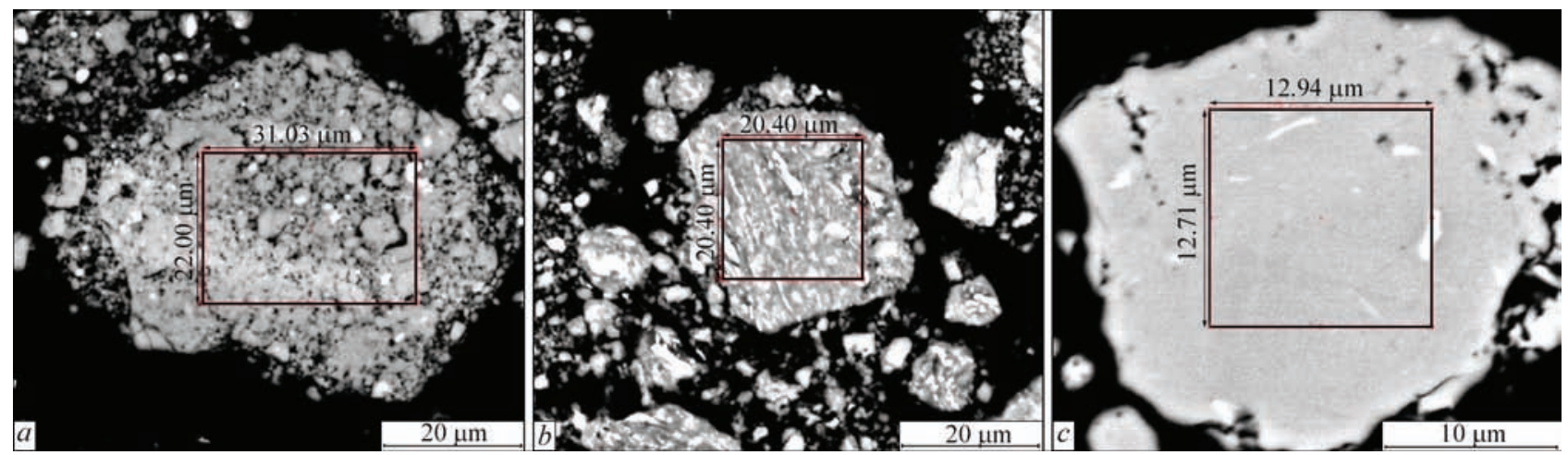

Figure 6. Types of powder structures at initial (a), intermediate $(b)$ and final stages of MCS process

Earlier carried investigations of phase and structural transformations in synthesis of $\mathrm{Fe}-\mathrm{Al}$ system intermetallics using MCS method [11] showed that the process consists of a range of sequential stages, namely 1 - refinement of particles of initial $\mathrm{Fe}$ and Al powders and formation of the conglomerates; 2 interphase interaction of the components with formation of Al solid solution in $\mathrm{Fe} ; 3$ - formation of $\mathrm{Fe}(\mathrm{Al})$ solid solution mixture and intermetallic phase $\mathrm{Fe}_{3} \mathrm{Al} ; 4$ - formation of single phase $\mathrm{Fe}_{3} \mathrm{Al}$ product. Analysis of XSPA data, received in the present work, showed that such a mechanism takes place in the synthesis of alloyed $\mathrm{Fe}_{3} \mathrm{Al}(\mathrm{Cr}, \mathrm{Zr}), \mathrm{Fe}_{3} \mathrm{Al}(\mathrm{Mg}), \mathrm{Fe}_{3} \mathrm{Al}-$ $(\mathrm{Mg}, \mathrm{La})$ powders. All three cases have a $\mathrm{Fe}_{3} \mathrm{Al}$ lattice with somewhat different values of the parameter and increased microhardness (Table 2) that is related with formation of solid solutions of alloying elements in $\mathrm{Fe}_{3} \mathrm{Al}$ lattice. In $\mathrm{Fe}-\mathrm{TiAl}$ system the phase transformations in MCS process are accompanied by gradual decrease of TiAl in the charge, formation of ferrotitanium and solution of $\mathrm{Al}$ in its lattice (Figure 9) up to formation of (Fe, Ti) ${ }_{3} \mathrm{Al}$ intermetallic. Except for increase of parameter of solid solution lattice from 0.2870 till $0.2937 \mathrm{~nm}$, there is an broadening of the lines of $(\mathrm{Fe}, \mathrm{Ti})_{3} \mathrm{Al}$ as well as TiAl intermetallics up to complete disappearance of the latter in five hours processing of the charge.

Breaking of the powder particles as well as their deformation take place in MCS, therefore broadening of the reflection lines on X-ray patterns can be a consequence of both these reasons. Division of these effects, as it well known, is based on different dependence of
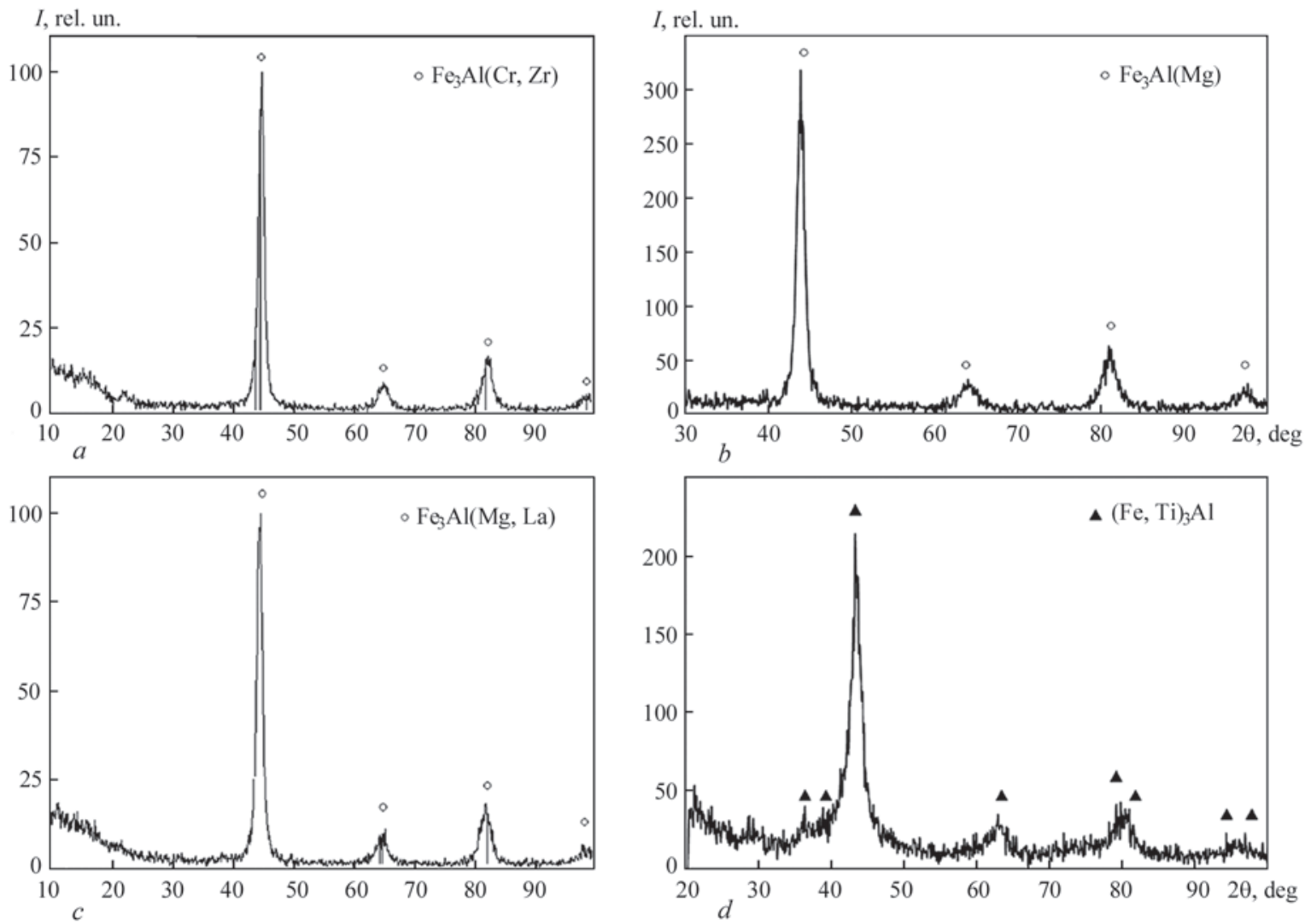

Figure 7. X-ray patterns of powders produced by MCS method in planetary mill during $5 \mathrm{~h}$ of mixtures (wt.\%): $a-86 \mathrm{Fe}+14$ $\mathrm{A} 11.5 \mathrm{Cr} 1 \mathrm{Zr} ; b-86 \mathrm{Fe}+14 \mathrm{Al} \mathrm{Mg} ; c-86 \mathrm{Fe}+14 \mathrm{Al} \mathrm{Mg} 1 \mathrm{La}, d-60.8 \mathrm{Fe}+39.2 \mathrm{TiAl}$ 
Table 2. Characteristics of alloyed powders based on $\mathrm{Fe}_{3} \mathrm{Al}$ intermetallic produced by MCS

\begin{tabular}{|c|c|c|c|c|}
\hline \multirow[b]{2}{*}{ Mixture content, wt.\% } & \multirow[b]{2}{*}{ Time of milling, $\mathrm{h}$} & \multicolumn{3}{|c|}{ MCS product } \\
\hline & & Microhardness ${ }^{*} H V 0.01 . \mathrm{MPa}$ & Phase composition & $\begin{array}{c}\text { Lattice parameter } a^{*} \text {, } \\
\mathrm{nm}\end{array}$ \\
\hline \multirow{4}{*}{$86 \mathrm{Fe}+14 \mathrm{Al} 1.5 \mathrm{Cr} 1 \mathrm{Zr}$} & 0.5 & $1680 \pm 440$ & $\mathrm{Fe}$, solid solution $\mathrm{Cr}$ and $\mathrm{Zr}$ in $\mathrm{Al}$ & - \\
\hline & 1.5 & $3490 \pm 1040$ & - & - \\
\hline & 3 & $3550 \pm 710$ & - & - \\
\hline & 5 & $3840 \pm 800$ & Solid solution $\mathrm{Cr}$ and $\mathrm{Zr}$ in $\mathrm{Fe}_{3} \mathrm{Al}$ & 0.5974 \\
\hline \multirow{4}{*}{$86 \mathrm{Fe}+14 \mathrm{Al} 5 \mathrm{Mg}$} & 0.5 & $2300 \pm 400$ & Solid solution $\mathrm{Mg}$ in $\mathrm{Al}$ & - \\
\hline & 1.5 & $5320 \pm 730$ & - & - \\
\hline & 3 & $4590 \pm 1050$ & - & - \\
\hline & 5 & $4630 \pm 950$ & Solid solution $\mathrm{Mg}$ in $\mathrm{Fe}_{3} \mathrm{Al}$ & 0.5812 \\
\hline \multirow{4}{*}{$86 \mathrm{Fe}+14 \mathrm{Al} 5 \mathrm{Mg} 1 \mathrm{La}$} & 0.5 & $980 \pm 240$ & $\mathrm{Fe}$, solid solution $\mathrm{Mg}$ and $\mathrm{La}$ in $\mathrm{Fe}_{3} \mathrm{Al}$ & - \\
\hline & 1.5 & $3860 \pm 500$ & - & - \\
\hline & 3 & $3950 \pm 1120$ & - & - \\
\hline & 5 & $5580 \pm 840$ & Solid solution $\mathrm{Mg}$ and $\mathrm{La}$ in $\mathrm{Fe}_{3} \mathrm{Al}$ & 0.5792 \\
\hline \multirow{4}{*}{$60.8 \mathrm{Fe}+39.2 \mathrm{TiAl}$} & 0.5 & $4400 \pm 1400$ & FeTi. FeAl & - \\
\hline & 1.5 & $7830 \pm 2070$ & - & - \\
\hline & 3 & $7170 \pm 1960$ & - & - \\
\hline & 5 & $7600 \pm 2190$ & $(\mathrm{Fe}, \mathrm{Ti})_{3} \mathrm{Al}$ & 0.2937 \\
\hline
\end{tabular}

increment of lines broadening on value of Bragg angle $\theta$. Evaluation of coherent scattering area (CSA) of MCS products after processing of powders of $\mathrm{Fe}-\mathrm{TiAl}$ system during $0.5-5.0 \mathrm{~h}$ was carried out in present work. The width of reflection lines was measured at half of their height with their doubling correction.

A template was made for taking into account an instrumental line broadening under similar conditions. It was produced of powder of superpure carbonyl iron. Then, real $\beta$ broadening of X-ray lines of specimen makes

$$
\beta=\sqrt{B^{2}-b^{2}},
$$

where $B$ is the experimental width of lines of examined specimen; $b$ is the template line width.

CSA value was determined on Scherrer formula $D=\kappa \lambda / \beta \cos \theta$, where $\kappa \approx 1$ is the Scherrer con-

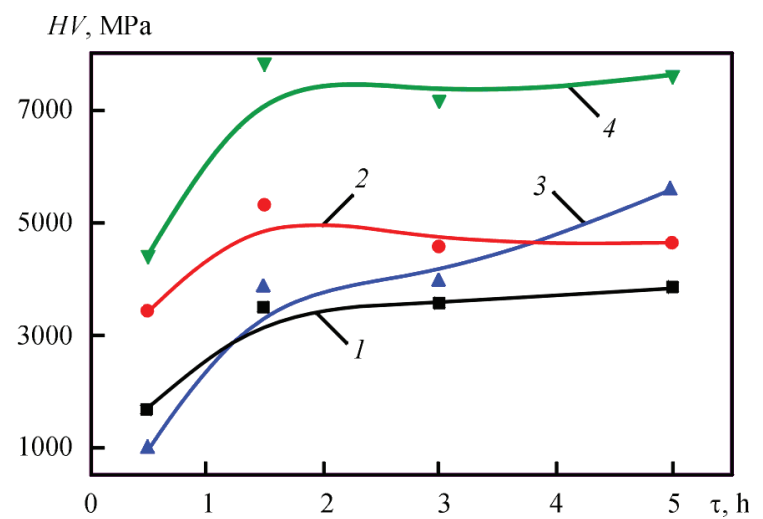

Figure 8. Effect of processing time on microhardness of MCS product - powders produced of mixtures $1-86 \mathrm{Fe}+$ 14A11.5Cr1Zr; $2-86 \mathrm{Fe}+14 \mathrm{Al} 5 \mathrm{Mg} ; 3-86 \mathrm{Fe}+14 \mathrm{Al} 5 \mathrm{Mg}-$ $1 \mathrm{La} ; 4-60.8 \mathrm{Fe}+39.2 \mathrm{TiAl}$

stant; $\lambda$ is the wave length of used radiation (for $\mathrm{Cu}-$ $K_{\alpha} \lambda=0.15418 \mathrm{~nm}$ ); $\theta$ is the reflection angle.

Carried evaluations showed that a product with nanodispersed structure (CSA 10-40 nm) is formed at all stages of synthesis of $\mathrm{Fe}-\mathrm{Ti}-\mathrm{Al}$ intermetallics, made using MCS method. Approximately the same CSA values, namely $10-30 \mathrm{~nm}$, were received using a program for harmonic PDXL analysis, which is included in Rigaku X-ray unit (CSA at MCS time increase from 0.5 to $5 \mathrm{~h}$ decreased from 30 to $10 \mathrm{~nm}$ ).

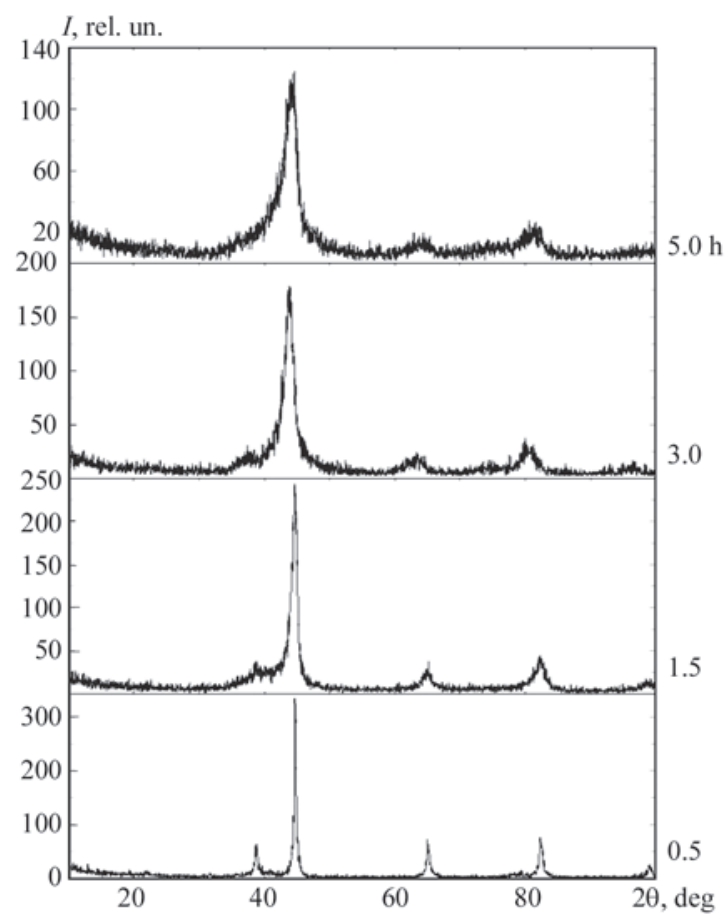

Figure 9. X-ray patterns of MCS products of powder mixture (wt.\%) $61 \mathrm{Fe}+39 \mathrm{TiAl}$ depending on processing time 
Thus, it can be stated that a product with nanodispersed structure is formed when producing alloyed powders based on $\mathrm{Fe}_{3} \mathrm{Al}$ intermetallic by means of MCS technology.

Effect of alloying on heat resistance of $\mathrm{Fe}_{3} \mathrm{Al}$ intermetallic powders was investigated on derivatograph of Q-1500 D grade (Hungary) in air atmosphere at heating rate $10 \mathrm{deg} / \mathrm{min}$ to $1000{ }^{\circ} \mathrm{C}$ temperature. Powder weight was located in preliminary burnt to necessary temperature crucible of $\mathrm{ZrO}_{2}$, cross-section area of which made $1 \cdot 10^{-4} \mathrm{~m}^{2}$, and continuously weighed during all thermal cycle with $5 \cdot 10^{-4} \mathrm{~g}$ accuracy.

One of the peculiarities of powders oxidation as a result of their sintering is decrease of free surface in process of thermal cycle. Since there is no mathematical dependence of its change for investigated materials, the value of specific weight increment was determined as relationship of specimen mass increase to initial weight value.

Comparing the thermal gravimetric curves of alloyed powders with unalloyed $\mathrm{Fe}_{3} \mathrm{Al}$ (Figure 10), we can evaluate effect of alloying elements on temperature of process start and its intensity in all temperature interval in comparison with $\mathrm{Fe}_{3} \mathrm{Al}$. Such elements as $\mathrm{Mg}, \mathrm{Mg}+\mathrm{La}, \mathrm{Cr}+\mathrm{Zr}$ rise the temperature of oxidation start from 300 to $500-540{ }^{\circ} \mathrm{C}$, at that oxidation intensity decreases. Titanium alloying in contrast reduces the temperature of oxidation start, and significantly rises its intensity. Thus, investigated powder on oxidation resistance parameter should be ranged as $(\mathrm{Fe}, \mathrm{Ti})_{3} \mathrm{Al} \rightarrow \mathrm{Fe}_{3} \mathrm{Al} \rightarrow \mathrm{Fe}_{3} \mathrm{Al}(\mathrm{Mg}) \rightarrow \mathrm{Fe}_{3} \mathrm{Al}(\mathrm{Cr}, \mathrm{Zr})$.

\section{Conclusions}

1. Iron aluminide powders, alloyed with $\mathrm{Ti}, \mathrm{Mg}, \mathrm{Cr}$, $\mathrm{Zr}$, La, were produced by mechanochemical synthesis method by means of introduction of aluminum alloys (A15Mg, Al1.5Cr1Zr, A15Mg1La) or titanium aluminide (TiAl) in the charge.

2. Mechanism of formation of particles alloyed with powders based on $\mathrm{Fe}_{3} \mathrm{Al}$ as well as non-alloyed particles $\mathrm{Fe}_{3} \mathrm{Al}$ consists of a series of subsequent stages, namely formation of conglomerates of mixture of initial powders of $\mathrm{Fe}$ and Al-alloys, formation of solid solutions of alloying elements $\mathrm{Mg}, \mathrm{Cr}, \mathrm{Zr}$ and $\mathrm{La}$ in $\mathrm{Fe}_{3} \mathrm{Al}$ lattice or solid solution of $\mathrm{Al}$ in FeTi lattice, transformation of solid solutions in single-phase products $\mathrm{Fe}_{3} \mathrm{Al}(\mathrm{Cr}, \mathrm{Zr}), \mathrm{Fe}_{3} \mathrm{Al}(\mathrm{Mg}), \mathrm{Fe}_{3} \mathrm{Al}(\mathrm{Mg}, \mathrm{La})$, $(\mathrm{Fe}, \mathrm{Ti})_{3} \mathrm{Al}$ having nanodispersed structure (CSA size $=10-30 \mathrm{~nm}$ ).

3. Magnesium, lanthanum and, in particular, titanium alloying of $\mathrm{Fe}_{3} \mathrm{Al}$ powder provokes increase of their microhardness. Powder resistance to oxidation, measured in non-isothermal conditions in heating on air to $1000{ }^{\circ} \mathrm{C}$, rises for all alloying elements except for titanium.

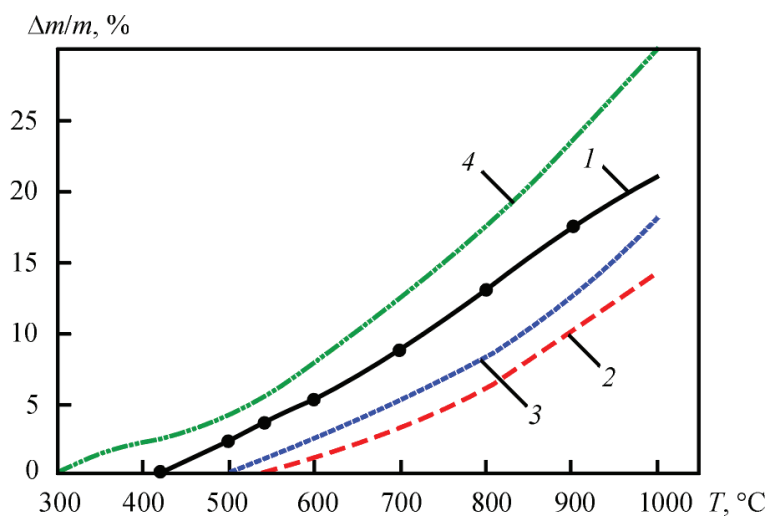

Figure 10. Specific increase of weight of powders in heating on air: $1-\mathrm{Fe}_{3} \mathrm{Al} ; 2-\mathrm{Fe}_{3} \mathrm{Al}(\mathrm{Cr}, \mathrm{Zr}) ; 3-\mathrm{Fe}_{3} \mathrm{Al}(\mathrm{Mg}) ; 4-(\mathrm{Fe}$, $\mathrm{Ti})_{3} \mathrm{Al}$

4. Developed powders of alloyed iron aluminide, produced by mechanochemical synthesis method, are designed for deposition of heat-resistant thermal coatings, including for applications in sulfur-containing media (in form of powders or filler for powder wire).

1. Sinelnikova, V.S., Podergin, V.A., Rechkin, V.N. (1965) Aluminides. Kiev: Naukova Dumka.

2. Deevi, S.C., Sikka, V.K. (1996) Nickel and iron aluminides: An overview on properties, processing and applications. Intermetallics, 4, 357-375.

3. Stoloff, N.S. (1998) Iron aluminides: present status and future prospects. Mater. Sci. Eng., A, 258, 1-14.

4. Palm, M. (2005) Concepts derived from phase diagram studies for the strengthening of $\mathrm{Fe}-\mathrm{Al}$-based alloys. Intermetallics, 13, 1286-1295.

5. Hadef, F. (2016) Solid-state reactions during mechanical alloying of ternary $\mathrm{Fe}-\mathrm{Al}-\mathrm{X}(\mathrm{X}=\mathrm{Ni}, \mathrm{Mn}, \mathrm{Cu}, \mathrm{Ti}, \mathrm{Cr}, \mathrm{B}, \mathrm{Si}$ systems: A review. J. Magn. Magn. Mater., 419, 105-118.

6. Guilemany, J.M., Cinca, N., Cassas, L., Molins, E. (2009) Ordering and disordering processes in MA and MM intermetallic iron aluminide powders. J. Mater. Sci., 44, 2152-2161.

7. Borisova, A.L., Adeeva, L.I., Tunik, A.Yu. et al. (2009) Investigation of powders of $\mathrm{Al}-\mathrm{Cu}-\mathrm{Fe}-\mathrm{Ti}-\mathrm{Cr}-\mathrm{Si}$ system for thermal spraying produced by mechanochemical synthesis with subsequent annealing. Poroshk. Metallurgiya, 9-10, 31-42.

8. Borisov, Yu.S., Borisova, A.L., Adeeva, L.I. et al. (2010) Production of powders for thermal coatings by methods of mechanical alloying and mechanochemical synthesis. Svarochn. Proizvodstvo, 12, 18-22.

9. Magnef, A., Offergeld, E., Leroy, M., Lefort, A. (1998) Fe-Al intermetallic coating application to thermal energy conversion advanced systems. In: Proc. of $15^{\text {th }}$ ITSC (Nice, France), 1091-1096.

10. Xiao, Ch. (2006) Sulfidation resistance of $\mathrm{CeO}_{2}$-modified HVOF sprayed Fe-Al coatings at $700^{\circ} \mathrm{C}$. Surf. Coat. Technol., 201, 3625-3632.

11. Borisova, A.L., Timofeeva, I.I., Vasilkovskaya, M.A. et al. (2015) Phase and structure transformations in formation of powders of $\mathrm{FeAl}$ system intermetallics using mechanochemical synthesis method. Poroshk. Metallurgiya, 7-8, 135-143.

12. Rafiei, M., Enayati, M.N., Karimzadeh, F. (2009) Caracterization and formation mechanism of nanocrystalline (Fe, Ti) ${ }_{3} \mathrm{Al}$ intermetallic compound prepared by mechanical alloying. $J$. of Alloys and Compounds, 480, 392-396. 


\title{
RESULTS OF IMPLEMENTATION OF ORBITAL WELDING IN MANUFACTURE AND REPAIR OF THIN-WALL PIPELINES
}

\author{
P.D. ZHEMANYUK, I.A. PETRIK and S.L. CHIGILEJCHIK \\ JSC «Motor Sich» \\ 11 Motorostroiteley Str., 69068, Zaporozye, Ukraine. E-mail: motor@motorsich.com
}

\begin{abstract}
Applied methods were analyzed for producing a permanent joint of thin-wall pipelines of aircraft gas-turbine engines. The peculiarities of application of mechanized and automated joining technologies were noted. The experimental works were carried out for mastering a technology of orbital welding of position butt joints of pipes of up to $0.5-1 \mathrm{~mm}$ wall thickness, providing high quality of joints and welding productivity. The developed technology of orbital unsupported pipe welding is used in serial production in JSC «Motor Sich». 5 Ref., 2 Tables, 4 Figures.
\end{abstract}

Keywords : aircraft engines, pipe, orbital welding, brazing

The main problem in designing and production of an aircraft engine (AE) is its service life. The AE service life is determined by durability of its structural elements. Around $7 \%$ of AE rejects $[1,2]$ comes for AE pipelines of external manifold (due to the damages in zone of welded and brazed seams).

The typical damages of pipelines of engine external manifold are fatigue cracks, fractures, dints, dents, damages related with defects of welded and brazed seams; corrosion damages of brazed structures.

All these defects can be conventionally divided on related with manufacture, operation and design.

The main methods of welding and brazing being earlier used in production and repair of AE pipelines (manual argon arc welding (AAW), induction and gas brazing) have, at that, a range of technological difficulties effecting process stability and weld quality.

- gas brazing is the human factor, need in flux residuals removal and necessity in application of special testing method;

- AAW is the human factor, difficulty of butt welding of pipes of small thickness $(0.5-1.0 \mathrm{~mm})$, impossibility of pipe rotation during welding (position joint) due to complex geometry of the most pipes, high labor content of the process;

- induction brazing has significantly limited field of application due to impossibility of brazing of complex geometry parts in steel fixture.

The relevance of this problem is related with production of welded and brazed seams of high strength and stable quality in welding of pipelines of AE external manifold.
The enterprise has made a decision on mechanizing and automation of processes of permanent joint production for solving the problems related with increase of quality stability in welded and brazed joints.

Thus, the technologists faced with the problem of welding and brazing process mechanizing and improvement due to this of product quality, receiving the joints having higher stability to fatigue loads.

Following the conditions of fatigue strength, the most acceptable are the brazed joints and butt welding [2].

It should be noted that mechanization of gas brazing is complicated since it requires bulky and complex in operation equipment and special devices.

Orbital welding $[3,4]$ is widely used in the world for mechanization of welding of pipe position butt welds. The widespread of this method of pipe welding is related with the fact that this method provides necessary penetration depth and shape, ensures quality formation of weld root, keeps arc in necessary state and guarantees similar welding conditions in any directions. «Orbital welding» concept means performance of the circumferential welds on a fixed part. At that a welding torch moves around the pipe on set circular orbit.

Known in domestic and world practice application of orbital welding for the moment of project creation (2003) is application of unsupported welding of pipe butt joints with wall thickness from $1 \mathrm{~mm}$ [3-5].

Aim of the present work is consideration of peculiarities in technology of mechanization of processes of pipe permanent joint production.

At that it was necessary to give proof of relevance of replacement of gas brazing and AAW for automatic 
AAW (AAAW) on criteria of strength and workability; outline the main principles for designing the joints in orbital welding at transfer from AAW and brazing as well as repair, propose the main technological approaches in unsupported butt welding of complex geometry pipes providing welded joints of high quality with wall thickness from 0.5 to $1 \mathrm{~mm}$; implement a new technological process into existing pipeline production cycle.

It was assumed that the following would be provided, namely increase of productivity or keeping its previous level, necessary conditions of assembly for orbital welding due to application of modern technologies of facing, calibration, special fixture for centering and assembly; requirements to selection of type of equipment are formed (main and auxiliary) based on determined technological problems.

The technology should provide stable quality and high fatigue strength of welded joints; rise of pipeline service life; expansion of fields of application of automatic orbital welding in manufacture and repair of AE pipelines.

The experiments were carried out on thin-wall parts (pipelines, nipples, connecting pipes) produced of 12Kh18N10T and 14Kh17N2 steels. Welding was carried out using a complex of special equipment including welding power sources (Fronius and Polysoude Companies) with a block of software control and set of heads for welding of different pipe structures and joint types (Polysoude Company). Open type heads (MU IV 38 and MU IV 115) are used for welds with reinforcement and that without reinforcement are made with heads of closed type (MW40 and MW65). Fatigue strength tests were performed in accordance with OST 1.41972-80.

The results of carried experiments allowed developing and implementing a technological process of orbital welding of AE pipelines, the main stages of which are edge preparation for welding, assembly, welding, weld quality control.

The edge preparation and assembly for welding are carried out in accordance with the requirements presented in Table 1.

Cutoff and facing machines (Georg Fisher and Protem Companies) were used for providing a necessary welding gap (see Table 1). They completely eliminate manual edge preparation for welding, at which treatment misalignment of pipe edge should not exceed $0.1 \mathrm{~mm}$ relatively to pipe axis.

Assembly and further tack welds were made in special centrators (Figure 1). Displacement of edges of butt joints should not be more than 0.1S.
Table 1. Requirements to edge preparation for orbital welding

\begin{tabular}{|c|c|c|c|c|}
\hline $\begin{array}{c}\text { Type of } \\
\text { welding } \\
\text { head }\end{array}$ & $\begin{array}{c}\text { Wall } \\
\text { thickness } S \text {, } \\
\text { mm }\end{array}$ & $b, \mathrm{~mm}$ & $l_{1}, \mathrm{~mm}$ & $l_{2}, \mathrm{~mm}$ \\
\hline Open & $\begin{array}{c}\leq 1.0 \\
1.0-1.5 \\
1.5-3.0 \\
\end{array}$ & $\begin{array}{c}0-0.1 \\
0-0.15 \\
0-0.2\end{array}$ & $\geq 100$ & $\geq 5$ \\
\hline Closed & $\begin{array}{c}\leq 1.0 \\
1.0-1.5 \\
1.5-3\end{array}$ & $\begin{array}{c}0-0.1 \\
0-0.15 \\
0-0.2 \\
\end{array}$ & $\geq 19$ & $\geq 19$ \\
\hline \multicolumn{5}{|c|}{$\begin{array}{l}\text { Note. } b \text { - welding gap; } l_{1} \text { - length of necessary straight section } \\
l_{2}-\text { distance from welded joint to fitting. }\end{array}$} \\
\hline
\end{tabular}

Quality control of the welds joints produced by orbital welding was performed by external inspection, hardware check of welding modes, and, depending on importance and designation of pipelines, one of non-destructive methods of testing:

- for fuel pipelines - $100 \%$ X-ray testing, leakage testing;

- for oil pipelines - $20 \% \mathrm{X}$-ay testing, leakage testing;

- for air pipelines - X-ray testing of one part from a batch.

The hardware check lies in verification of current welding modes, which are printed with the modes entered in the technology.

The fatigue strength is the main criterion for providing safe operation of pipeline in AE content. Therefore, the main reason for implementation of orbital welding for a designer is ensuring high strength characteristics of welded joints under cyclic alternating loads. Pilot works on determination of ultimate strength of different configuration pipelines were performed for this. The check was performed in a range of parameters from 10 to $80 \mathrm{~mm}$ on OST 1.41972-80.

The results of tests showed that welded joints produced by orbital welding equal on fatigue strength to the joints produced with gas brazing, and significantly exceed ones produced by AAW (Table 2).

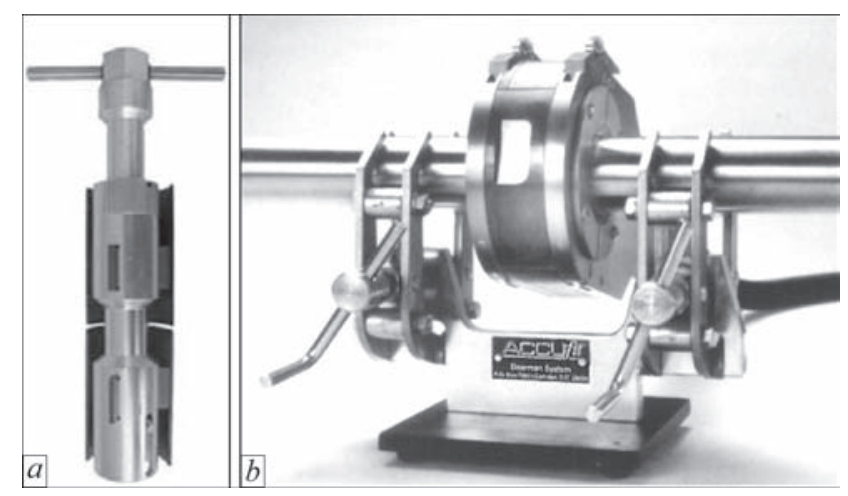

Figure 1. Centrators for pipe assembly ( $a$ - type $1, b$ - type 2 ) 
Table 2. Comparative analysis of fatigue strength of welded and brazed joints of steel pipelines

\begin{tabular}{|c|c|c|c|}
\hline \multirow[b]{2}{*}{ Unit design characteristics } & \multicolumn{3}{|c|}{ Fatigue strength $\sigma_{-1}, \mathrm{~kg} / \mathrm{mm}^{2}$} \\
\hline & $\begin{array}{c}\text { Manual AAW with } \\
\text { backing }\end{array}$ & Gas brazing & $\begin{array}{l}\text { Orbital welding } \\
\text { (AAAW) }\end{array}$ \\
\hline Pipe + pipe $10 \times 1 \mathrm{~mm}, 12 \mathrm{Kh} 18 \mathrm{~N} 10 \mathrm{~T}$ & - & 14 & 18 \\
\hline Pipe + pipe $14 \times 0.5$ mm, 12Kh18N10T & - & 16 & 16 \\
\hline Pipe + pipe $18 \times 1 \mathrm{~mm}, 12 \mathrm{Kh} 18 \mathrm{~N} 10 \mathrm{~T}$ & - & 14 & 18 \\
\hline Pipe+Pipe $18 \times 0.5$ mm, 12Kh18N10T & - & 14 & 14 \\
\hline Pipe + pipe $22 \times 0.5 \mathrm{~mm}, 12 \mathrm{Kh} 18 \mathrm{~N} 10 \mathrm{~T}$ & - & 12 & 14 \\
\hline Pipe + pipe $25 \times 0.5$ mm, 12Kh18N10T & - & 10 & 12 \\
\hline Nipple (12Kh18N10T) + pipe 18×1 mm (12Kh18N10T) & 6 & 16 & 16 \\
\hline Nipple (12Kh18N10T) + pipe 32×1 mm (12Kh18N10T) & 4 & - & 10 \\
\hline Nipple (12Kh18N10T) + pipe 40×1 mm (12Kh18N10T) & 4 & - & 10 \\
\hline Nipple (12Kh18N10T) + pipe 50×1 mm (12Kh18N10T) & 4 & - & 10 \\
\hline Nipple (12Kh18N10T) + pipe 80×1 mm (12Kh18N10T) & 4 & - & 8 \\
\hline Connecting pipe $(14 \mathrm{Kh} 17 \mathrm{~N} 2)+$ pipe $18 \times 1 \mathrm{~mm}(12 \mathrm{Kh} 18 \mathrm{~N} 10 \mathrm{~T})$ & 6 & 16 & 16 \\
\hline Connecting pipe $(14 \mathrm{Kh} 17 \mathrm{~N} 2)+$ pipe $32 \times 1 \mathrm{~mm}(12 \mathrm{Kh} 18 \mathrm{~N} 10 \mathrm{~T})$ & 6 & - & 14 \\
\hline Connecting pipe $(14 \mathrm{Kh} 17 \mathrm{~N} 2)+$ pipe $40 \times 1 \mathrm{~mm}(12 \mathrm{Kh} 18 \mathrm{~N} 10 \mathrm{~T})$ & 4 & - & 12 \\
\hline
\end{tabular}

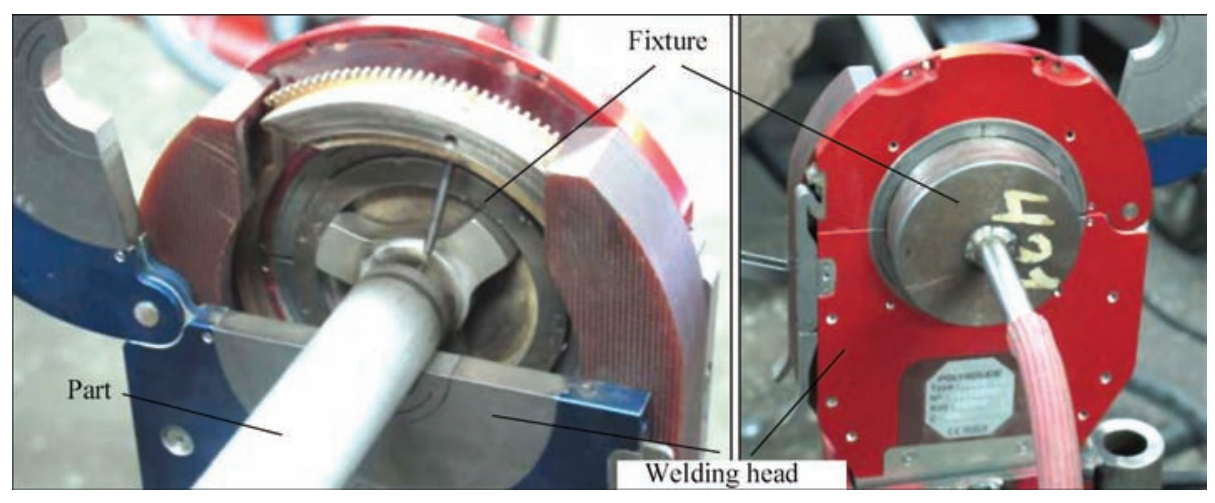

Figure 2. Fixing of closed type welding head to special fixture

The main problems appearing at implementation of orbital welding of pipes and AE parts are the following. The first one is part configuration, location of welded joint directly close to flange or pipe bend radius, at that straight area $\left(l_{1}, l_{2}\right.$ see Table 2$)$ is necessary for fixing welding automatic units (heads). The second is small thickness of welded edges (from $0.5 \mathrm{~mm}$ ).

The first problem was solved by production of special fixture, to which welding head was attached (Figures 2, 3).

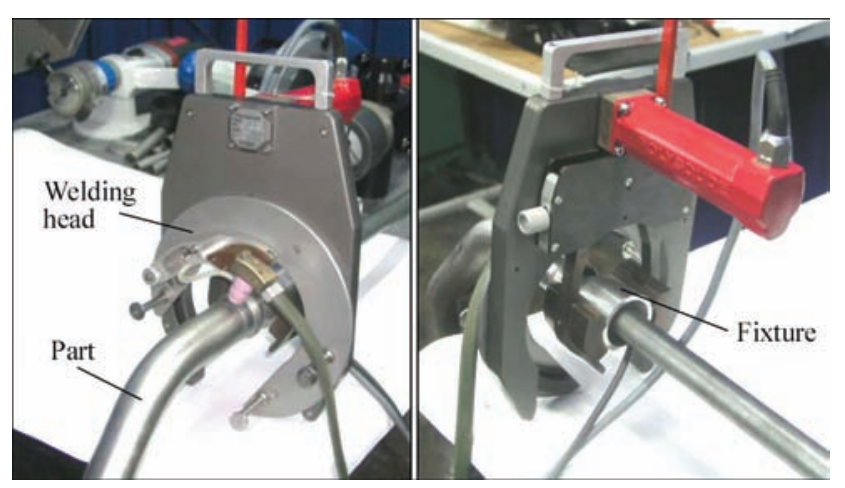

Figure 3. Fixing of open type welding head to special fixture

The second problem was solved due to application of inverter welding power sources from Fronius and Polysoude Companies with microprocessor, synergy control of the key welding parameters (welding current (from 5A), welding rate, wire feed rate and arc

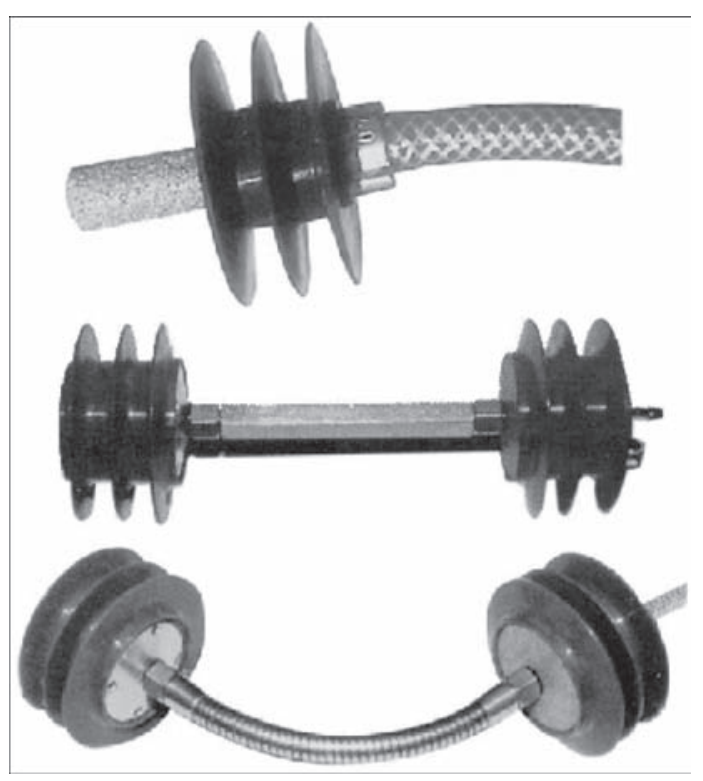

Figure 4. Auxiliary devices for formation of weld backside

ISSN 0957-798X THE PATON WELDING JOURNAL, No. 9, 2017 
voltage) and application of special devices for improvement of formation of weld backside (Figure 4).

The special device was used for argon supply inside the pipe during welding and due to small excessive pressure a weld pool was kept.

Orbital welding is implemented in manufacture of more than 50 dimension types of steel pipelines of up to $0.5 \mathrm{~mm}$ wall thickness and $6-90 \mathrm{~mm}$ diameter; in repair of steel pipelines of wall thickness up to $0.5 \mathrm{~mm}$ and 10-90 mm diameter. Replacement of pipelines for new ones (before that 18-25 pipelines were replaced for new ones in one engine) was virtually eliminated in engine repair and it is used in manufacture of more than 100 dimension types of power assemblies in helicopters and engines of structural steels and titanium alloys of 1-6 mm thickness.

\section{Conclusions}

1. Butt joints of pipes produced by orbital welding are not inferior to traditional brazed joints on fatigue strength. This allows their application in new structures designing as well as replacement of existing (brazed) joints.

2. Technological approaches were proposed and equipment and fixture were selected. This allowed welding of pipe-to-pipe, pipe-to-fitting (flange, connecting pipe, nipple) joints in any configuration of pipelines independent on distance of welded joint from flange or pipe bending radius.

3. Technical requirements to edge preparation and assembly for welding were determined and modes were selected. They could provide unsupported welded joints of high quality with wall thickness from 0.5 to $1 \mathrm{~mm}$ and 6-90 mm diameter.

4. JSC «Motor Sich» implemented in serial production a welding bench for manufacture and repair of thin-wall pipes of aircraft engineering, design documentation was improved and technological procedures and technological processes were developed.

1. Boguslaev, V.A., Kachan, A.Ya., Kalinina, N.E. et al. (2009) Aerospace materials. Ed. by V.A. Boguslaev. Zaporozhie, OJSC Motor Sich.

2. Boguslaev, V.A., Kachan, A.Ya., Mozgovoj, V.F. et al. (2004) Technology of production of aircraft engines. Zaporozhie, OJSC Motor Sich.

3. Ostrovsky, O.E. (1992) Orbital welding of pipelines. Svarochn. Proizvodstvo, 10, 10-13.

4. Khavanov, V.A. (1995) Equipment for automatic orbital welding of technological pipelines. Ibid., 6, 22-24.

5. Poloskov, S.I. (2003) Analysis of factors determining weld pool formation in orbital position butt welding of pipes (Review). Ibid., 2, 11-19. 


\title{
CLASSIFICATION AND CHARACTERISTIC OF DEFECTS OF DEPOSITED LAYERS ACCORDING TO THE INTERNATIONAL STANDARD ISO 6520-1:2007
}

\author{
I.A. RYABTSEV ${ }^{1}$, R. ROZERT ${ }^{2}$, E. TURYK ${ }^{3}$ and I.I. RYABTSEV ${ }^{1}$ \\ ${ }^{1}$ E.O. Paton Electric Welding Institute, NASU \\ 11 Kazimir Malevich Str., 03150, Kiev, Ukraine. E-mail: office@paton.kiev.ua \\ ${ }^{2}$ Rosert RCT GmbH, Dresden, Germany \\ ${ }^{3}$ Welding Institute, ul. B. Czeslawa 16-18, 44-100, Gliwice, Poland
}

\begin{abstract}
The review of defects of deposited layers on the basis of their classification system according to the International standard ISO 6520-1:2007 and its analogue GOST R ISO 6520-1:2012 was carried out. According to these standards, the welding (surfacing) defects are divided into six main groups with the corresponding three-digit number: cracks (100-106), cavities (200-203), solid inclusions (300-304), lacks of fusion and lacks of penetration (400-403), deviation from shape and sizes (500-521) and other defects (600-618), i.e. the defects, which are not included into the first five groups. Within each group, the defects are divided into the corresponding subgroups with four-digit numbers. The nature of defects of deposited layers was analyzed from the point of view of their admissibility and inadmissibility in the process of operation of deposited parts. 9 Ref., 17 Figures.
\end{abstract}

Keywords: surfacing, deposited metal, defects of deposited layers, classification of defects, admissible defects, inadmissible defects, quality evaluation

The reliability, serviceability, efficiency of manufacture and safety of the subsequent service of deposited parts depend mainly on the quality of deposited metal and the presence or absence of different defects in it. The origin of these defects is associated with metallurgical, hydrodynamic and thermal processes occurring in surfacing. Thus, their appearance depends mainly on chemical composition of the base and deposited metals, methods, technology and technique of surfacing.

A detailed analysis of defects of the deposited metal, the causes of their formation and methods of their prevention are given in the work [1]. The aim of this publi-

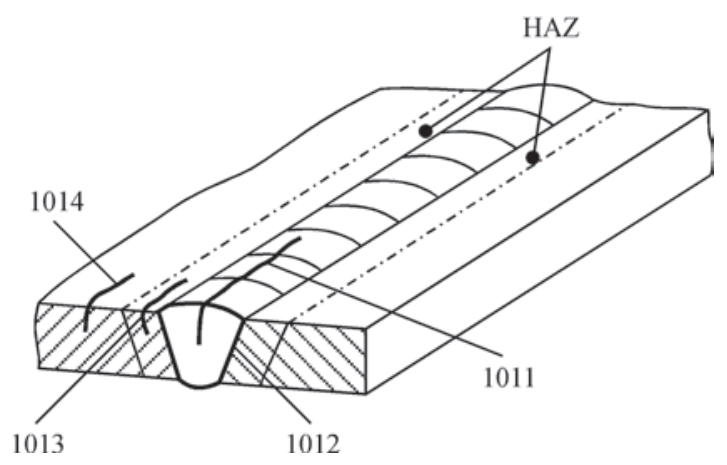

Figure 1. Weld with longitudinal cracks: 1011 — in weld metal; 1012 - in fusion zone; 1013 - in HAZ metal; 1014 — in base metal [2, 3]

(C) I.A. RYABTSEV, R. ROZERT, E. TURYK and I.I. RYABTSEV, 2017 cation is the characteristic of different groups of defects of deposited layers, given in the standards [2, 3].

In welding (surfacing) practice the concept of defect as discontinuity or other flaw is widespread, which is admissible (if its parameters do not exceed the limit value according to the corresponding standard or technical specifications) or inadmissible. In this paper the traditional definition of a defect as a discontinuity in a weld (deposited metal) or deviation from the required shape and sizes of weld (deposited bead), accepted in the standard ISO 6520-1:2007 [2] and its analogue GOST R ISO 6520-1:2012 [3] is used.

According to the standards $[2,3]$, the welding (surfacing) defects are divided into six main groups having the corresponding three-digit number: cracks (100-106), cavities (200-203), solid inclusions (300$304)$, lacks of fusions and lacks of penetration (400403), deviation from shape and sizes (500-521) and other defects (600-618), i.e., the defects which are not included into the first five groups. Within each group, the defects are divided into subgroups. For example, the number 101 denotes longitudinal cracks, $102-$ transverse, 103 - radial cracks, etc. In their turn, the defects in subgroups are divided into separate types with four-digit numbers.

Cracks (100-106). The cracks are macro- or microscopic discontinuities which have the character of a notch. In the standards $[2,3]$, the cracks are char- 


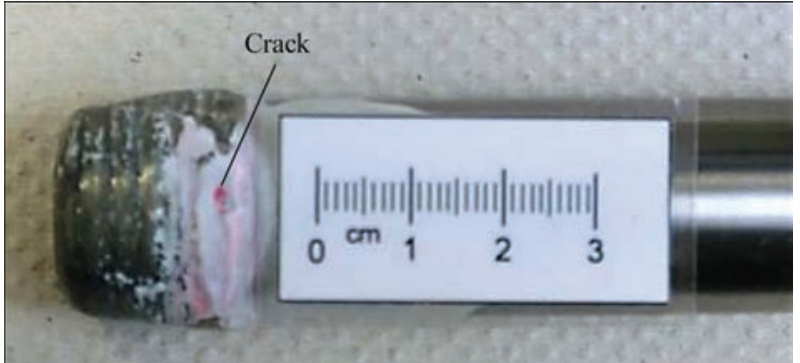

Figure 2. Crack in crater (104) of closing bead of deposited layer performed by arc surfacing using flux-cored wire in inert gas (process 132, deposited metal of the group $\mathrm{CO}_{2}$ [4-6])

acterized mainly from the geometric point of view. As an example, Figure 1 shows the numerical indices of longitudinal cracks, which are located in different zones of a weld [2, 3].

The cracks, like most other defects, can be admissible and inadmissible. For the process of surfacing, the admissibility of cracks in the deposited metal is determined primarily by the conditions of service of parts.

The cracks are inadmissible in the case when they can cause damage of the part or impossibility of its further service. Among such parts there are plungers of hydraulic presses, mill rolls, parts of stop valves, valves of internal combustion engines, etc.

The examples of inadmissible defects are cracks in the crater (104) of the closing bead of deposited layer of the reinforced surface of the stop valve part (Figure 2); microcracks in the deposited layer (1001) of cast iron parts due to violation of the surfacing technology (Figure 3); longitudinal cracks in the deposited layer (1011), which are the result of using a poor-quality wire during surfacing (Figure 4) or violation of surfacing mode (Figure 5). The used processes and consumables of surfacing are marked in accordance with the requirements [4-6].

Inadmissible are also the transverse cracks in the HAZ metal (1023) in case of surfacing the broach of

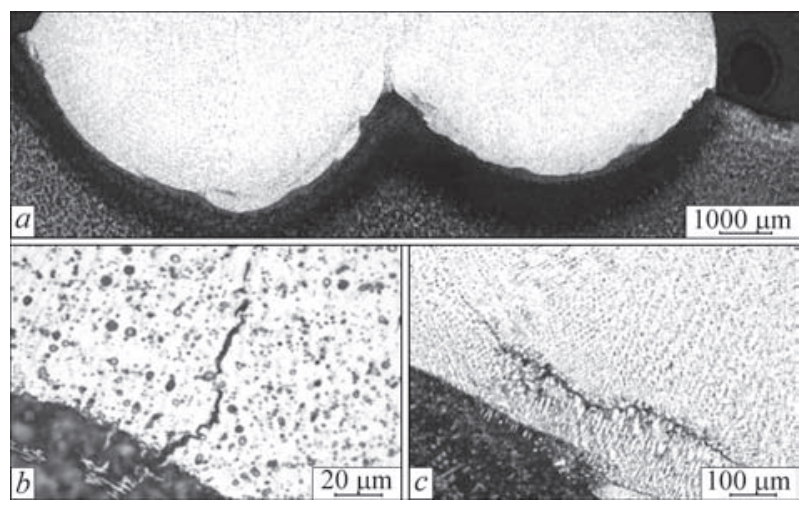

Figure 3. Microcracks in deposited layer (1001) produced by arc welding in $\mathrm{CO}_{2}$ using flux-cored wire (process 136, deposited metal of the group Fe-2 M [4-6]): $a$ - part of cross-section of deposited layer, $\times 50 ; b-$ microstructure of fusion zone with a microcrack, $\times 200 ; c$ - the same, $\times 500$

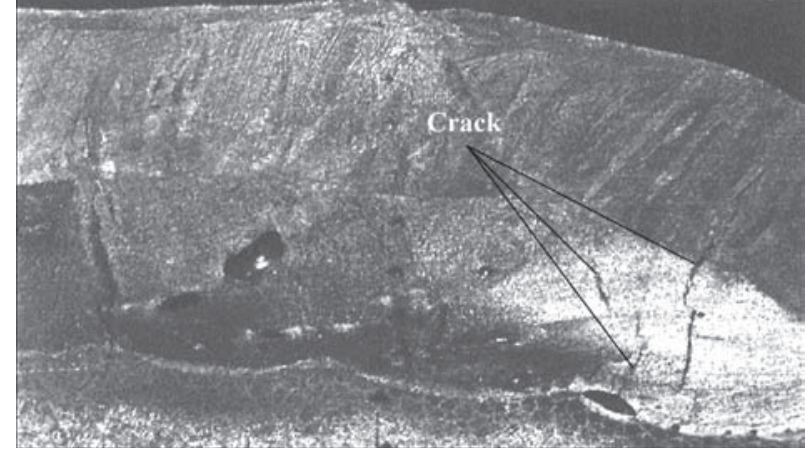

Figure 4. Longitudinal cracks in the deposited layer (1011) produced by arc surfacing using solid wire in active gas (process 135, deposited metal of the Fe1 group [4-6])

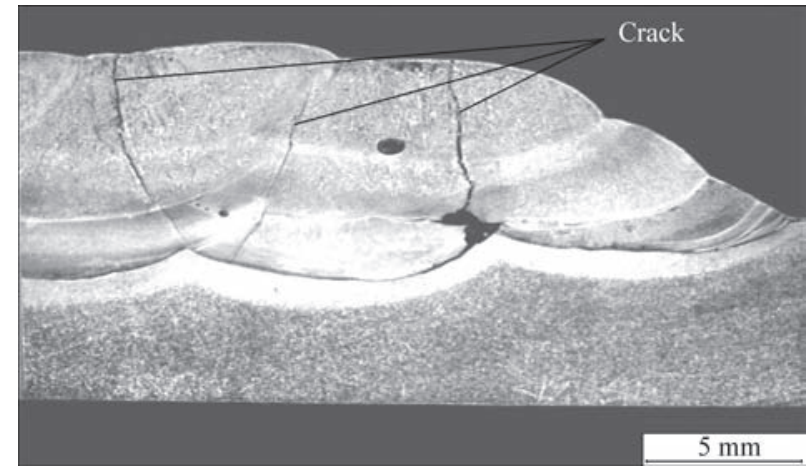

Figure 5. Longitudinal cracks in deposited layer (1011), produced by arc surfacing using flux-cored wire in inert gas (process 132, deposited metal of the $\mathrm{CO}_{2}$ group [4-6])

hardened steel $38 \mathrm{Kh} 2 \mathrm{MYuA}$. The cracks have a character of tear in the HAZ metal (Figure 6,a) or spalling of the deposited layer (Figure $6, b$ ). The cause for their appearance can be violation of the surfacing technology.

For some parts, the cracks have no such a decisive significance, especially if they do not transfer into the base metal or are not oriented parallel to the fusion surface and do not lead to spallings of the deposit-
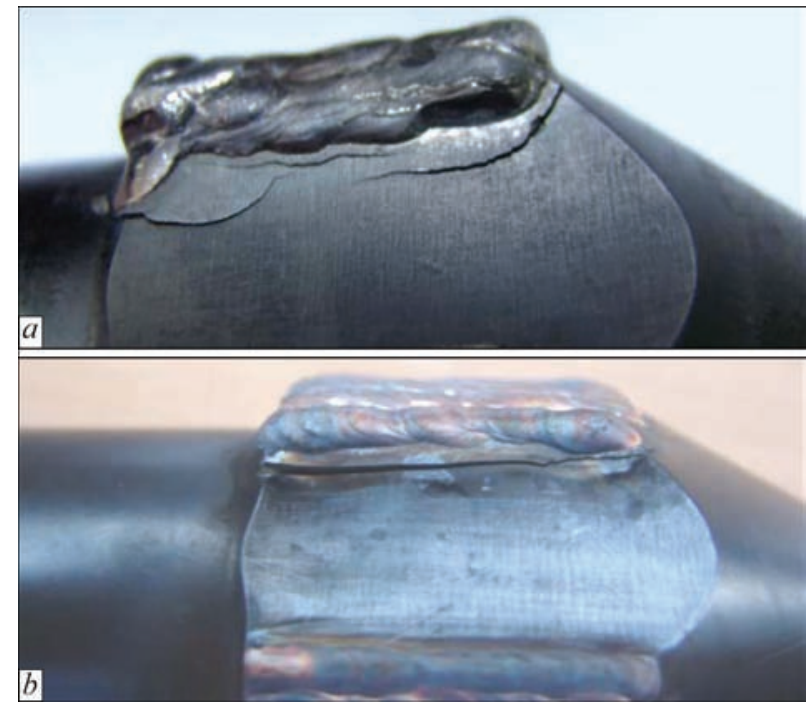

Figure 6. Cracks in HAZ metal (1023) of deposited layer $(a)$ and the spalling (1023) of deposited layer $(b)$ of steel 38Kh2MYuA 


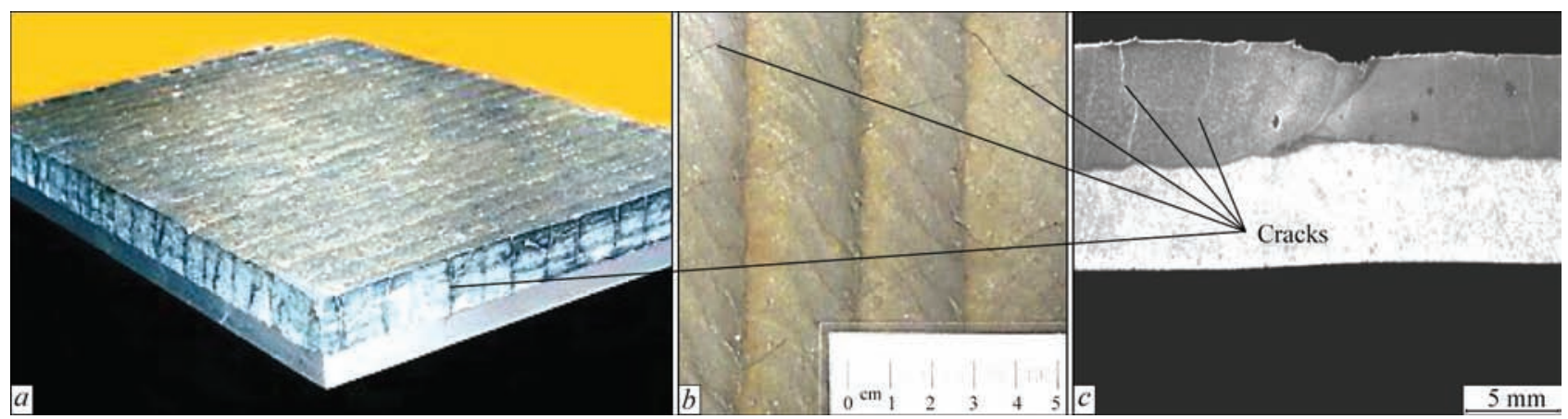

Figure 7. Admissible longitudinal (1011) and transverse (1021) cracks in wear-resistant layer of bimetal sheets, deposited by high-chromium cast iron (process 114, deposited metal of the group Fe14 [4-6]): $a$ - deposited bimetal sheet with cracks; $b$ - cracks in separate deposited beads; $c$ - macrostructure of deposited bimetal sheet

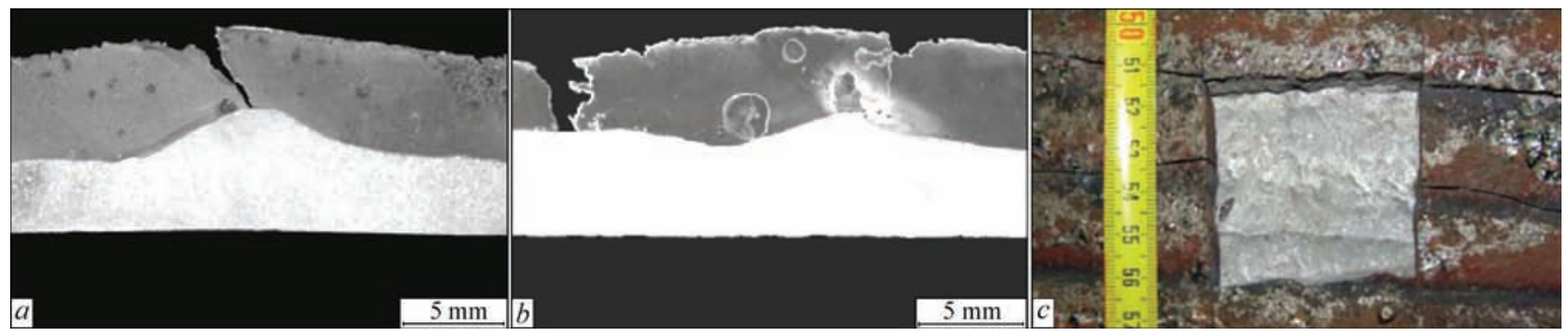

Figure 8. Inadmissible cracks (1011) $(a, b)$ and separation (1023) (c) of wear-resistant layer of sheets deposited by high-chromium cast iron [4]

ed metal. They include cones and bowls of charging equipment of blast furnaces, different chutes for transportation of abrasive materials, hoppers and other parts that operate under conditions of different types of intensive abrasive wear. These parts are deposited using the materials of groups Fe13-Fe16 and Fe20 [5, 6]. The examples of admissible longitudinal (1011) and transverse (1021) cracks in the deposited layer of wear-resistant bimetal sheets are shown in Figure 7.

In some cases, cracks in the operating layer, deposited by high-chromium cast iron, can lead to inadmissible spalling and separation of the deposited layer (1011 and 1023) (Figure 8).

It should be noted that in the standards [2, 3], an alphabetical (of two letters) classification according to the types of welding cracks is given as a reference appendix. All cracks are denoted by the capital Latin letter «E». Accordingly, hot cracks have the designa-

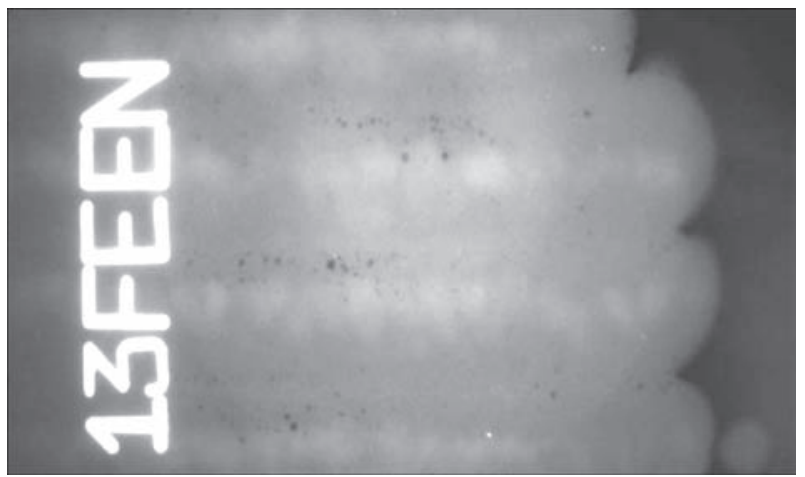

Figure 9. Pore clusters (2013) in the layer deposited by MIG method using solid bronze wire [7] tion «Ea»; crystallization cracks — «Eb»; subsolidus cracks - «Ec $» ;$ cold cracks - $\langle\mathrm{Ef}\rangle ;$; cracks, caused by hydrogen — «Ei»»; lamellar cracks — «Ej», etc.

Cavities (200-203). The cavities of different shapes in welds (in the deposited layer) are classified as follows [2, 3]: 201 - gas cavities formed by a delayed gas evolved during crystallization; $202-$ shrinkage cavities, i.e. the cavities formed as a result of shrinkage during crystallization; 203 - microshrinkage (shrinkage cavity), visible exclusively under the microscope.

At the same time the gas pores, which are most often found in the welds, are understood as gas cavities of almost spherical shape, which are denoted by the index 2011.

In most cases, the pores in the deposited layer can be detected using radiographic or ultrasonic testing. In Figure 9 [7] a radiogram of the layer with pore clusters is presented, deposited by the MIG method using a solid bronze wire (2013).

The pores, similar to cracks, can be admissible or inadmissible defect in the deposited layer. An example of admissible surface pores (2017) in the deposited layer of wear-resistant bimetal sheets is shown in Figure 10.

In other cases, for example, in the layer deposited on critical cast iron parts, which operate under the conditions of high contact pressure and friction of metal against metal, the inner gas pores (2011) are not admitted (Figure 11). 


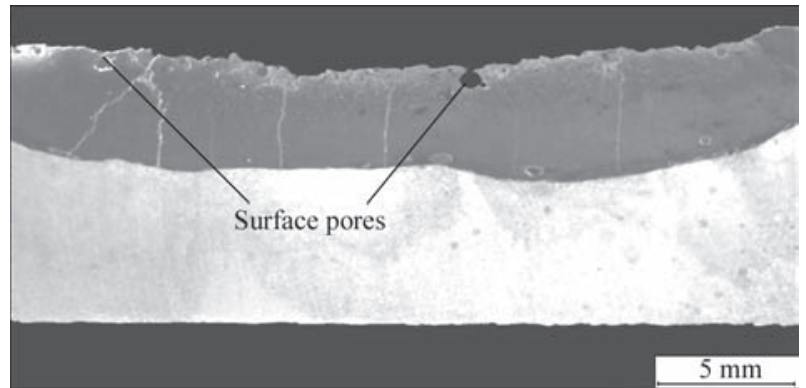

Figure 10. Admissible surface pores (2017) in wear-resistant layer of bimetal sheets deposited by high-chromium cast iron (process 114, deposited metal of the Fe14 group [4-6])

Solid inclusions (300-304). The solid inclusions in the deposited metal are foreign substances of a small volume of nonmetallic or metallic origin $[2,3]$. They include slag (301), flux (302), oxide (303) and metal (304) inclusions among. Among the metal inclusions there are inclusions of tungsten (3041), copper (3042) or other metals (3043).

The slag inclusions can form in the welds (deposited metal) during manual arc welding or surfacing using stick electrodes, during welding or surfacing using self-shielding flux-cored wires (Figure 12, a) and during automatic submerged arc surfacing (Figure 12,b).

Lacks of fusion and lack of penetration (400 402). The lacks of fusion (401) is the absence of a joint between the base and deposited metal or between separate layers (beads). Due to their shape, which is mostly flat, the lacks of fusion can act as stress concentrators, significantly reducing the fatigue life of deposited parts [9]. The examples of interlayer (4011) and interbead (4012) lacks of fusion formed during mechanized surfacing of the inner surface of a position pipe applying MAG method are shown in Figure 13. The cause of appearance of these defects is the violations of surfacing technology.

Lacks of fusion (4011) can appear when the modes of other surfacing methods are violated, as for exam-

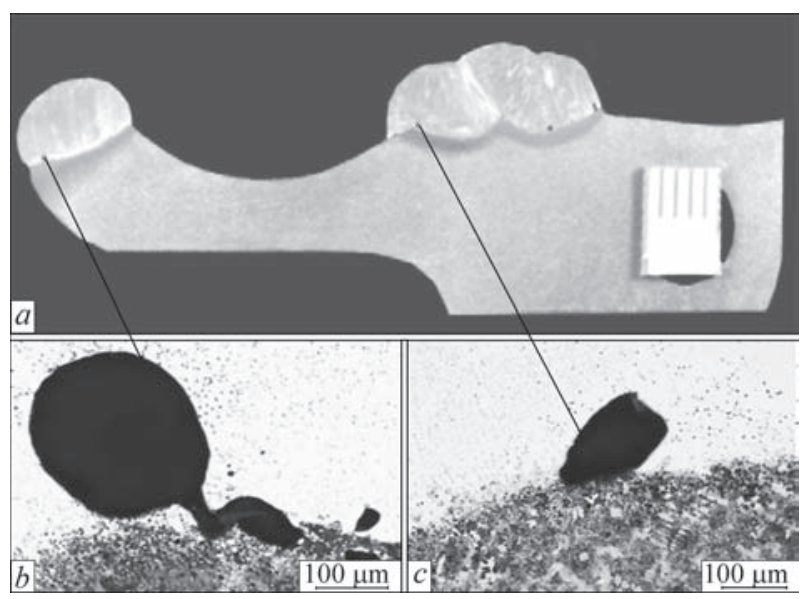

Figure 11. Inadmissible inner gas pores (2011) in the layer deposited on critical cast iron parts: $a$ - macrostructure of deposited part; $b, c$ - gas pores in deposited metal at the fusion boundary

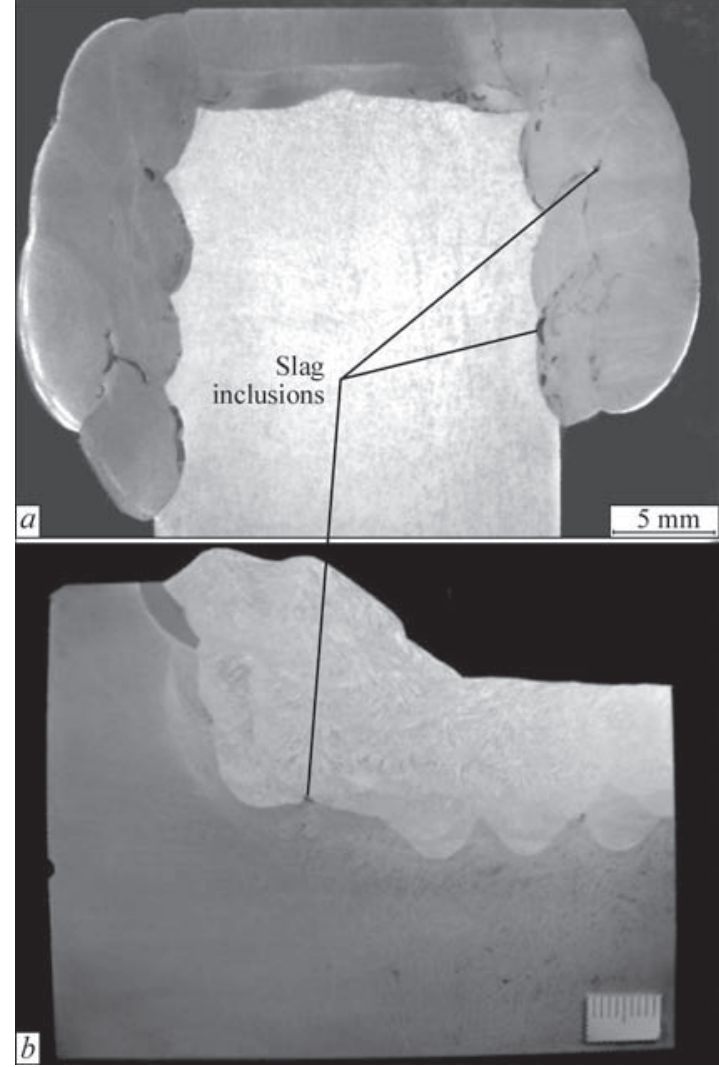

Figure 12. Macrostructure of cross-section of deposited mandrel (a) [4] and crane wheel (b) with slag inclusions (301) [8]

ple, in plasma-powder (Figure 14, a) and laser-powder (Figure 14, b) surfacing.

Lack of penetration (402), according to the standards $[2,3]$ is the difference between the actual and nominal penetration depth. During surfacing these defects occur rather rare.

Deviation from shape and size (500-521). This is the most numerous group of defects which, in particular, includes undercuts (501), excess of penetra-

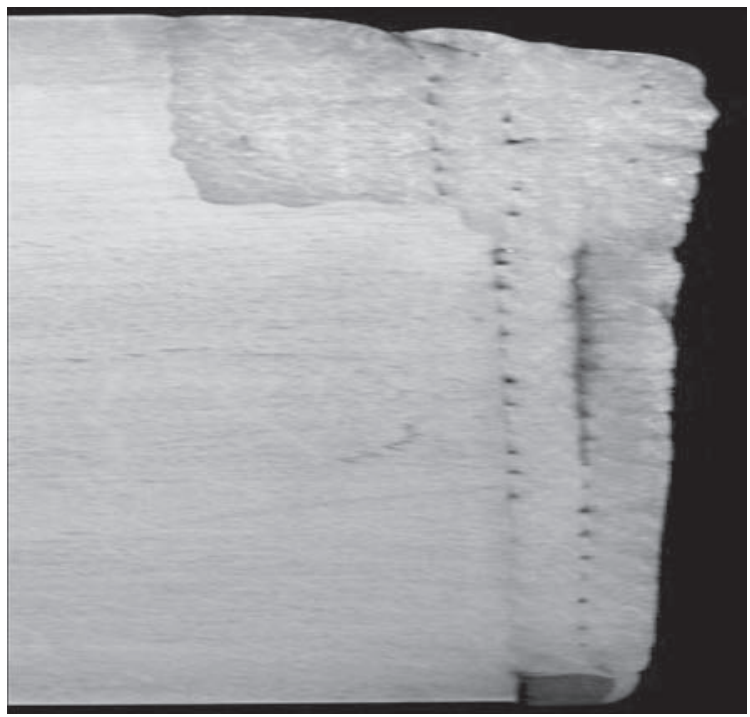

Figure 13. Interlayer (4011) and interbead (4012) lacks of fusion in surfacing of inner surface of $170 \mathrm{~mm}$ diameter position pipe applying MAG method 


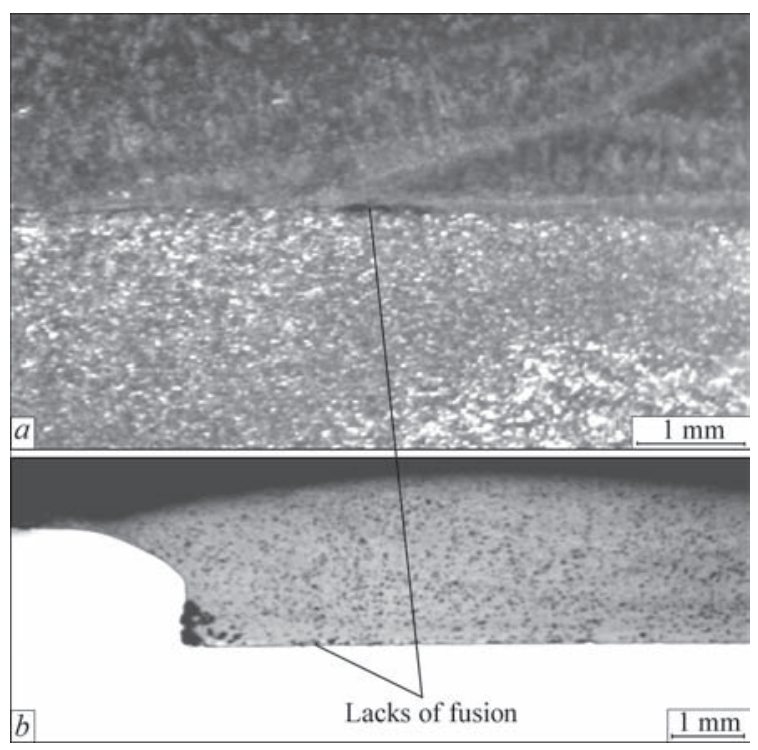

Figure 14. Lacks of fusion at the interface of joint of base and deposited metals (4011) in plasma-powder (a) and laser-powder surfacing $(b)[4]$

tion (504), irregular weld profile (505), lapping (506), linear displacements (507), burnouts (510), lack of groove filling (511), non-uniform width of weld (513), uneven weld surface (514), poor re-exciting of the arc (517), distortion (520), irregular weld sizes (of deposited bead) (521) [2, 3].

For surfacing the most characteristic of them are:

- undercut (501) - deepening at the interface of bead in the base metal or in the previous deposited bead;

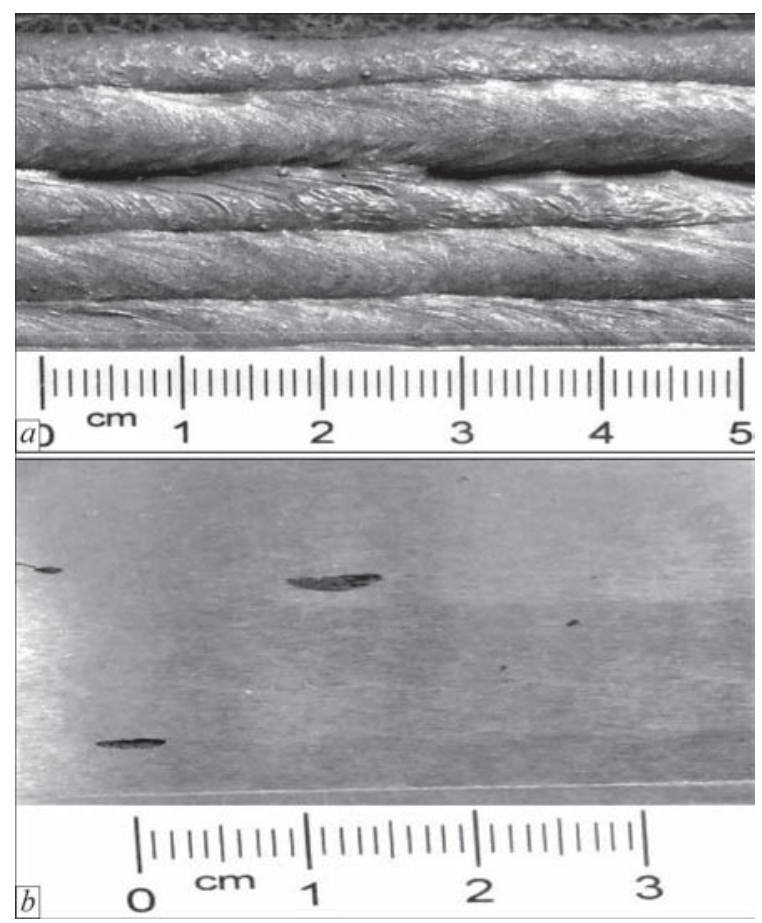

Figure 15. Appearance of deposited surface with non-uniform reinforcement of deposited beads and insufficient overlapping of adjacent beads (514) directly after surfacing $(a)$ and after mechanical treatment $(b)[4]$
- excess of penetration (504) and burnouts (510), which can appear during surfacing of thin-walled parts in case of violation of surfacing technology;

- non-uniformity of the reinforcement of the deposited bead along the length or insufficient overlapping of beads across the width of the deposited layer, related to the violation of surfacing technology (514);

- poor reexciting of the arc (517) - local unevenness of the surface at the site of welding (surfacing) renewal;

- distortion (520) - deviation of dimensions of a part from those specified by the drawing, arisen from welding (surfacing) deformations;

- irregular sizes of deposited bead (521) due to violation of surfacing mode, magnetic blowing or low skill of a surfacing operator.

During surfacing of flat or cylindrical surfaces of a large area, quite often such a defect (514) occurs as a non-uniform reinforcement of deposited bead along the length or insufficient overlapping of beads across the width of the deposited layer. After mechanical treatment, this leads to appearance of grooves of different depth and extension (Figures 15, 16) on the surface of the deposited layer.

Figure 17 shows the appearance of beads deposited by two stainless steel strips of $120 \mathrm{~mm}$ width. Depending on the place of current supply, the character of formation of deposited beads is changed. If the current supply is carried out at a considerable distance from the axis of the bead (Figure 17, $a, b$ ), then as a result of arising effect of magnetic blowing, the formation of deposited bead is deteriorated (defect 521).

Other defects (600-618). The rest ones include all the defects, which are not mentioned in the groups

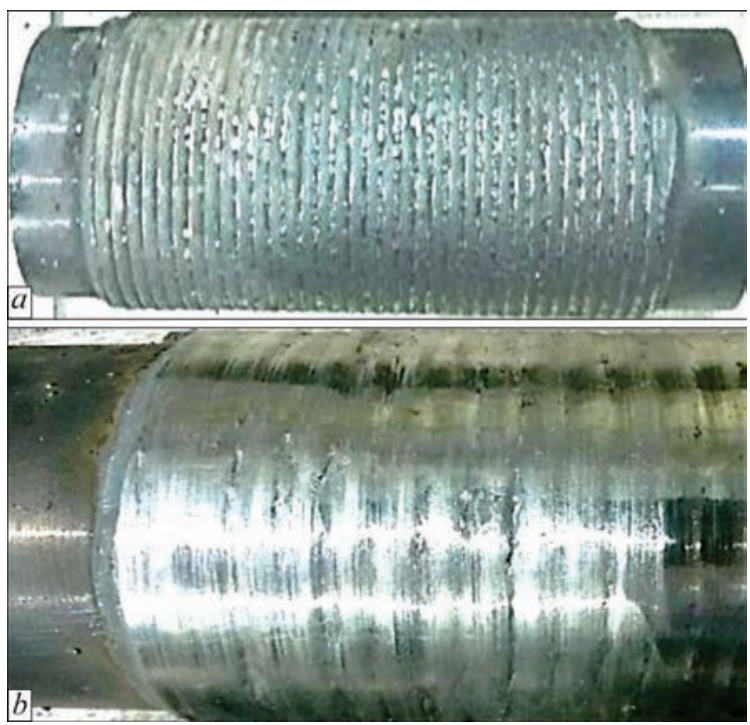

Figure 16. Appearance of deposited surface of $70 \mathrm{~mm}$ diameter bead with non-uniform reinforcement of deposited beads and insufficient overlapping of adjacent beads (514) directly after surfacing $(a)$ and after mechanical treatment $(b)$ 


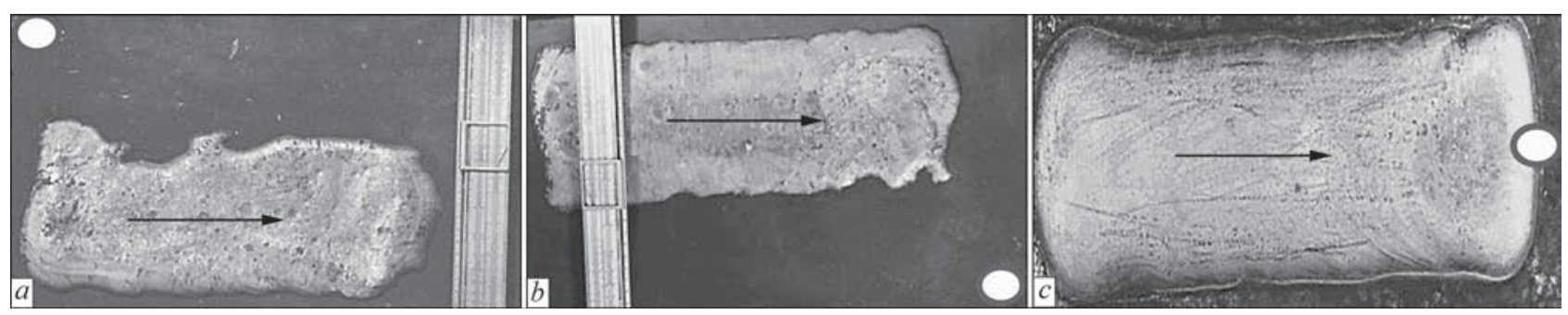

Figure 17. Violation of bead shape (521), depending on place of current supply to the workpiece and effect of magnetic blowing: $a-$ current supply on the left side of weld axis; $b$ - current supply on the right side of weld axis; $c$ — current supply along the weld axis (o - location of current supply, $\rightarrow$ - direction of surfacing)

1-5. Among them, the most significant for surfacing are: arc burn (601); spatters of metal (602); tempering colors (610); slag remnants (615). In detail:

- 601 - local damage of the surface of base metal adjacent to deposited layer, which occurred as a result of accidental ignition of the arc;

- 602 - drops of deposited metal, which are formed during surfacing process and are welded-on to the surface of the solidified deposited layer or nearweld zone of base metal;

- 610 - thin colored oxide film on the surface in the welding (surfacing) zone, for example, in welding of stainless steel, the appearance of which is caused by heating during welding (surfacing) and/or insufficient protection, for example, during welding (surfacing) of titanium;

- 615 - slag, not completely removed from the surface of weld or deposited metal.

The carried out review of different groups of defects of deposited layers confirmed the possibility of their classification and characteristics according to the standard ISO 6520-1:2007 and its analog GOST R ISO 6520-1:2012 Welding and related processes. Classification of geometry defects and continuities in metallic materials. Part 1. Fusion welding.
1. Ryabtsev, I.A., Senchenkov, I.K., Turyk, E.V. (2015) Surfacing. Materials, technologies, mathematical modeling. Gliwice, Poland: SPI.

2. ISO 6520-1:2007: Welding and allied processes: Classification of geometric imperfections in metallic materials. Pt 1 : Fusion welding.

3. GOST R ISO 6520-1-2012: Welding and related processes: Classification of defects of geometry and continuity in metallic materials. Pt 1: Fusion welding.

4. DVS-Merkblatt DVS 0945-2: Unregelmaessigkeiten geschweisster Beschichtungen. DVS Media GmbH.

5. DSTU EN 14700:2008: Welding consumables. Welding consumables for hard-facing.

6. Protsenko, N.A., Ryabtsev, I.I. (2007) Harmonization of standards on surfacing consumables in accordance with European Standard EN 14700: Welding consumables for hard-facing. Svarshchik, 5, 30-38.

7. Goral, T. (2007) Wplyw technologicznych parametrow napawania brazu na podloze stalowe na wybrane wlasciwosci uzytkowe napoin: Syn. of Thesis for Dr. of Sci. Degree, Krakow. http:// winntbg.bg.agh.edu.pl/rozprawy/9900/full9900. pdf

8. Riabtsev, I.A.,Rosert, R., Senchenkow, I.K., Turyk, E. (2017) Niezgodnosci spawalnicze warstw napawanych. Biul. Instytutu Spawalnictwa, 3, 26-36.

9. Chukhry, Ya. (1988) Fatigue resistance of specimens from 34KhNM steel, deposited by different methods. Avtomatich. Svarka, 9, 66-67. 


\title{
APPROXIMATE CALCULATION OF RADIUS OF WELD TRANSITION TO BASE METAL OF WELDED BUTT JOINT ACCORDING TO NORMALIZED PARAMETERS
}

\author{
A.V. MOLTASOV \\ E.O. Paton Electric Welding Institute, NASU \\ 11 Kazimir Malevich Str., 03150, Kiev, Ukraine. E-mail: office@paton.kiev.ua
}

\begin{abstract}
The aim of the present work was to establish mathematical dependencies between geometric parameters of welded bead, taken into account the stress concentration factor in welded butt joints and standard parameters of height and width of weld reinforcement during calculation. It was suggested to describe fillets and a convex part of the reinforcement of a welded butt joint in the form of arcs of contacting circumferences, which allowed establishing the functional relation between the side angle and the height-to-width ratio of the reinforcement. Using this relation, the values of the height-to-width ratio of the reinforcement and the values of radius of weld transition to base metal, corresponding to them, were determined on the basis of the known dependences of this radius on the side angle for different types of fusion welding. By plotting the regression dependencies using the computer-aided design system MathCAD, the mathematical formulas were obtained to determine the radius of weld transition to base metal through the height-to-width ratio of the butt welded joint produced by submerged arc welding and welding in shielding gases. 13 Ref., 3 Tables, 3 Figures.
\end{abstract}

Keywords : welded butt joint, stress concentration, weld geometry, radius of weld transition to base metal, side angle, normalized parameters, approximate calculation

The stress concentration, caused by geometrical heterogeneity of welded joints, is one of the main factors determining their fatigue resistance [1]. For a quantitative evaluation of this phenomenon, as a rule the stress concentration factor (SCF) is used, which depends primarily on such parameters of the welded joint geometry as the radius of weld transition to base metal $r$ and the side angle $\theta$ [2], however, the standards on welded joints (GOST 14771-76, GOST 8713-79, GOST 14806-80 and GOST 5264-80) do not regulate these parameters. Therefore, establishing the relation between the radius of transition and side angle with the normalized parameters of height $h$ and the width $g$ of the reinforcement remains an urgent problem for today in the field of practical calculations for strength, reliability, and durability of welded joints and structure elements.

The value of radius of weld transition to base metal depends on many factors, in particular, on welding mode and thermophysical properties of the metal joined, surface tension of weld metal and purity of surface of the elements joined [3].

In general form, this dependence is presented in the work [4] as follows:
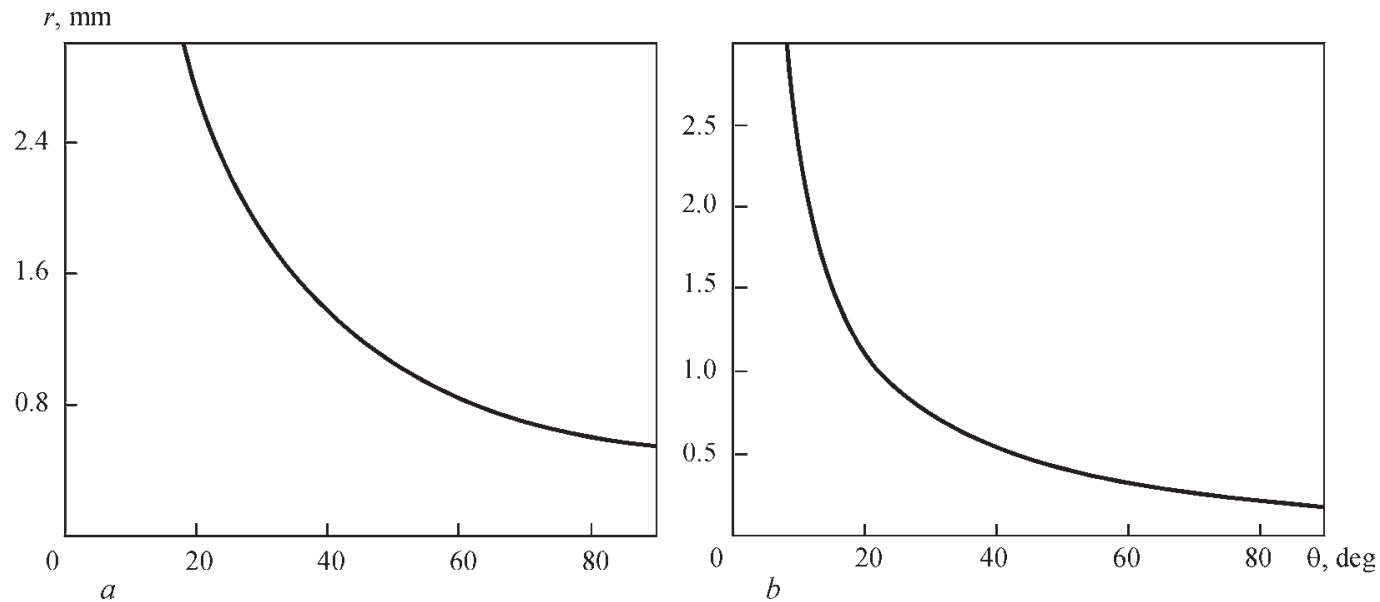

Figure 1. Diagrams of dependence of radius of weld transition to base metal from side angle for welded joints, made by submerged arc welding $(a)$ and welding in shielding gases $(b)$ 
Table 1. Dependence of radius of weld transition to base metal for different values of side angle

\begin{tabular}{|c|c|c|c|c|c|c|c|c|c|c|c|c|}
\hline \multicolumn{2}{|c|}{ Side angle $(\theta)$, deg } & 90 & 80 & 70 & 60 & 50 & 40 & 30 & 20 & 18 & 10 & 8 \\
\hline \multicolumn{2}{|c|}{$h / g$} & 0.5 & 0.42 & 0.35 & 0.29 & 0.23 & 0.18 & 0.135 & 0.09 & 0.08 & 0.045 & 0.035 \\
\hline \multicolumn{2}{|c|}{$(\mathrm{h} / \mathrm{g})^{1 / 2}$} & 0.707 & 0.65 & 0.59 & 0.54 & 0.48 & 0.424 & 0.367 & 0.3 & 0.283 & 0.212 & 0.187 \\
\hline $\begin{array}{c}\text { Transition radius } r, \mathrm{~mm} \text { for } \\
\text { type of welding }\end{array}$ & Submerged & 0.55 & 0.6 & 0.7 & 0.83 & 1.05 & 1.37 & 1.85 & 2.7 & 3.0 & - & - \\
\cline { 2 - 22 } & In shielding & 0.18 & 0.22 & 0.27 & 0.33 & 0.41 & 0.54 & 0.74 & 1.10 & - & 2.31 & 3.0 \\
\hline
\end{tabular}

$$
r=f_{1}\left(\frac{h}{g}\right)+f_{2}\left(T_{0}\right)+f_{3}(\sigma)+f_{4}\left(R_{z}\right),
$$

where $f_{1}-f_{4}$ are the terms taking into account dimensions of the reinforcement, initial temperature of welded plates, surface tension of the weld metal and roughness of surface of elements joined.

In the work [4] it was proved that the initial temperature and surface purity have a comparatively small influence on weld formation and the surface tension changes in the narrow interval and its influence can also be neglected. Therefore, the terms $f_{2}-f_{4}$ as compared to the term $f_{1}$ are the values of the second order of smallness. Hence, if the other conditions are equal, the first factor has a primary importance, and in the first approximation the radius of transition depends on height and width of the reinforcement, since they determine the ratio $\mathrm{h} / \mathrm{g}$. Therefore, the aim of the present work is to find this dependence in the form of a mathematical formula.

All the parameters of weld convexity profile, predetermined by welding process, are interrelated. Thus, the transition radius and side angle are related by dependence of the form [5]

$$
r=f(1 / \theta) \text {. }
$$

The existence of such dependence is confirmed by experimental measurements of geometry of welded joints produced by different types of fusion welding in the zones of weld transition to base metal (Figure 1) [6].

Here, the side angle can be unambiguously determined through the height and width of the reinforcement if the shape of convexity is described by parabola [7], by circumference arc [8], or other more complex integral or differential dependence $[9,10]$.

In the present work it is proposed to describe the shape of reinforcement in the form of arcs of the contacting circumferences (Figure 2), then, the side angle will be determined through the ratio $h / g$ by the dependence

$$
\theta=2 \arctan \frac{2 h}{g} \text {. }
$$

Having expressed the ratio $h / g$ from the formula (3), it is possible to determine its values for different values of side angle, and the values of radii of weld transition to base metal, corresponding to these values (Table 1), by using the diagrams (Figure 1).

On the basis of discrete data, the system of the computer-aided design MathCAD allows plotting the regression dependence of one value from another in the form of a polynomial of the $n$-th power, where $n$ is a positive integral number [11]. However, since in the given case (Table 1) the ratio $h / g$ takes the values differing from each other by more than an order, then it is rational to seek the dependence of the radius of weld transition to base metal on this parameter in the form of a polynomial with fractional degrees

$$
r\left(\frac{h}{g}\right)=\sum_{i=0}^{n} a_{i}\left(\frac{h}{g}\right)^{\frac{1}{2}},
$$

where $a_{i}$ are the factors of regression function.

By successive increasing the number of terms of the approximating series (4), it was established that for the case of submerged arc welding, the deviation of the experimental results (Table 1) from the results of calculation, according to the formula with retention of the first five terms of this series,

$$
\begin{aligned}
r\left(\frac{h}{g}\right) & =15-77.64\left(\frac{h}{g}\right)^{\frac{1}{2}}+166.7\left(\frac{h}{g}\right)- \\
& -168.45\left(\frac{h}{g}\right)^{\frac{3}{2}}+66.6\left(\frac{h}{g}\right)^{2}
\end{aligned}
$$

amounts to not more than $0.43 \%$ (Table 2).

The investigation of function (5), according to the well-known method [12], showed that it decreases in a strict monotonous way at the interval of changes in the ratio $h / g$ from 0 to 0.5 (Figure 3,a).

For the case of welding in shielding gases, it was established that deviation of the calculated values of transition radius according to the formula, obtained by retention of the first seven terms of the series (4) from the experimental results (Table 1), amounts to not more than $1.212 \%$ (Table 3 ).

The investigation of function (6) showed that, similar to the function (5), it decreases in a strict monotonous way at the interval of change in the ratio $\mathrm{h} / \mathrm{g}$ from 0 to 0.5 (Figure $3, b$ ).

Thus, using the formula (3), as well as the formulae (5) or (6), depending on welding method, having

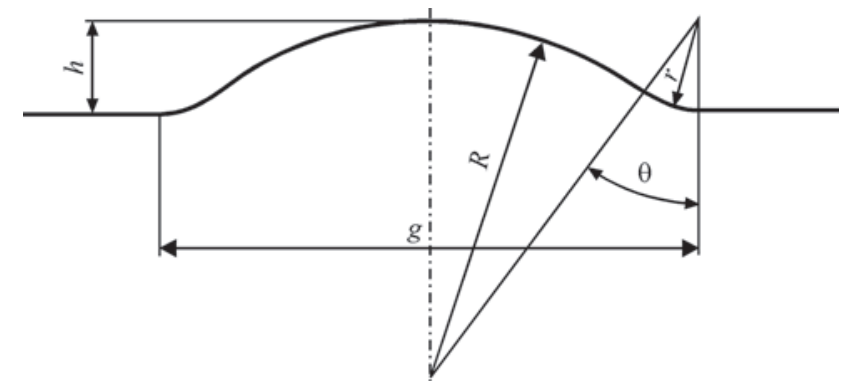

Figure 2. Geometric parameters of idealized model of reinforcement on one of the sides of welded butt joint, made by fusion welding 
Table 2. Experimental and calculation values of radius of weld transition to base metal of the butt joint, made under the flux

\begin{tabular}{|l|c|c|c|c|c|c|c|c|c|}
\hline \multicolumn{1}{|c|}{$\mathrm{h} / \mathrm{g}$} & 0.5 & 0.42 & 0.35 & 0.29 & 0.23 & 0.18 & 0.135 & 0.09 & 0.08 \\
\hline Measured transition radius, $\mathrm{mm}$ & 0.55 & 0.6 & 0.7 & 0.83 & 1.05 & 1.37 & 1.85 & 2.7 & 3.0 \\
\hline Calculated transition radius, $\mathrm{mm}$ & 0.55 & 0.601 & 0.697 & 0.832 & 1.053 & 1.368 & 1.847 & 2.709 & 2.994 \\
\hline Deviation, \% & 0 & 0.17 & 0.43 & 0.24 & 0.29 & 0.15 & 0.16 & 0.33 & 0.20 \\
\hline
\end{tabular}

Table 3. Experimental and calculation values of radius of weld transition to base metal of the butt joint, made in shielding gases

\begin{tabular}{|l|c|c|c|c|c|c|c|c|c|c|}
\hline \multicolumn{1}{|c|}{$h / g$} & 0.5 & 0.42 & 0.35 & 0.29 & 0.23 & 0.18 & 0.135 & 0.09 & 0.045 & 0.035 \\
\hline Measured transition radius, $\mathrm{mm}$ & 0.18 & 0.22 & 0.27 & 0.33 & 0.41 & 0.54 & 0.74 & 1.10 & 2.31 & 3.0 \\
\hline Calculated transition radius, $\mathrm{mm}$ & 0.18 & 0.219 & 0.272 & 0.326 & 0.413 & 0.542 & 0.735 & 1.103 & 2.308 & 3.001 \\
\hline Deviation, \% & 0 & 0.45 & 0.74 & 1.21 & 0.73 & 0.37 & 0.68 & 0.27 & 0.09 & 0.03 \\
\hline
\end{tabular}
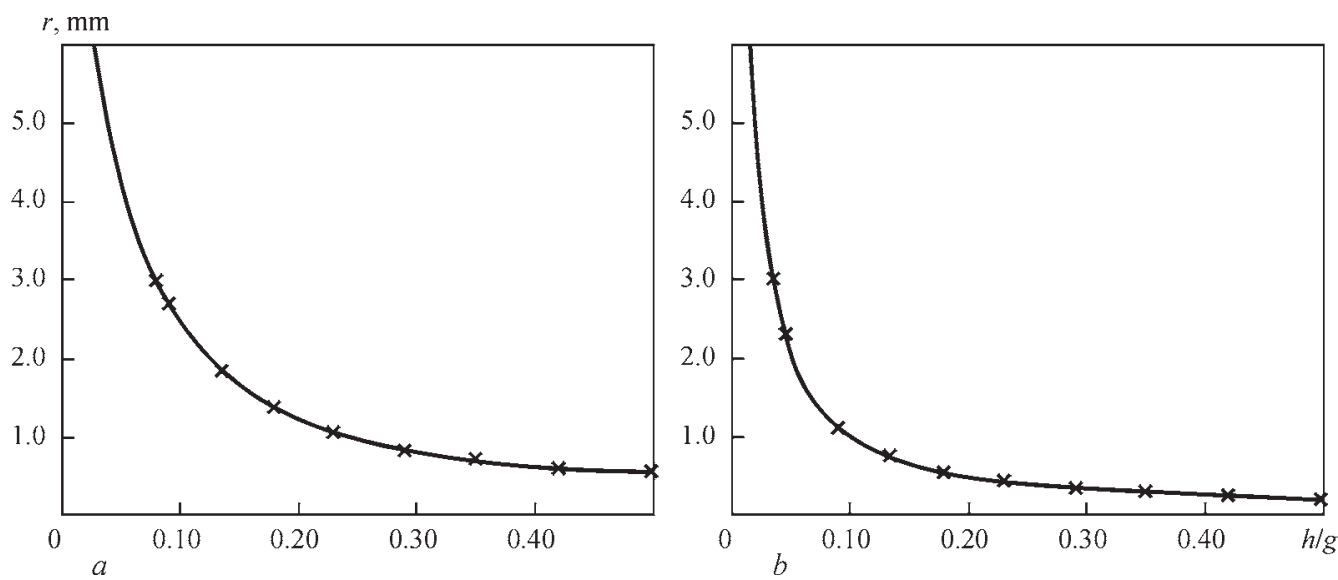

Figure 3. Diagram of dependence of radius of weld transition to base metal on height-to-width ratio of reinforcement and experimental points $(\times)$ for butt welded joint made by submerged arc welding $(a)$ and welding in shielding gases $(b)$

the parameters of height and width of the reinforcement regulated by the standards, it is possible to establish all the geometric characteristics, necessary for determination of the SCF value in butt welded joints according to the known calculated dependences [13].

\section{Conclusions}

1. An idealized model of the shape of butt weld reinforcement was proposed, according to which the curve, formed by the fillets and a convex part of the reinforcement is described by arcs of contacting circumferences. The use of the proposed model allows an unambiguous determination of the side angle as a continuous function of height-to-width ratio of the reinforcement.

2. By approximating the discrete data with polynomials with fractional powers, using the system of the computer-aided design MathCAD, the mathematical formulae were obtained for determination of the radius of weld transition to base metal through the height-to-width ratio of the reinforcement of butt joint, made by submerged arc welding and welding in shielding gases.

1. Trufyakov, V.I., Dvoretsky, V.I., Mikheev, P.P. (1990) Strength of welded joints under alternating loads. Kiev: Naukova Dumka.

2. Knysh, V.V., Klochkov, I.N., Pashulya, M.P. et al. (2014) Increase of fatigue resistance of sheet welded joints of aluminum alloys using high-frequency peening. The Paton Welding J., 5, 21-27.
3. Belchuk, G.A., Naletov, V.S. (1972) On some dependencies of weld formation in zone of weld-base metal junction. Svarka $v$ Sudostroenii, 79, 32-35.

4. Belchuk, G.A. (1969) Welded joints in hull structures. Leningrad: Sudostroenie.

5. Shonin, V.A., Poklyatsky, A.G. (2001) Low-cycle fatigue of welded butt joints made from alloy AMg6 in inert atmosphere. The Paton Welding J., 3, 18-22.

6. Berezovsky, B.M., Stikhin, V.A. (1981) Peculiarities of transition zone formation from butt weld reinforcement to base metal. Voprosy Svarochn. Proizvodstva, 266, 99-106.

7. Belchuk, G.A. (1964) Approximate calculation of geometric shape and stress concentration coefficient of welded butt joints on welding mode. Leningrad: LDNTP.

8. Kaufmann, P. (1970) Ermuedungsverhalten von Stumpfnaehten. Schweisstechnik, 20(1), 38-41.

9. Patskevich, I.R., Ryabov, V.R., Deev, G.F. (1991) Surface phenomena in welding of metals. Kiev: Naukova Dumka.

10. Pankov, V.V., Pankov, S.V., Bogorodsky, I.G. et al. (2015) Measure function of weld as the basis in development of digital technologies of weld quality. Zh. Neftegazovogo Stroitelstva, 2, 20-26.

11. Alekseev, E.R., Chesnokova, O.V. (2006) Solution of problems of computational mathematics in packets Mathcad 12, MATLAB 7, Maple 9. Moscow: NT Press.

12. Bugrov, Ya.S., Nikolsky S.M. (2004) Higher mathematics: Manual for inst. of higher education. Moscow: Drofa. Vol.2: Differential and integral calculus.

13. Makhnenko, V.I., Mosenkis, R.Yu. (1985) Calculation of stress concentration coefficients in joints with butt and fillet welds. Avtomatich. Svarka, 8, 7-18. 


\title{
ENGINEERING APPROACH TO DETERMINATION OF STRESS INTENSITY FACTOR AND PARAMETERS OF GROWTH OF AXIAL CRACK IN CIRCUMFERENTIAL WELD OF PIPELINE
}

\author{
V.V. KYRYCHOK and V.M. TOROP \\ E.O. Paton Electric Welding Institute, NASU \\ 11 Kazimir Malevich Str., 03150, Kiev, Ukraine. E-mail: office@paton.kiev.ua
}

\begin{abstract}
The problem of evaluation of stress intensity factors in the zone of residual welding stresses was considered. The joint application of the software packages Ansys Workbench and Abaqus/CAE and the compiler Python for accurate determination of parameters of crack resistance of pressure pipelines and vessels was proposed. On the example of the pipe specimen $133 \times 13 \mathrm{~mm}$, the simulation of welding process and subsequent opening of semi-elliptic crack in the zone of residual stresses was carried out. The analysis of the possible further growth of defect from the action of cyclic loads in the weld region was performed and the most dangerous zones of location of axial cracks were found. 6 Ref., 5 Figures.
\end{abstract}

Ke y w or d s : stress intensity factor, finite element method, residual stresses, crack, script, weld

In welds of pressure pipelines and vessels, which worked out a significant part of their life, crack-like defects are often revealed. The cause for their formation is mechanical, structural and chemical heterogeneity, corrosion, static and cyclic loads. In order to determine whether the pipeline can serve with a detected defect, it is necessary to evaluate the stress intensity factor (SIF) and J-integral or critical crack opening for the existing crack. For the area, which is located far from the weld, the methods were created which provide an accurate evaluation of these parameters. However, in the area of weld the plastic deformations are formed which cause residual stresses and have a non-uniform distribution. They depend on properties of the material, geometry of the pipe and welding mode. These factors do not enable the evaluation of SIF with minimal errors. At the present moment the standardized method [1] for determination of this parameter exists. It envisages the determination of $K_{\mathrm{I}}$ by superposition of the working component $K_{\mathrm{I}}$ and the component from residual stresses. The disadvantage of this algorithm is the fact that it does not envisage the peculiarities of redistribution of residual stresses after loading, does not take into account the welding parameters and does not provide accurate information of the area which should be considered as a weld.

In the given work the specified procedure is described, with the use of which SIF $K_{I}$ can be evaluated by the finite elements method. To do this, it is necessary to perform simulation of the thermal cycle of welding and to solve the problem of residual stress-strain state on the

(C) V.V. KYRYCHOK and V.M. TOROP, 2017 basis of it. After that it is necessary to evaluate how the stresses will be redistributed after inducing a crack. Analytical determination of the residual stress-strain state after welding is a complex problem, but today we can select software tools and even ready-made subprograms in the known software complexes of finite element analysis, with the help of which it can be calculated at a high accuracy. However, for simulation of a crack, which will open on the specimen after solution of thermo-mechanical problem, the use of special techniques is necessary. In general, it is possible to do this with the help of the software packages Ansys and Abaqus. Unfortunately, it is impossible to directly implement this task in the user-friendly interface Ansys Workbench or Abaqus/CAE, since the most commands, which should be at the same time broadcasted to the solver, are absent in them.

A direct study of the problem with a crack, which appears at the last step of the algorithm, can be realized using the parametric modeling in the APDL (Ansys Parametric Design Language) medium, the work in which assumes scripting in a language, which is similar to FORTRAN. Another way is the use of the solver Abaqus/Standard with a parallel parametric modeling in the language FORTRAN. The both methods envisage the need in textual programming of the model and due to this reason they are too complicated for realization for the majority of users. Therefore, the creation of special methods which would allow evaluating the process of crack formation with a high accuracy without parametric modeling represents a significant practical and scientific interest. 


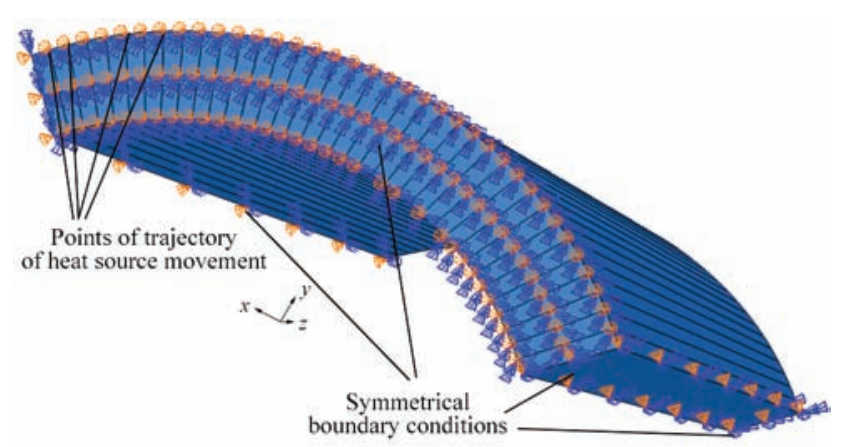

Figure 1. Calculation model of thermo-mechanical problem

The paper presents the results of successful combination of capabilities of Ansys Workbench and Abaqus/CAE for obtaining the required parameters of crack resistance. The problem was solved on the example of the pipe $133 \times 13 \mathrm{~mm}$ made of steel 20 . The mechanical and physical properties of the specimen material, as well as their dependence on temperature, were simulated with the help of the program «JMatPro» (this module allows obtaining a wide range of properties of the material depending on its chemical composition and structure). It was also taken into account that the characteristic of crack resistance (fracture toughness) $K_{1 c}$ for hot-rolled tube specimens of steel 20 is about $160 \mathrm{MPa} \cdot \mathrm{m}^{0.5}$, and the threshold value $K_{\text {th }}$ was assumed as equal to $8 \mathrm{MPa} \cdot \mathrm{m}^{0.5}$ [2].

According to the work [3], the steel pipes with a wall thickness of up to $16 \mathrm{~mm}$ and the yield strength of up to $600 \mathrm{MPa}$ are not prone to brittle fracture. However, if the stress intensity factor exceeds the value of $K_{\text {th }}$ in the field of variable loads, then one should expect the further growth of fatigue crack. The process of growth of fatigue crack is described by the Walker equation [2]:

$$
\frac{d a}{d N}=\frac{C(\Delta K)^{n}}{(1-R)^{n(1-\gamma)}},
$$

where $d a / d N$ is the rate of crack increment for 1 cycle; $\Delta K$ is the range of SIF of the component $K_{I} ; R$ is the coefficient of cycle asymmetry according to SIF; $n, C$, $\gamma$ are the constants of material.

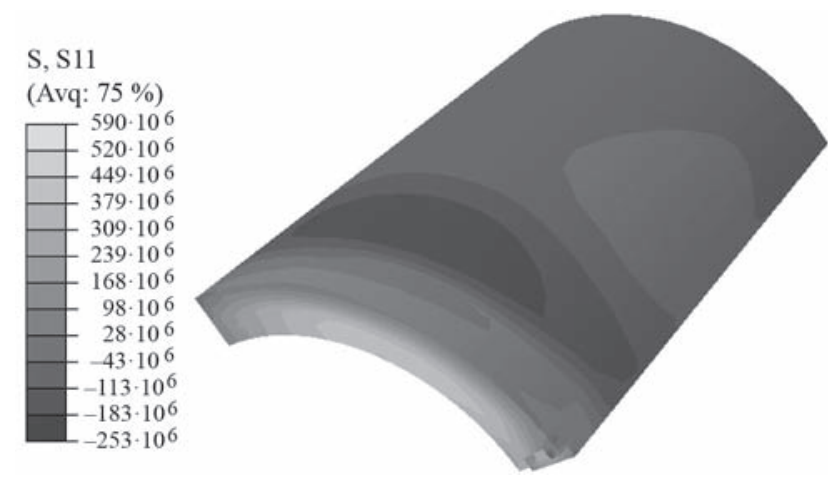

Figure 2. Distribution of circumferential residual stresses after welding $(\mathrm{Pa})$
For simulation of thermal cycle of welding the Abaqus/CAE in combination with Pyton script [4] (in general, Python subprograms have the same capabilities as CAE interface, however their use is convenient for automated plotting of a model with a large number of operations) was applied. To reduce the calculation time, one eight part of the pipe was considered applying the symmetric boundary conditions to it (Figure 1). The thermal cycle was simulated for two-pass welding. The first pass was conditionally performed on the inner radius of pipe and the second one was done after cooling of the first one, i.e. on the outer radius. To simulate the arc movement and energy evolution from the arc process along the trajectory of welding in the arrays of points, the point heat sources were alternately activated, acting for some time and then deactivated. This method is described in details in the work [5]. With the help of the scrypt Python it was managed to create a dense automatic breakdown of the trajectory of arc movement in such a way that to minimize the «jerkiness» of this process.

The result of thermo-mechanical problem on the circumferential stresses is shown in Figure 2. After simulation of welding process, an operating pressure of $22.5 \mathrm{MPa}$ was applied to the pipe.

During loading of welded pipe with the operating inner pressure, it was revealed that additional plastic deformation in the vicinity of a weld is almost absent, which allows applying the elastic model for this specimen at the next stage of finding SIF.

The introduction of a crack into the model was realized with the help of Ansys Workbench. To do this, the procedure of mapping the stress fields from the first stage was used. In addition, for the possibility of simulating a crack in its asymmetric location relative to the weld, a part of the pipe was plotted in the axial direction. If the area under consideration is not fixed, then the stresses induced with the help of mapping are redistributed and we will not be able to obtain an adequate picture. Therefore, a rigid fixation at the ends

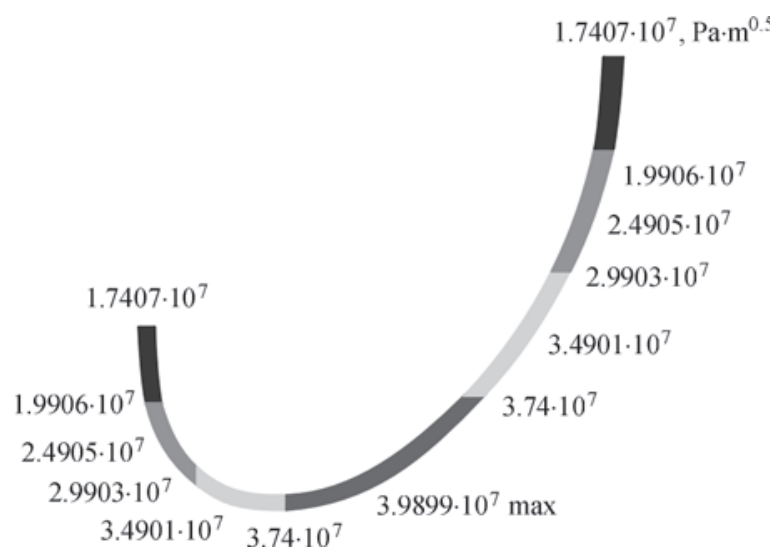

Figure 3. Distribution of SIF of a crack depending on residual stresses 


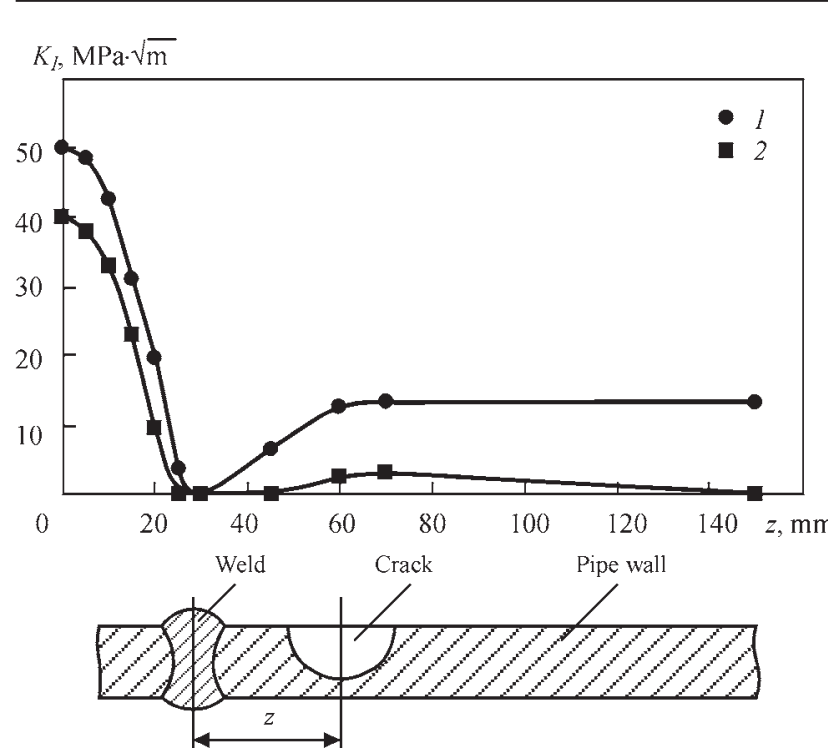

Figure 4. Distribution of maximum SIF in pipe axis in the vicinity of a weld: 1 - welding + operating pressure; 2 - welding

and a cylindrical fixation in the radial direction were applied to the specimens under consideration. This made it possible to leave the residual stresses and provide the possibility of opening the crack lips during its inducing. In this case, the error of transfer of component of circumferential residual stresses S11 from Abaqus to Ansys after balancing of stresses does not exceed $10 \%$.

In the work, the postulated axial defect of a semi-elliptical shape outside the pipe of $16 \mathrm{~m}$ length and $8 \mathrm{~mm}$ depth was considered. The crack was alternately located in the weld center and at different distances from it in the zone of residual stresses. For example, the results of SIF distribution from residual stresses in the weld center are presented in Figure 3.

At the some distance of crack from the weld, at first the maximum SIF decreases to 0 and then increases. The distribution of this value, depending on the distance to the center, is shown in Figure 4.

The next task was to evaluate how SIF will change in the heat-affected zone if operating pressure is applied to the pipe. To do this, a similar simulation was carried out with the difference that at the first stage in Abaqus the inner pressure was applied after the welding process. The distribution of SIF, depending on the distance to the weld center under the operating load, is shown in Figure 4.

For the pipeline, the evaluation of value of defect growing in a one cycle according to the formula (1) was performed, depending on the location of a crack relative to the weld axis (Figure 5). At the same time, the values $n, c$, and $\gamma$ were obtained from the operation diagrams [6]. According to the operation [6], these constants for different ferrite-pearlite steels almost do

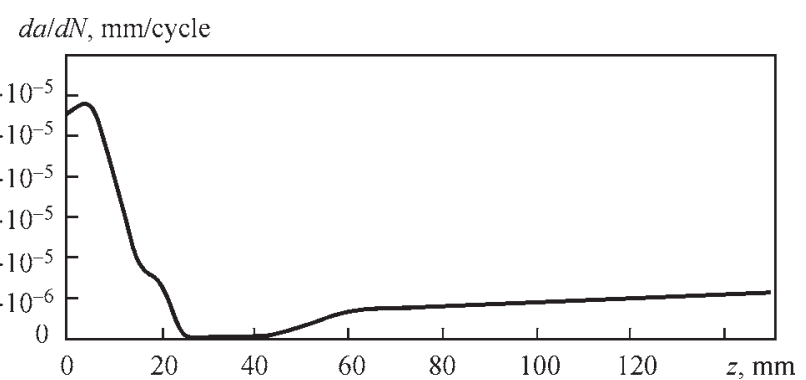

Figure 5. Distribution of crack growth rate depending on its location in the vicinity of a weld

not differ. For the specimen under consideration, the martensitic phase is mostly not formed during welding, therefore, the same parameters of crack resistance were taken for the weld and base metal. The results of calculations showed that in the heat-affected zone the amplitudes of $\Delta K_{I}$ are smaller than for the weld-free area of a pipe, but the cycle asymmetry contributes to the fact that the rate of growth of a defect in the weld zone several times exceeds the rate of growth in the pipe region, which is distant from the zone of plastic deformations.

\section{Conclusions}

The methods for determination of stress intensity factors in the heat-affected zone are given using the finite element method. The capabilities of different software means for simulation of a welding process and determination of stress fields of pipe specimens with defects are presented. The given results of SIF distribution and the rates of growth of a defect are presented, depending on the distance of a crack to the circumferential weld. It was analytically shown that in case of assumed homogeneity in the mechanical properties of base metal, weld zone and heat-affected zone, the axial defects in the zone of welded joints of pressure pipelines and vessels are more dangerous than cracks at an arbitrary point of the pipe, especially in the cyclic types of loads.

1. DSTU-N B.2.3-21:2008: Determination of residual strength of main pipelines with defects.

2. Stephens, R., I., Ali Fatemi, Stephens, R. R., Fuchs, H. O. (2001) Metal fatigue in engineering. $2^{\text {nd }}$ ed. New York, John Wiley \& Sons.

3. PNAEG-7-002-86 (1989): Codes of design on strength of equipment and pipelines of nuclear power plants. Moscow: Energoatomizdat.

4. (2010) Abaqus Scripting Reference Manual. USA, Providence, RI.

5. Yakhno, B.O. (2013) Calculation of welded joints using program complex Abaqus: Guidelines. Kyiv, NTUU KPI.

6. Suryanarayana, C. (2003) Experimental techniques in material and mechanics. Boca Rathon, USA, Taylor \& Francis Group. 


\title{
PATON PUBLISHING HOUSE
}

\author{
www.patonpublishinghouse.com
}

\section{SUBSCRIPTION}

\section{The ifitiolonal \\ Автоматическая B P}

"The Paton Welding Journal» is Published Monthly Since 2000 in English, ISSN 0957-798X.

"Avtomaticheskaya Svarka» Journal (Automatic Welding) is Published

Monthly Since 1948 in Russian, ISSN 005-111X.

«The Paton Welding Journal» is Cover-to-Cover Translation of

Avtomaticheskaya Svarka» Journal into English.

If You are interested in making subscription directly via Editorial Board, fill, please, the coupon and send application by Fax or E-mail.

The cost of annual subscription via Editorial Board is $\$ 348$ for «The Paton Welding Journal» and $\$ 180$ for «Avtomaticheskaya Svarka» Journal.

«The Paton Welding Journal» can be also subscribed worldwide from catalogues subscription agency EBSO.

\section{SUBSCRIPTION COUPON \\ Address for journal delivery \\ Term of subscription since \\ Name, initials \\ Affiliation \\ Position \\ Tel., Fax, E-mail}

20

till

20

We offer the subscription all issues of the Journal in pdf format, starting from 2009.

The archives for 2009-2014 are free of charge on www.patonpublishinghouse.com site.
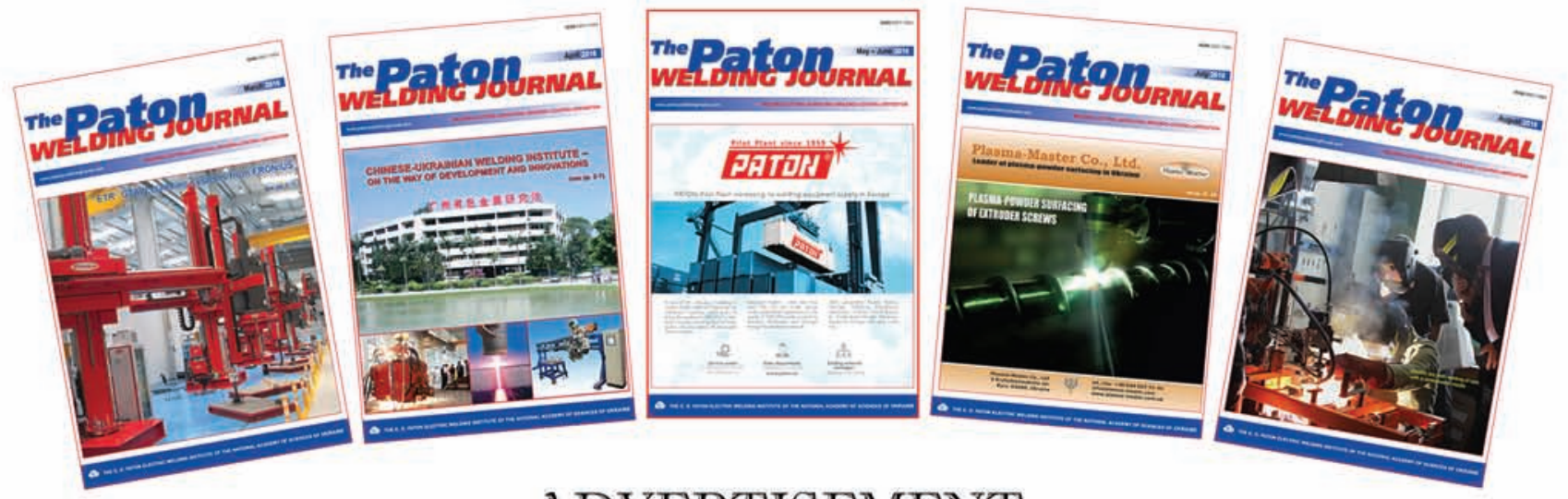

ADVERTISEMENT

in "Avtomaticheskaya Svarka" and "The Paton Welding Journal"

External cover, fully-colored:

First page of cover $(190 \times 190 \mathrm{~mm})-\$ 700$

Second page of cover $(200 \times 290 \mathrm{~mm})-\$ 550$

Third page of cover

$(200 \times 290 \mathrm{~mm})-\$ 500$

Fourth page of cover

$(200 \times 290 \mathrm{~mm})-\$ 600$
Internal cover, fully-colored: First/second/third/fourth page of cover $(200 \times 290 \mathrm{~mm})-\$ 400$

Internal insert: Fully-colored $(200 \times 290 \mathrm{~mm})$ $\$ 340$

Fully-colored (double page A3) $(400 \times 290 \mathrm{~mm})-\$ 500$
- Article in the form of advertising is $50 \%$ of the cost of advertising area

- When the sum of advertising contracts exceeds $\$ 1001$, a flexible system of discounts is envisaged

Size of journal after cutting is $200 \times 290 \mathrm{~mm}$

Editorial Board of Journal «Avtomaticheskaya Svarka» and \& The Paton Welding Journal» E.O. Paton Electric Welding Institute of the NAS of Ukraine International Association «Welding» 